\title{
WestVirginiaUniversity
}

THE RESEARCH REPOSITORY @ WVU

Graduate Theses, Dissertations, and Problem Reports

2009

\section{Development of a Web-based woody biomass energy expert system}

\author{
Sabina Dhungana \\ West Virginia University
}

Follow this and additional works at: https://researchrepository.wvu.edu/etd

\section{Recommended Citation}

Dhungana, Sabina, "Development of a Web-based woody biomass energy expert system" (2009). Graduate Theses, Dissertations, and Problem Reports. 2751.

https://researchrepository.wvu.edu/etd/2751

This Thesis is protected by copyright and/or related rights. It has been brought to you by the The Research Repository @ WVU with permission from the rights-holder(s). You are free to use this Thesis in any way that is permitted by the copyright and related rights legislation that applies to your use. For other uses you must obtain permission from the rights-holder(s) directly, unless additional rights are indicated by a Creative Commons license in the record and/ or on the work itself. This Thesis has been accepted for inclusion in WVU Graduate Theses, Dissertations, and Problem Reports collection by an authorized administrator of The Research Repository @ WVU. For more information, please contact researchrepository@mail.wvu.edu. 
DEVELOPMENT OFA WEB-BASED WOODY BIOMASS ENERGY EXPERT SYSTEM

By

\author{
Sabina Dhungana
}

Thesis submitted to the Davis College of Agriculture, Forestry and Consumer Sciences at West Virginia University in partial fulfillment of the requirements for the degree of

Master of Science

in

Forestry

\author{
Approved by \\ Dr. Jingxin Wang, Committee Chairperson \\ Dr. Joseph F. McNeel \\ Dr. Bhaskaran Gopalakrishnan
}

Division of Forestry and Natural Resources

Morgantown, West Virginia

2009

Keywords: Woody biomass, bioenergy, expert system, wood residues, forest management 


\section{A B S T R A C T \\ Development of a Web-Based Woody Biomass Energy Expert System}

\section{Sabina Dhungana}

Woody biomass is evolving as a potential bioenergy feedstock at an industrial scale to provide the required supply for industries relying on these resources at necessary levels and feasible costs. In order to effectively utilize woody biomass for energy, it is essential to know in advance the availability of biomass, the equivalent energy provided, and the associated procurement costs. Expert systems, using computer based programming and containing knowledge bases reflecting the knowledge of human experts in the field, are being used in industrial facilities for real time problem analysis and knowledge enhancement. This study draws on this approach and attempts to fill gaps in energy information by designing an expert system capable of predicting the amount of biomass residue, energy equivalent provided, and the cost of procurement for biomass availability across the state of West Virginia. The system employs the latest web based database technique in providing real time and continuous feedback to its intended users. Procurement distance, biomass handling systems, and associated costs needed to collect required energy amounts are primary factors in the analysis tool. Biomass availability, procurement distance, and delivered costs were analyzed under different biomass feedstocks, equipment combinations, and operational conditions. The developed knowledge base system can be used to promote sustainable and efficient utilization of woody biomass in West Virginia. 


\section{LIST OF SYMBOLS I NOMENCLATURE}

\begin{tabular}{ll} 
API & Application Programming Interface \\
ATS & Apache Tomcat Server \\
BTU & British thermal unit \\
ES & Expert Systems \\
FEMP & Federal Energy Management Program \\
GIS & Geographic Information System \\
html & Hyper Text Transmission Protocol \\
J2EE & Java Enterprise Edition \\
JSP & Java Server Page \\
Lat & Latitude \\
Long & Longitude \\
MD & Maryland \\
OH & Ohio \\
PA & Pennsylvania \\
PMH & Productive machine hour \\
RD & Relational Database \\
RDBMS & Relational Database Management System \\
SMH & Scheduled Machine Hour \\
SQL & Structured Query Language \\
TPO & Timber product output \\
USDA & United Stated Department of Agriculture \\
USDOE & United States Department of Energy \\
WV & West Virginia \\
\hline
\end{tabular}




\section{A C K N O W LE D GEM E N T S}

I would like to thank my major professor, Dr. Jingxin Wang, for his continuous guidance. Moreover, I am deeply indebted to Dr. Wang for his flexibility in research schedule, patience and full fledged support during several of my important and critical stages of family life, especially during the birth of my baby girl Opal, without which everything would have been different and difficult.

I am also grateful to my committee members, I am grateful to professor Dr. Joseph McNeel, committee member and Director, Division of Forestry and Natural Resources, for his every support, valuable time and critical suggestions during my entire graduate studies. Similarly, I would like to extend my thanks to Professor Dr. Bhaskaran Gopalakrishnan for his valuable time, efforts and guidance for this research as a committee member. .

I would also like to thank my parents, for the roles they played in supporting my academic endeavor to this point. I am grateful to my father for inspiring me to achieve higher education in the field of forestry. I am especially appreciative to my mother's support for my accomplishments.

I am grateful to my husband for his time, effort and love throughout. Without his support and help, it would have a lot different in my life. Last but not the least I am very thankful to my daughter Opal for providing me satisfaction and pleasure while I was feeling so tired from my work and working late on my thesis.

I would also like to thank Shawn Gruscheky, Steve Haroff and Ben Spong for their various support. I would like to thank my graduate student fellows, staff at Division of Forestry and Natural Resources, and several professors whom I took class at WVU during my graduate studies especially Drs. John Brooks and Ben Dawson-Andoh. 
TABLE OF CONTENTS

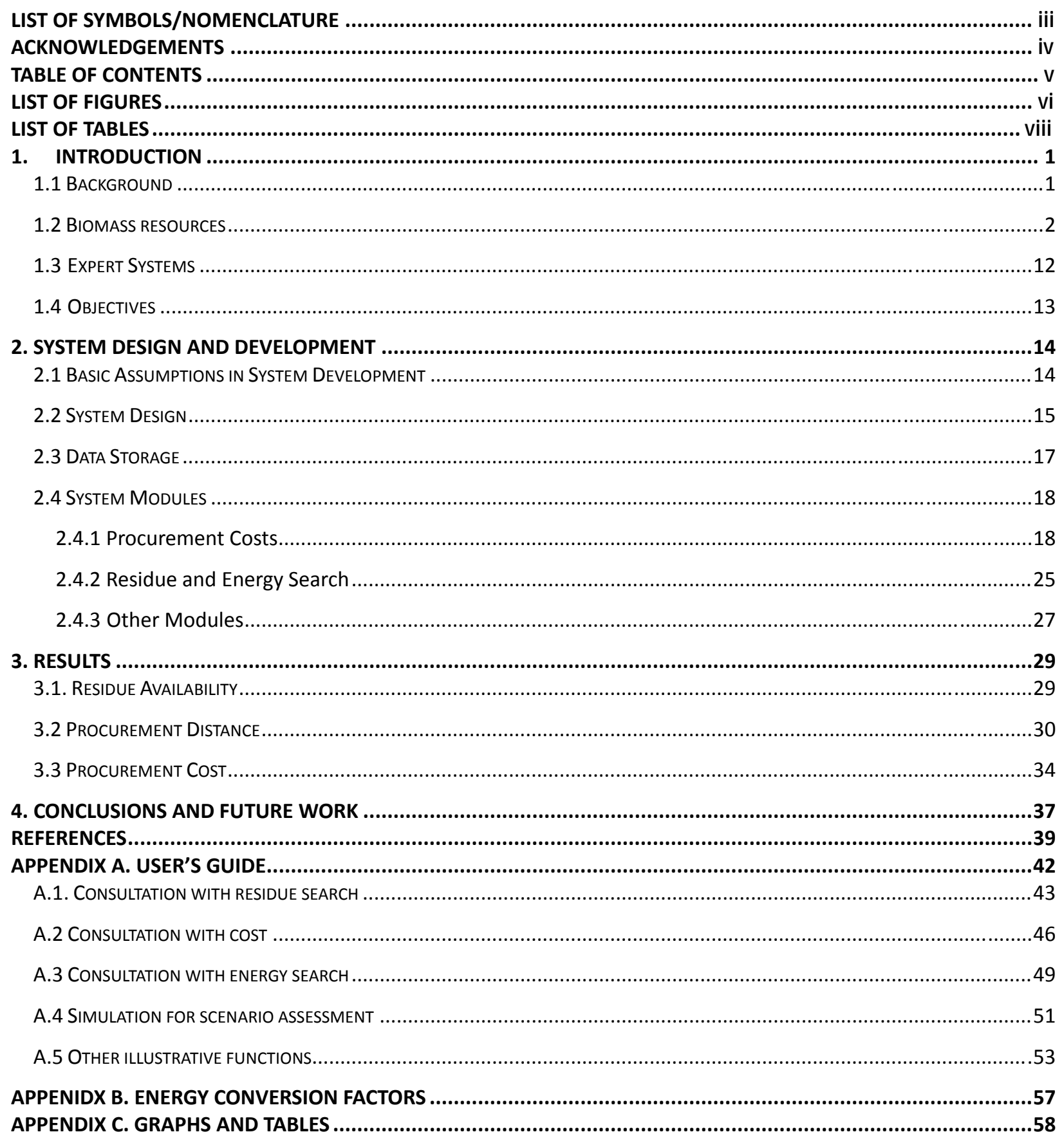




\section{LIS T OF FIG URES}

Figure1.1 Wood residue distribution over different counties in West Virginia in tons................... 4

Figure 1.2 Wood residue distribution over different counties in Pennsylvania in tons................... 5

Figure 1.3 Wood residue distribution over different counties in Ohio in tons. ........................... 6

Figure 1.4 Wood residue distribution over different counties in Virginia in tons. ............................ 7

Figure 1.5 Wood residue resource distribution over different counties in Maryland in tons. ..........8

Figure 1.6 Spatial search space for different amounts of mill residues from three different counties i.e. Hancock, Gilmer, and McDowel located respectively in north, center and south part of the state. The search space varies significantly for same amount of residues. Five contiguous states and their counties are overlaid to provide an overview of counties to cover to procure the required residue amount. Map Source: Base map of state and counties were obtained from USGS Topographic Data 2002. Residue information from Timber Products Output Data (2007) was fitted into the base map).

Figure 1.7 Spatial search space for different amounts of logging residues from three different counties i.e. Hancock, Gilmer, and McDowel located respectively in north, center and south part of the state. The search space varies significantly for same amount of residues. Five contiguous states and their counties are overlaid to provide an overview of counties to cover to procure the required residue amount. Map Source: Base map of state and counties were obtained from USGS Topographic Data 2002. Residue information from Timber Products Output Data (2007) was fitted into the base map.

Figure 2.1 System diagram of the web based woody energy expert system. ........................... 15

Figure 2.2 Implementation of system components. ..................................................................... 16

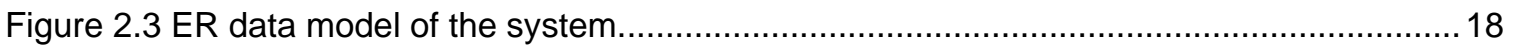

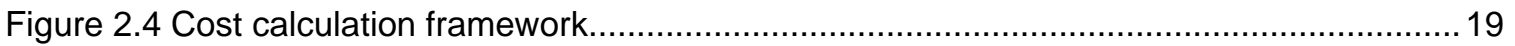

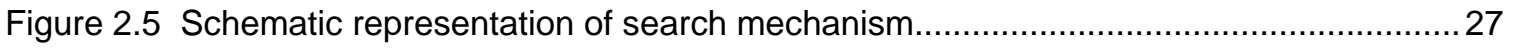

Figure 3.1 Procurement distance for various amounts of mill residues in WV. This box plot was generated by simulating the procurement distance for each of the 55 counties in WV for different amounts of mill residue. The boxes show minimum, maximum and quartile of number of counties where given residue amounts indicated in $\mathrm{X}$-axis are available within the distance shown in $\mathrm{Y}$ axis. The mean value for the entire state is shown by a ' + ' and connected with a line.

Figure 3.2 Procurement distance for various amounts of logging residues in WV. This box plot was generated by simulating the procurement distance for each of the 55 counties in WV for different amounts of logging residue. The boxes show minimum, maximum and quartile of number of counties where given residue amounts indicated in $\mathrm{X}$-axis are available within the distance shown in Y-axis. The mean value for the entire state is shown by a ' + ' and connected with a line. 
Figure 3.3 Delivered costs for various amounts of mill residues in WV. This box plot was generated by simulating the procurement cost for each of the 55 counties in $\mathrm{WV}$ for different amounts of mill residue. The boxes show minimum, maximum and quartile of number of counties where given residue amounts indicated in X-axis are available within the distance shown in $\mathrm{Y}$ axis. The mean value for the entire state is shown by a ' + ' and connected with a line. 35 Figure 3.4 Delivered costs for various amounts of logging residues in WV. This box plot was generated by simulating the procurement cost for each of the 55 counties in WV for different amounts of logging residue. The boxes show minimum, maximum and quartile of number of counties where given residue amounts indicated in X-axis are available within the distance shown in Y-axis. The mean value for the entire state is shown by a '+' and connected with a line. .........36 Figure A.1 System index page that appears when the program is first run on a web browser...... 42 Figure A.2 Search for available woody residue (the default screen). ........................................ 43

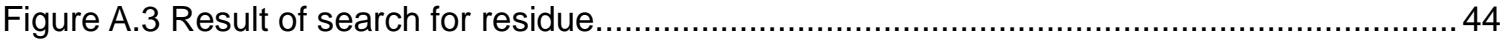
Figure A.4 Cost parameter specification page. By clicking on Estimate button of any parameter, user can customize the parameter and override the default.

Figure A.5 Final cost calculation for mill residue search with information on distance, unit delivered cost and total cost for the required amount of residues. ........................................... 46

Figure A.6 Cost page from this page, search can be changed by clicking "modify search"......... 47

Figure A.7 Popup window with estimate button.

Figure A.8 By changing values in machine rates, "Estimate" button will update the final cost and "User rate" button will close the pop-up window and update the main window with new rate....... 49 Figure A.9 Energy search page which is seeking 1000 Ethanol gallon equivalent from mill residue from WV, Monongalia. 50

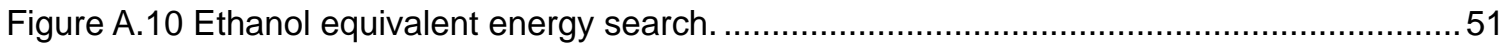

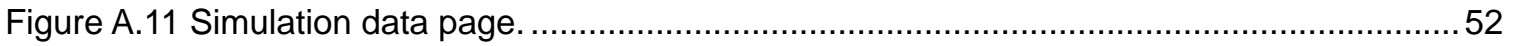

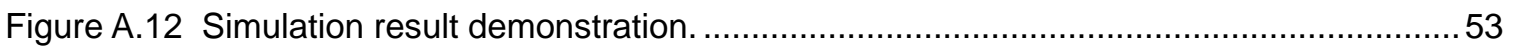

Figure A.13 Biomass residue use illustration in West Virginia.................................................5 55

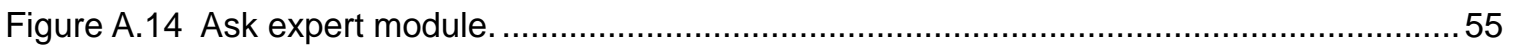

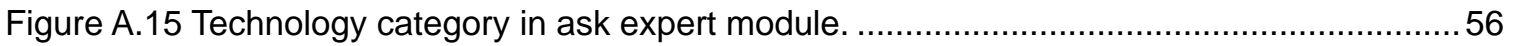

Figure A.16 Terms used in the system.

Figure C.1 Minimum, maximum and average cost and distance of mill residue in WV..............58

Figure C.2 Minimum, maximum and average cost and distance of logging residue in WV..........59

Figure C.3 Minimum, maximum and average cost and distance of both mill and logging residues

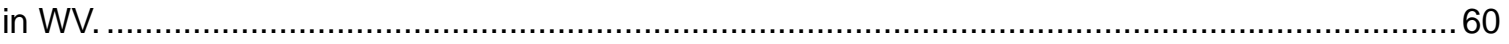

Figure C.4 Delivered cost and amount of mill residue searched by county in WV. .....................61

Figure C.5 Delivered cost and amount of logging residue searched by county in WV ................... 62

Figure C.6 Delivered cost and amount of mill and logging residues searched by county in WV.. 63 


\section{LIST OF TABLES}

Table 2.1. Assumptions for logging residue extraction/handling machines. 24

Table 2.2 Fuel consumption per ton handling and processing of logging residue.......................25

Table 2.3 Default search parameter.

Table 2.4 Required parameters and default values for simulation module.................................28

Table 3.1 Availability of mill and logging residue in five states included in the system.................29

Table C.1 Distance to travel (miles) for mill residue procurement in different counties of WV. .....64

Table C.2 Distance to travel for logging residue procurement in different counties of WV........... 65

Table C.3 Distance to travel (miles) for both mill and logging residue procurement in different

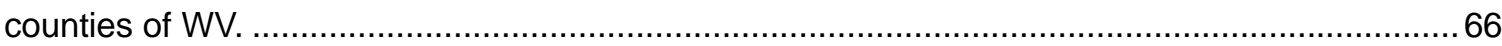




\section{IN TROD U C T ION}

\subsection{Background}

Fossil fuels, nonrenewable resources, are currently the most commonly used fuel for power generation. The availability and cost of these resources are variable due to their foreign origin and declining resource base. The foreign dependency makes their availability sensitive to global politics and economic shifts. These factors along with environmental concerns have resulted in researching sources of alternative fuels for power generation. Increased concerns over energy security, high natural gas/ crude oil prices and global warming, have prompted broad interest in using biomass as a feedstock for bioenergy. Potential benefits of shifting to a biomass energy source include reduced use of nonrenewable fuels, less dependency on foreign fuels, stabilization of income in rural areas, and reduced carbon dioxide emissions to the atmosphere. Biomass supplies and costs are generally independent of global, political and economic shifts (Maker 2004), as they can be produced with the resources available in the US.

Mill residue, a waste product from wood industries and logging residue, a waste product from logging operations, could be important bio-based energy raw materials, particularly in West Virginia (WV). These waste products can be used to produce energy at an industrial scale and reduce our dependence on expensive foreign based fossil fuels. A shift to biomass for energy needs might also reduce carbon emission as carbon neutrality is becoming a more important concern relative to global warming issues from an environmental viewpoint (Sims et al. 2003). Although energy from woody biomass has played a relatively small role in terms of overall US energy use, it comprises only 3 percent of the total energy consumed in the nation (Duncan 2004). Efficient use of logging residues and underutilized mill residues to produce energy could result in wise economic utilization of energy that might otherwise be unused. Biomass derived from woody residue is not only an important raw material for energy production, but can also be used to produce transportation fuels, electricity and serve as a feedstock for chemical industries.

Due to the rising cost of fossil fuel and increasing concern about green house gas emission from large industries, many companies have begun to explore alternative sources for energy production. One such company, Cytec Inc, a specialty chemicals and materials Technology Company with international sales of about $\$ 3.0$ billion, is interested in researching the feasibility of producing steam from woody biomass at a polymer additive facility in WV realizing that woody biomass is an important raw material to produce steam in a cost efficient manner. Cytec industries are also unique in terms of the availability of wood biomass fuels because of their location i.e., in WV. Increased markets for woody residues would help increase the value of waste stream products from the forest products industry as well as reducing fuel wood loadings and in 
turn increased value can be placed on timber harvesting residue utilization.

Although it has been recognized that biomass energy can be significant and produced from low cost energy resources, no large scale commercial facility is currently operating in the state and opportunities for the development and adaptation of technologies for utilizing residues as an energy source have been limited. The lack of information on cost and productivity of woody biomass in WV has been realized by others in this field (McNeel et al. 2008). Industries that could use woody biomass as feedstock, such as biorefining, biochemical and biopolymers, have limited start up potential due to lack of solid economic and business related information about woody biomass. Those industries interested in converting existing systems or in developing new systems for energy production from biomass face a number of challenges. These include the development of detailed feasibility analysis for the conversion process as well as current information on the availability, characteristics and economic constraints of woody biomass resources. There is a need to quantify the availability of potential biofuel sources and identify the most profitable mechanism to obtain fuel from biomass resources. This bears special significance when the current thrust of government energy policy is oriented towards utilizing forest based residues for energy supplement. These woody biomass residues are cheap as they do not have sufficient alternative uses at present and are usually left unutilized in most cases.

\subsection{Biomass resources}

Biomass is a plant matter of recent (non geologic) origin or materials derived there from. Biomass, composed of a wide variety of forest and agricultural residues, is identified as the only current renewable source of liquid transportation fuel (Perlack et al. 2005). The forest derived biomass includes residues produced during harvesting of forest products, fuel wood extracted from forest lands, residues generated at primary and secondary wood processing facilities, and biomass from fuel treatments (Wang et al. 2006). Wood and wood fiber products (including paper and paper- based products) are the largest component of the municipal waste stream in the United States, and account for more than $60 \%$ of total municipal solid wastes generated in US (McKeever 2004). In US production of wood residues from primary and secondary wood processing mills are about 107 million dry tons annually. Logging residue (49 million dry tons) and other removals (18 million dry tons) totaled nearly 67 million dry tons annually (Perlack et al. 2005). Woody biomass used for fuels consists of whole tree, scraps from manufacturing process which use wood, residue from thinning forests, and urban wood wastes. It is possible that industries will manage forests for producing biomass because of market limitation for fuel wood production. However, the primary focus of the wood producing land should be to produce timber but along with other small limbs, tops and branches of the trees that can be utilized as energy sources. Many wood processing industries produce residues such as lumber industry, furniture industry, and hardwood flooring industry. The unused wood scraps produced from those 
industries can be processed and used as fuel for different purposes.

Urban wood wastes are another type of biomass residues, which refer to items such as damaged pallets or wood materials recovered from a demolition site. Urban wood wastes are most likely to be disposed of in a landfill if not used for another application. This creates another cost to properly manage those useless materials. But if we could use those materials as a source of fuel then management costs of those materials can be reduced significantly.

The state of West Virginia is the third most heavily forested state in the U.S and has 12 million acres of forested land (Griffith and Widmann 2003). The state produces 2.4 million dry tons of wood residues per year among which 1.4 million dry tons is from logging residue and 941,868 dry tons from mill residues (Wang et al. 2006). A survey of logging residues in West Virginia conducted in 1995 revealed that the average volume of logging residue left on the ground after harvest in West Virginia was 8.4 tons /acre in weight with the average volume in any one piece of residue of $12.9 \mathrm{cu} \mathrm{ft}$ statewide. A small portion of logging residue might be used for firewood or other purposes in West Virginia. However, there is inconsistent statistical data in the state to indicate the amount of logging residues being used annually. There is a growing interest in efficient utilization of logging residues and conversion of underutilized materials to produce bioproducts or bioenergy (Wang et al. 2006). Biomass availability and distribution in WV and four neighboring states, i.e., Virginia (VA), Maryland (MD), Ohio (OH) and Pennsylvania (PA) are shown in Figures 1.1 to 1.5. Red color stack represents mill residue amount and green color stack represents amount of logging residue available in different counties in five contiguous states. In states, WV, MD and PA amount of logging residue is greater than the mill residue but in $\mathrm{OH}$ and VA amount of mill residue is greater than the logging residues. 


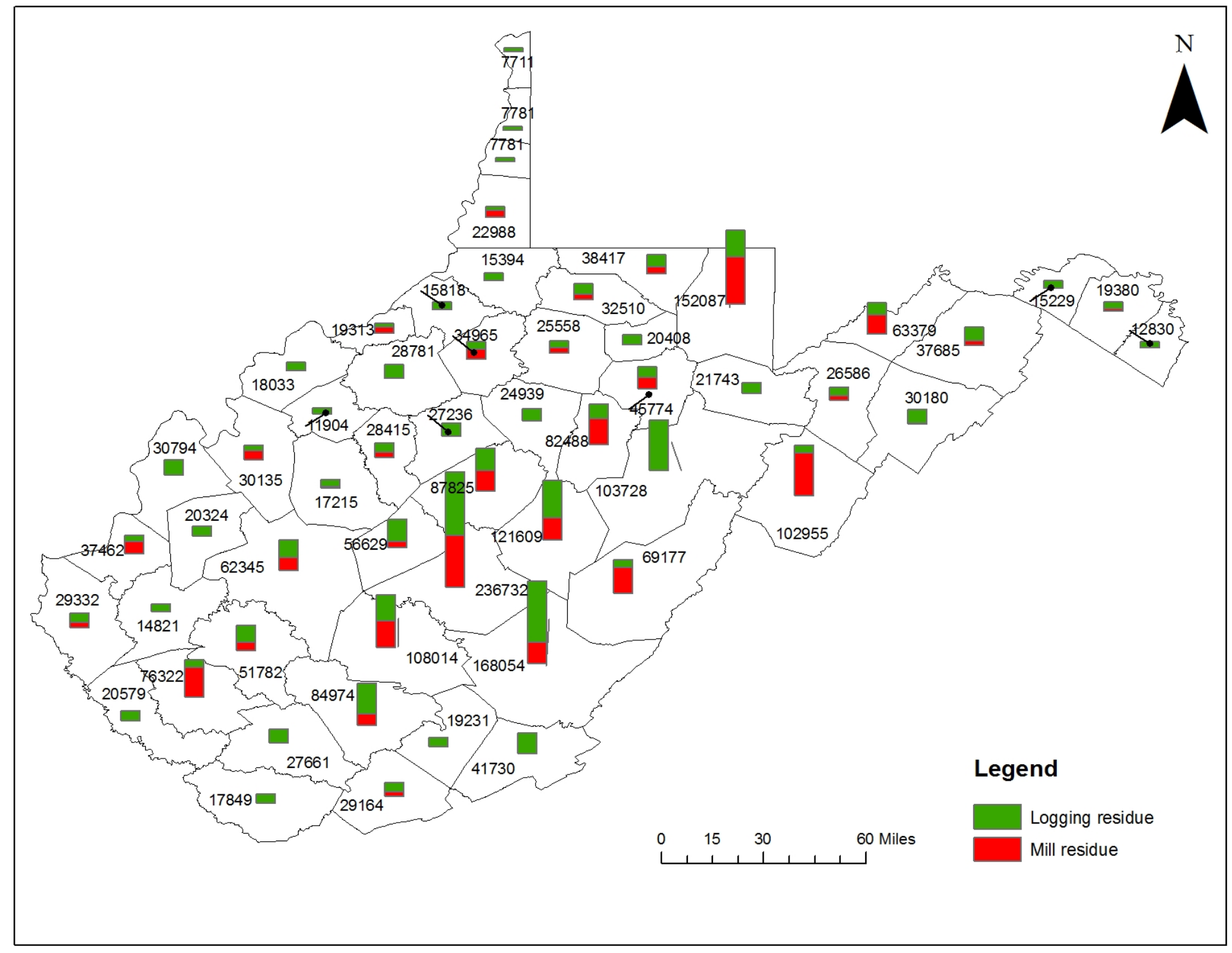

Figure1.1 Wood residue distribution over different counties in West Virginia in tons.

(Data Source: USFS 2008) 


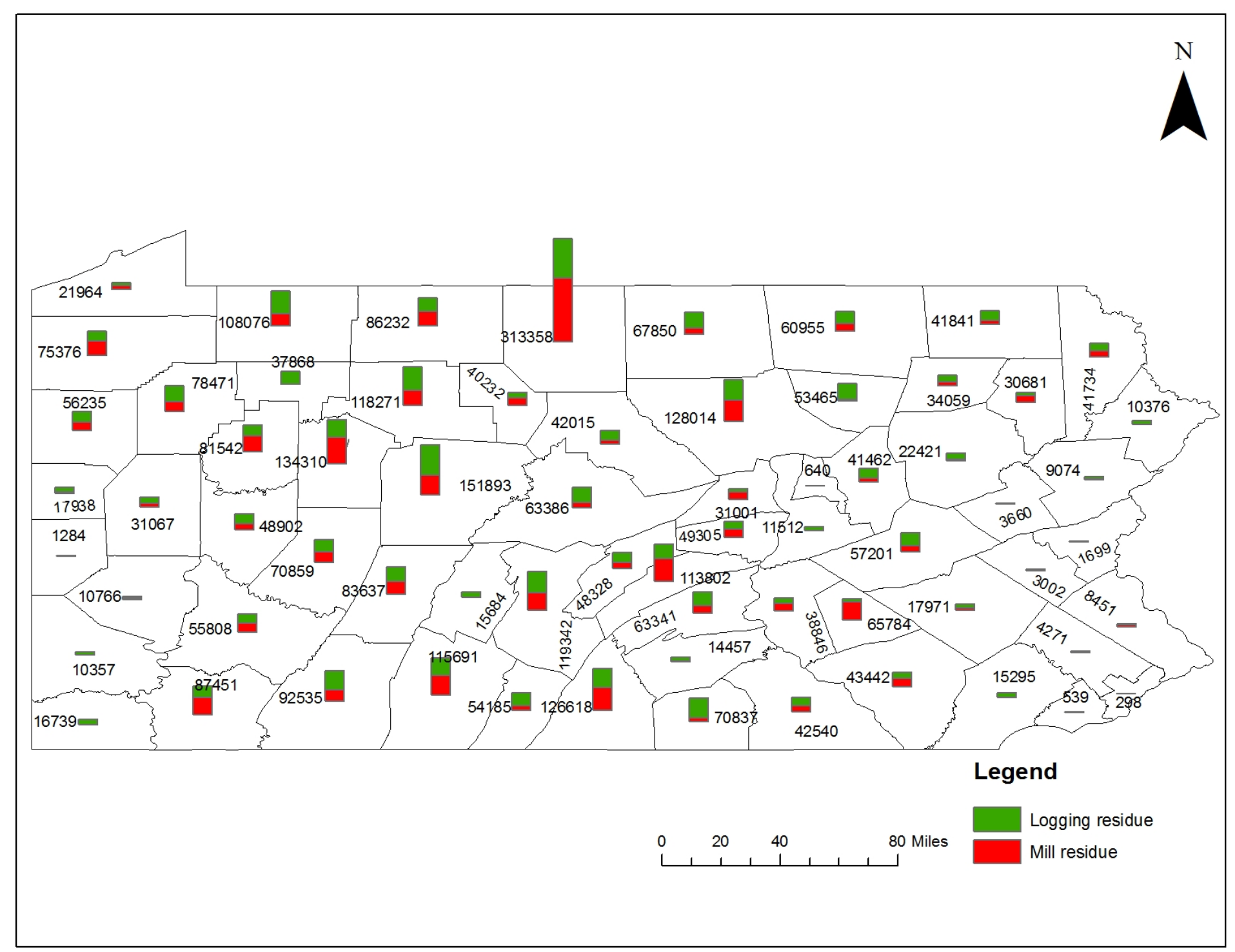

Figure 1.2 Wood residue distribution over different counties in Pennsylvania in tons.

(Data Source: USFS 2008) 


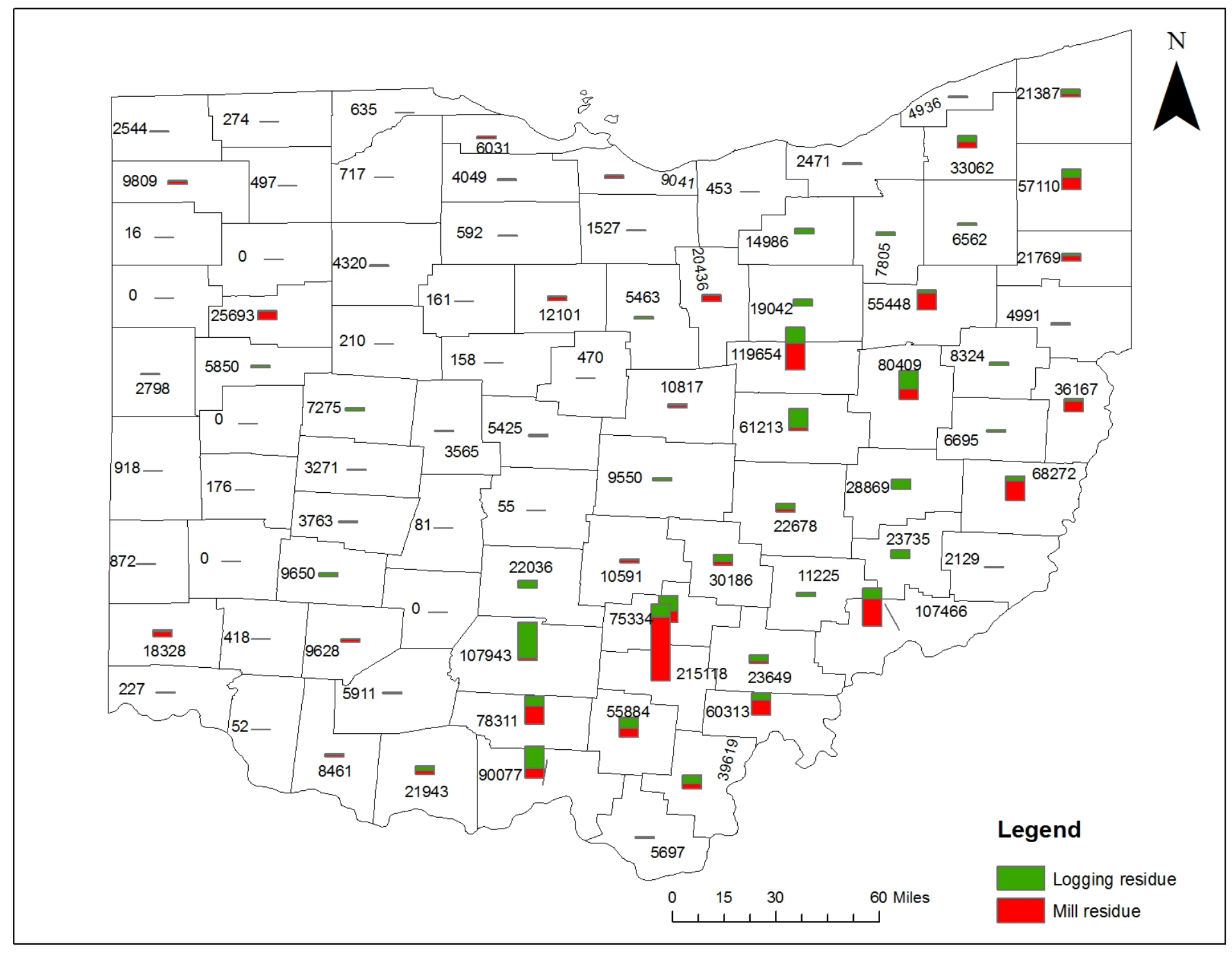

Figure 1.3 Wood residue distribution over different counties in Ohio in tons.

(Data Source: USFS 2008) 


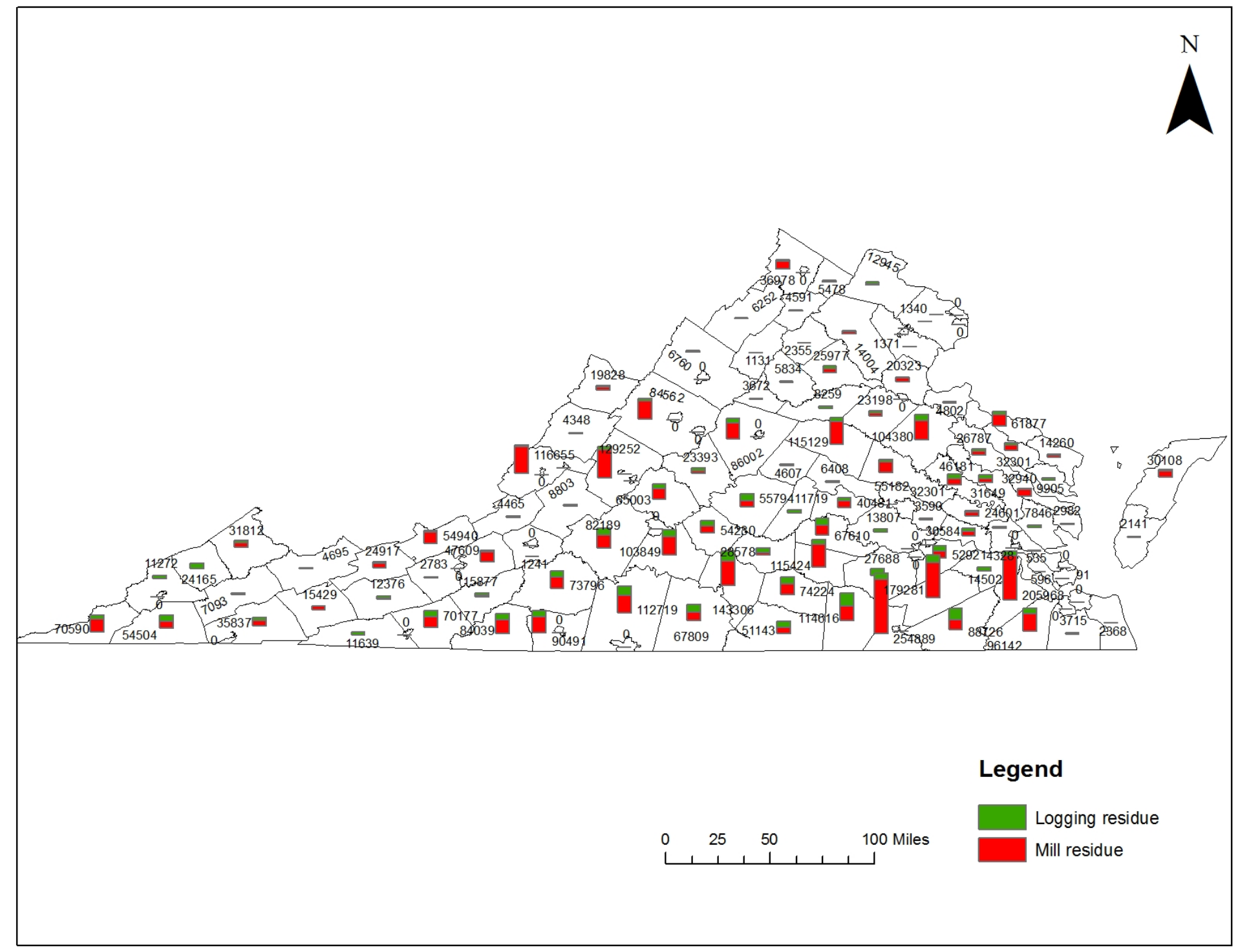

Figure 1.4 Wood residue distribution over different counties in Virginia in tons.

(Data Source: USFS 2008) 


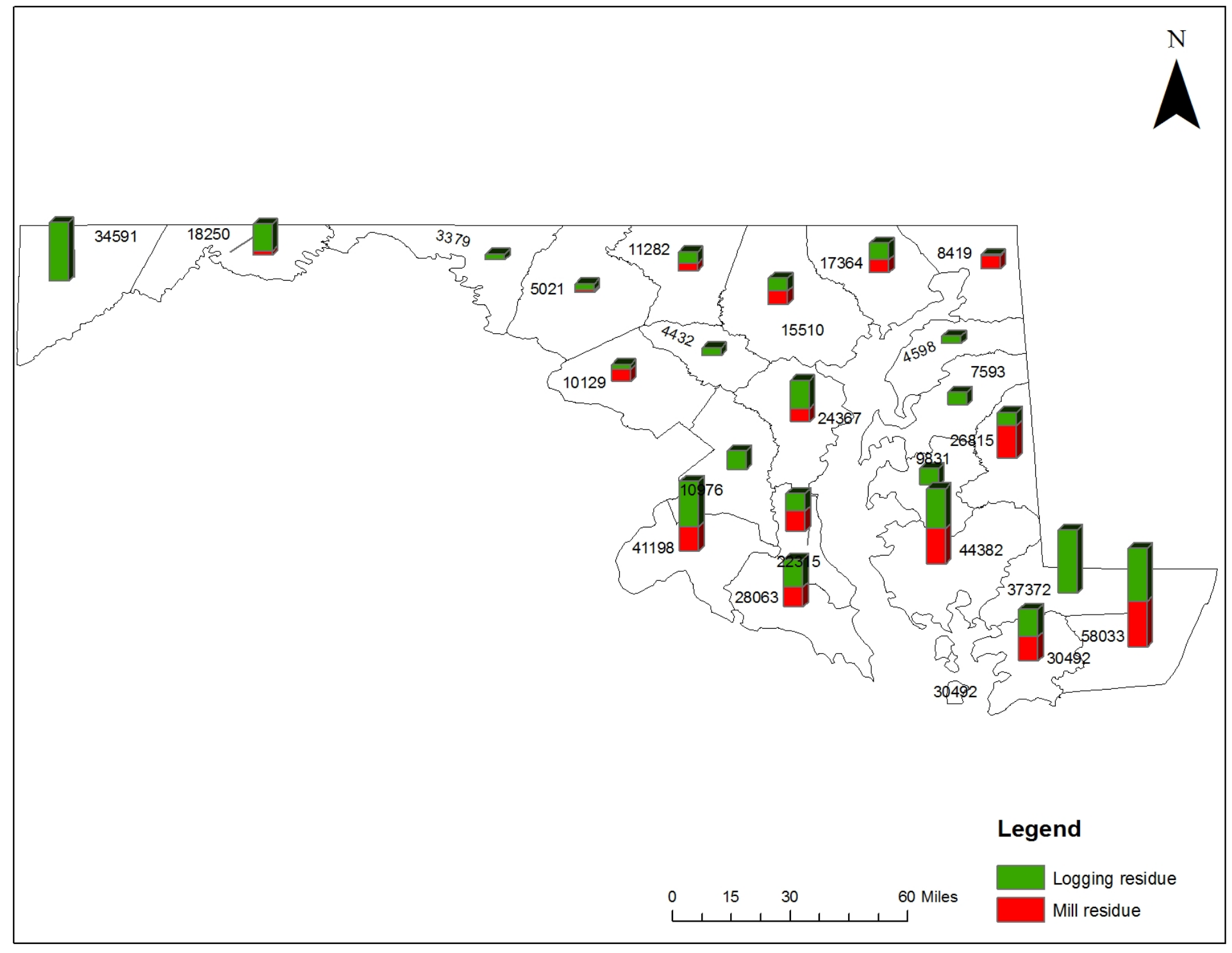

Figure 1.5 Wood residue resource distribution over different counties in Maryland in tons.

(Data Source: USFS 2008) 
If residue is required at one of the 55 counties, the distance required to travel for procurement varies by the location of counties and is not same. In order to verify this, residue availability and required procurement distance were estimated in GIS for 3 counties representing northern, central and southern region of the state for both mill and logging residue (Figure 1.6 and 1.7).

In case of mill residue search counties Hancock, Gilmer and McDowell were selected. From Hancock to collect 0.5 million dry tons distance to be travelled is $<36$ miles, for 3 million dry tons distance to be travelled is $<180$ miles and $<311$ miles for 6 million dry tons of mill residue ,from Gilmer county for 0.5 million dry tons distance to be travelled is $<17$ miles, $<156$ miles for 3 million dry tons and $<261$ for 6 million dry tons and from McDowell county distance to be travelled is $<35$ miles for 0.5 million dry tons of mill residue, $<202$ for 3 million dry tons and $<347$ miles for 6 million dry tons of mill residue (Figure 1.6).Similarly, from Hancock county in $W V$ to collect 0.5 million dry tons of logging residue distance to be travelled is $<29$ miles ,for 3 million dry tons travelling distance is $<156$ miles and for 6 million dry tons that distance is $<311$ miles, in case of Gilmer county distance to be travelled is $<17$ miles for 0.5 million dry tons of logging residue, for 3 million dry tons distance to be travelled is $<152$ miles and for 6 million dry tons distance to be travelled is $<303$ miles and similarly for McDowell county that distance is $<18$ miles for 0.5 million dry tons of logging residue, $<206$ miles for 3 million dry tons of logging residue and $<401$ miles for 6 million dry tons of logging residue (Figure 1.7). 


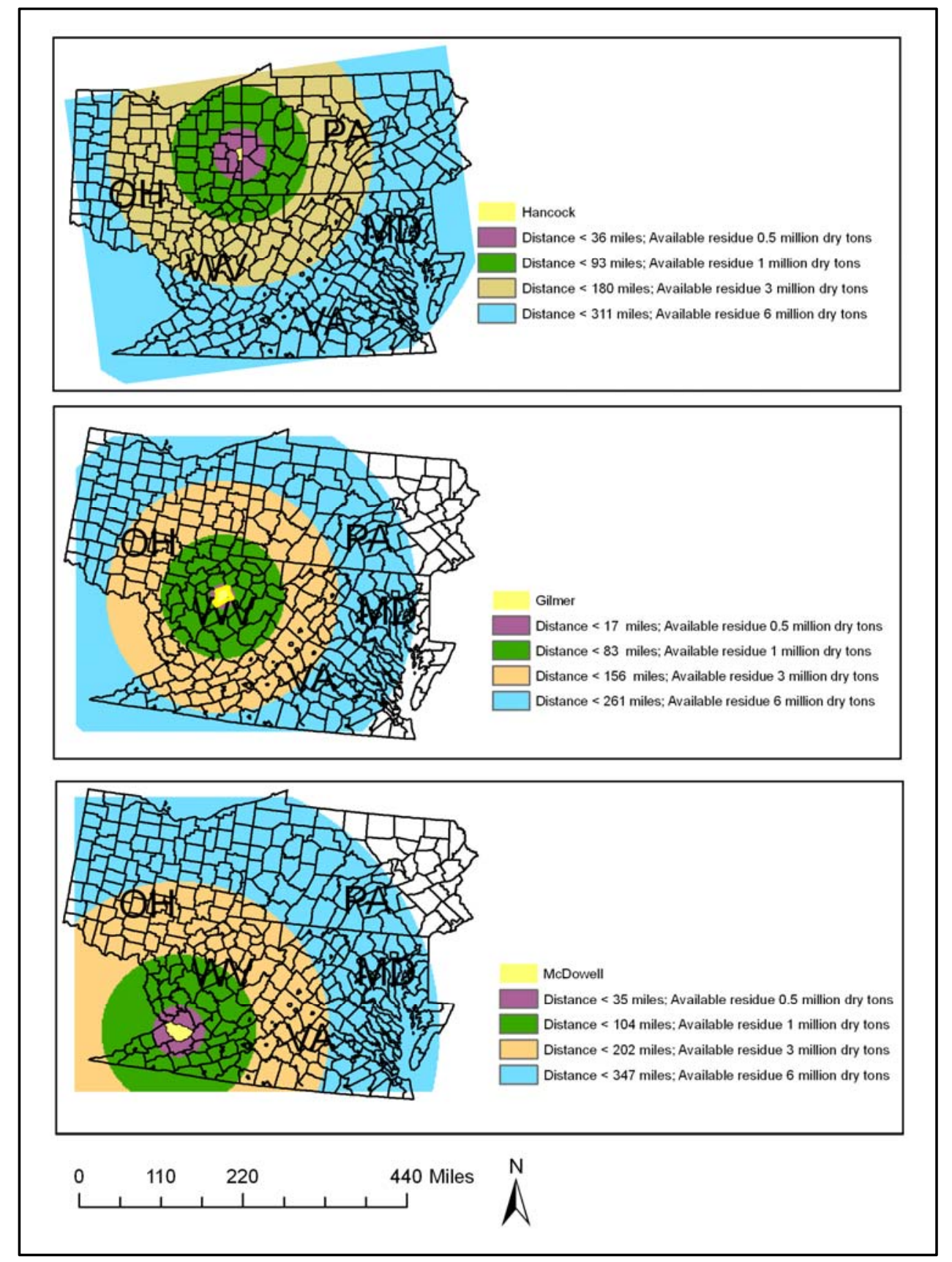

Figure 1.6 Spatial search space for different amounts of mill residues from three different counties i.e. Hancock, Gilmer, and McDowel located respectively in north, center and south part of the state. The search space varies significantly for same amount of residues. Five contiguous states and their counties are overlaid to provide an overview of counties to cover to procure the required residue amount. Map Source: Base map of state and counties were obtained from USGS Topographic Data 2002. Residue information from Timber Products Output Data (2007) was fitted into the base map). 


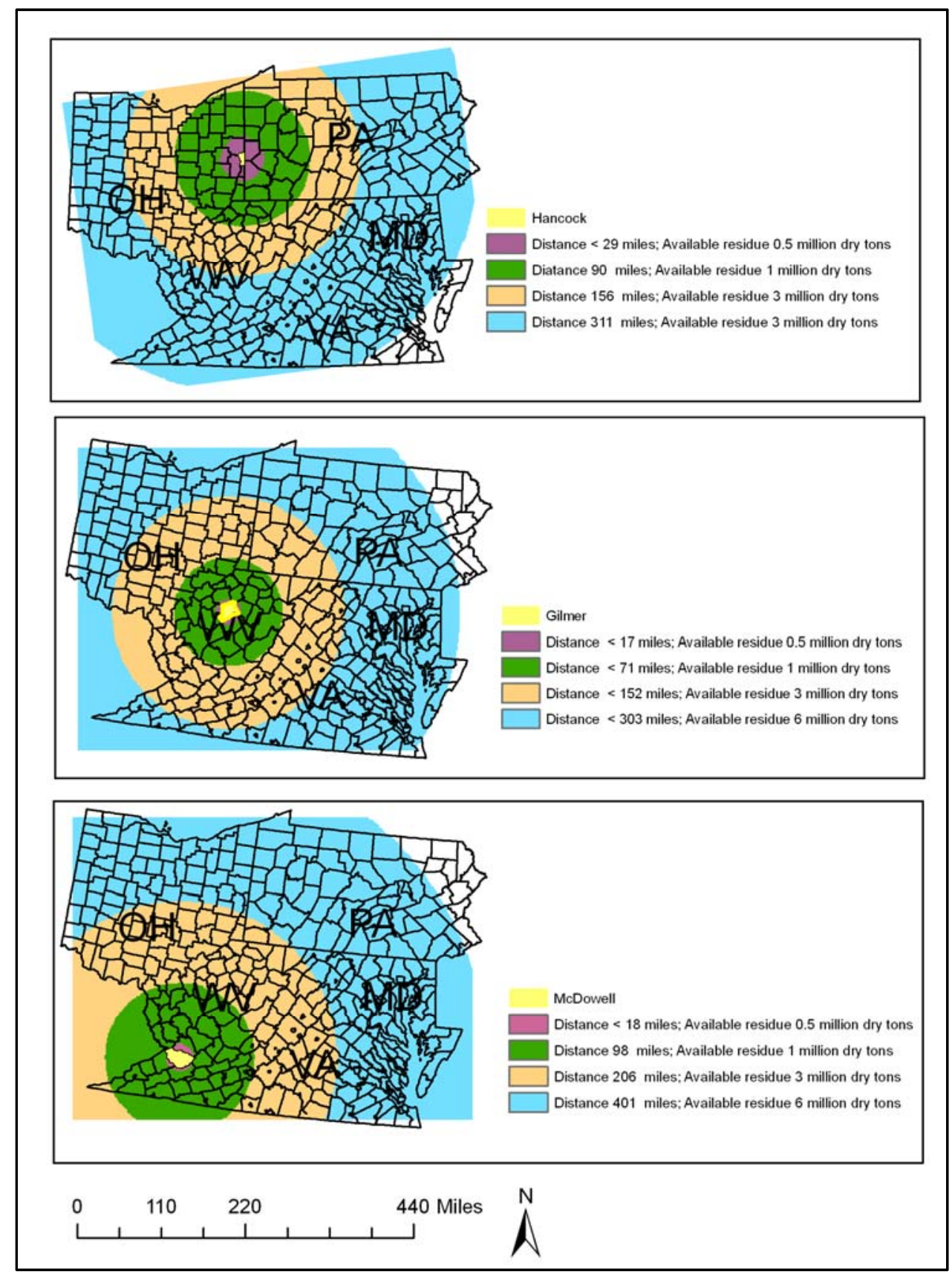

Figure 1.7 Spatial search space for different amounts of logging residues from three different counties i.e. Hancock, Gilmer, and McDowel located respectively in north, center and south part of the state. The search space varies significantly for same amount of residues. Five contiguous states and their counties are overlaid to provide an overview of counties to cover to procure the required residue amount. Map Source: Base map of state and counties were obtained from USGS Topographic Data 2002. Residue information from Timber Products Output Data (2007) was fitted into the base map.

These figures show that the counties located in central part of the state require less distance to procure equivalent amount of residues as compared to counties in northern or southern parts of the state. 


\subsection{Expert Systems}

Expert systems (ES) are computer-based tools, which are used to solve problems that require a significant amount of human expertise otherwise. These systems are developed based on existing knowledge pertaining to a specific domain, incorporating reasoning techniques which a human expert would employ in analyzing a problem and thus act as advisory tools. In a general human to human interaction, we ask individual experts in the related field about certain aspects of a question. For example, we might need to know how much biomass is available in a defined area and what is the cost, and if that cost is feasible in terms of an alternative for energy production. We might need several experts to address this kind of problem/question. A computer based expert system could be an alternative in which such expert's knowledge is captured and systematically linked with each of such problems. Such ES apply expert's knowledge in the related field which resides within these systems in the form of a knowledge base. Like a human expert, an expert system gives advice by drawing from stored knowledge and by requesting information to a specific problem at hand (Pabba et al. 1998). ENERGEX, software, is capable of recommending energy conservation opportunities in areas such as lighting, boilers, motor selection, analysis of belt driven systems, desertification, insulation of heated surfaces and air compressor operation (Nagarajan et al.1995). In addition, the system offers expert advice on power factor improvement possibilities. The system has been designed so as to query the industrial user on aspects related to the plant, from which the most appropriate energy conservation opportunity list is generated and presented for further analysis.

As far as the development of computer-based energy management systems are concerned, only special research work has been done for selected industries such as the steel industry, paper industry, and pulp industry. However, no such system can be found specifically related to woody biomass utilization for biofuels. There have been several expert systems developed for specific problems in forestry. For example, SILVAH is an expert system for stand analysis, prescription and management for hardwood stands in the Alleghenies (Marquis and Richard 1992). Forest Map Updating Expert System integrates low level image analysis and photo interpretation techniques in classifying and updating forests map using ES reasoning (Voirin et al. 2000). Insect Identification Expert System was developed to identify insects in forest and obtain recommendation on proper treatment to reduce spread of insects in forest (Kaloudis et al. 2005). THINEX is an expert system for estimating forest harvesting productivity and cost for different silvicultural activities ranging from thinning, group selection, and shelterwood harvests (LeDoux et al. 1998). A web-based expert system for advising on herbicide use in Great Britain utilizes ES to advice different herbicides for mixes of weed and crop species at different times of the year in a forestry and farm forestry setting based on weed identification and impact assessment (Thomson et al. 2004). An expert system for tree selection in urban forestry (Beck et al. 1994) uses rule based ES in selecting appropriate tree species for urban setting. VEGEVIC is an expert system for analysis and management of environmental impact assessment (EIA) information for terrestrial vegetation distribution, potential impact and mitigation measures in tropical rainforest of Malaysia (Nair et al. 1999). 
Majority of expert systems developed in forestry sector are stand alone computer programs. Such programs have limited applications in comparison to web-based systems which can be utilized by multiple users at the same time. Also, there has not been any expert system available in literature that has been developed for the central Appalachian woody biomass residue analysis.

\subsection{Objectives}

This study utilizes the principles and practices of expert system framework which is an intelligent system composed of a knowledge base, an interface engine, a working memory, user interface and an explanation based subsystem, capable of solving problems which are generally unstructured and difficult enough for human beings to solve manually. Based on search distance, types of residues, and handling machines, the system should be able to examine the costs for woody biomass to produce certain amounts of energy and to aid in the decision making process. Specifically the objectives of this study are to:

(1) Develop a web-based woody biomass energy expert system which is capable of searching and reasoning for specific questions related to wood residue energy production (available amount, cost, energy production, uses) through the use of knowledge of individuals, professionals and research outcomes in this field, and

(2) Analyze available woody biomass resources for energy production and procurement (limited from wood residue production to transportation to final destination) in terms of cost, availability, and energy equivalency. 


\section{S Y S TEM DESIG N A N D E V L OPM E N}

\subsection{Basic Assumptions in System Development}

The system development and underlying analyses were based on few assumptions. Some common assumptions applicable to the whole documents are listed here. Assumption relevant to specific component of the system and analyses were presented in respective sections.

(1) Timber Product Output (TPO) datasets of USDA for year 2007 was used in the system. The annual estimate of logging and mill residue is assumed constant. This assumption is drawn by looking at the TPO data from previous years i.e. year 1997 and 2002. The logging and mill residue output in past have been close to year latest report on 2007. Thus, it is fair to assume that this annual estimate will be valid for the purpose of this study. The system relies on the data on available mill and logging residues. For logging residues, there have been minimal alternative uses. But for mill residues, some of the residues might already have some uses. The system, however, does not consider the mill residues with alternative uses as unavailable.

(2) Both mill and logging residues are assumed to be available in system in dry tons. Standard conversion factor was used to convert cubic feet green tons volume of logging residue to dry ton i.e. 1 ton per 29.22 per cubic feet volume(Smith 1991; Ron Piva Research Forester/USDA/FS, pers. comm.).

(3) It was assumed that 1 dry ton of woody biomass can produce 1,500,000 BTUs of energy. Other related conversions are listed in Appendix $C$. These conversions were used by researchers for similar purposes in this region (see Wang et al. 2006, 2007).

(4) During the spatial search process, centroid to centroid distance was assumed to be valid measure of distance. At instances, the centroid to centroid distance may slightly be underestimated if compared with actual road distance. In general this variation is assumed to be negligible based on what we found out in some test cases during the study. The spatial information on availability of residues is limited to county. The system does not consider distance the caused by spatial location of available residue within county. Thus, if the required residue is available within the county, the distance for that amount is the average radius of the county. This method was used to incorporate variation in distance due to shape of county.

(5) For cost calculation purpose logging residue purchase price in system was assumed to be $\$ 0$ and mill residue cost was assumed to be $\$ 20 /$ green ton. These estimates were based on previous studies carried out in this region (Wu et. al. 2008). However, if a price tag for certain residue is known, this can be easily added to the price. Machine rate method was used for cost calculation and current regional values for the variables were used. Assumptions made for those variables are presented in respective section.

(6) It is assumed that logging residues require processing like extraction, chipping, and transportation. The system assumes that chipped materials are loaded directly onto dump truck. For mill residues, processing includes loading, unloading and transportation. 


\subsection{System Design}

A schematic representation of expert system for using woody biomass for energy is described in Figure 2.1, where user information and inputs, expert's knowledge and available biomass data resources are integrated. Components of the expert system include knowledgebase, database and inference mechanism and rules (Giarratano and Riley 2004). The system contains a user interface at the front end and knowledge base and database at the back end. Entire knowledge base search is processed at a server running at a central location. The program uses Apache Tomcat Server (version 6.0) (ASF 2007). Information from server to client is deployed by JSP through http (hyper text transmission protocol). HTML (hyper text markup language) and JavaScripts are used to communicate with users in JSP pages at the client side. Appropriate feedback mechanism from server to client is secured by using JavaBeans.

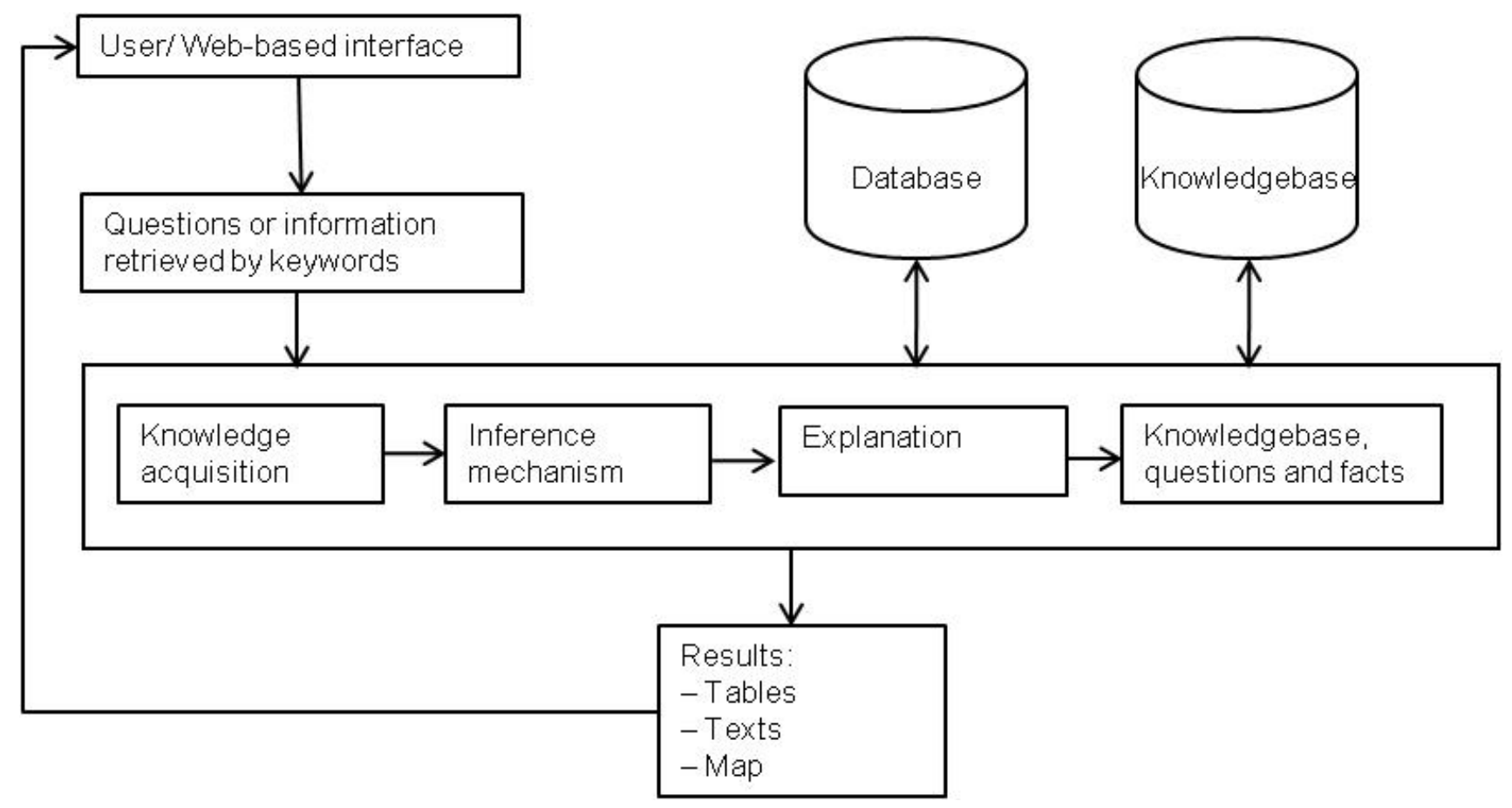

Figure 2.1 System diagram of the web based woody energy expert system.

User has to enter parameters specific to his/her problem in order to retrieve information / knowledge stored in the system. Knowledge base is the primary knowledge that is captured from experts in the field of woody biomass utilization and bioenergy. Database is used to store the data to facilitate user in solving user's specific problem. Inference mechanism is the mechanism that is developed inside the system to understand specific problem of the user such that would be done by the real expert in real world. In an ES, such understanding mechanisms are stored inside the system in different sets of rules.

To achieve the system robustness, flexibility and dynamics, the popular three-layer architecture, also known as multi-tiered architecture in client server applications (Eckerson 1995) is deployed in the 
system. The architecture is composed of three layers: the user interface layer, the functional (inference and conclusion) layer, database layer which is built up java EE (java enterprise edition) which is extremely powerful for developing enterprise level java based applications, primarily for servers (Mukhar et al. 2005). The three-layer architecture aims to solve a number of recurring design and development work efficiently (Figure 2.2). The interface layer in three-layer architecture offers the user a friendly and convenient entry to communicate with the system while the functional layer is the main program controller in manipulation and conclusion drawn based on user's entered parameters, finally the database layer contains information for the system to complete the searching mechanism and problem solution. All layers of the system have been explained in successive sections.

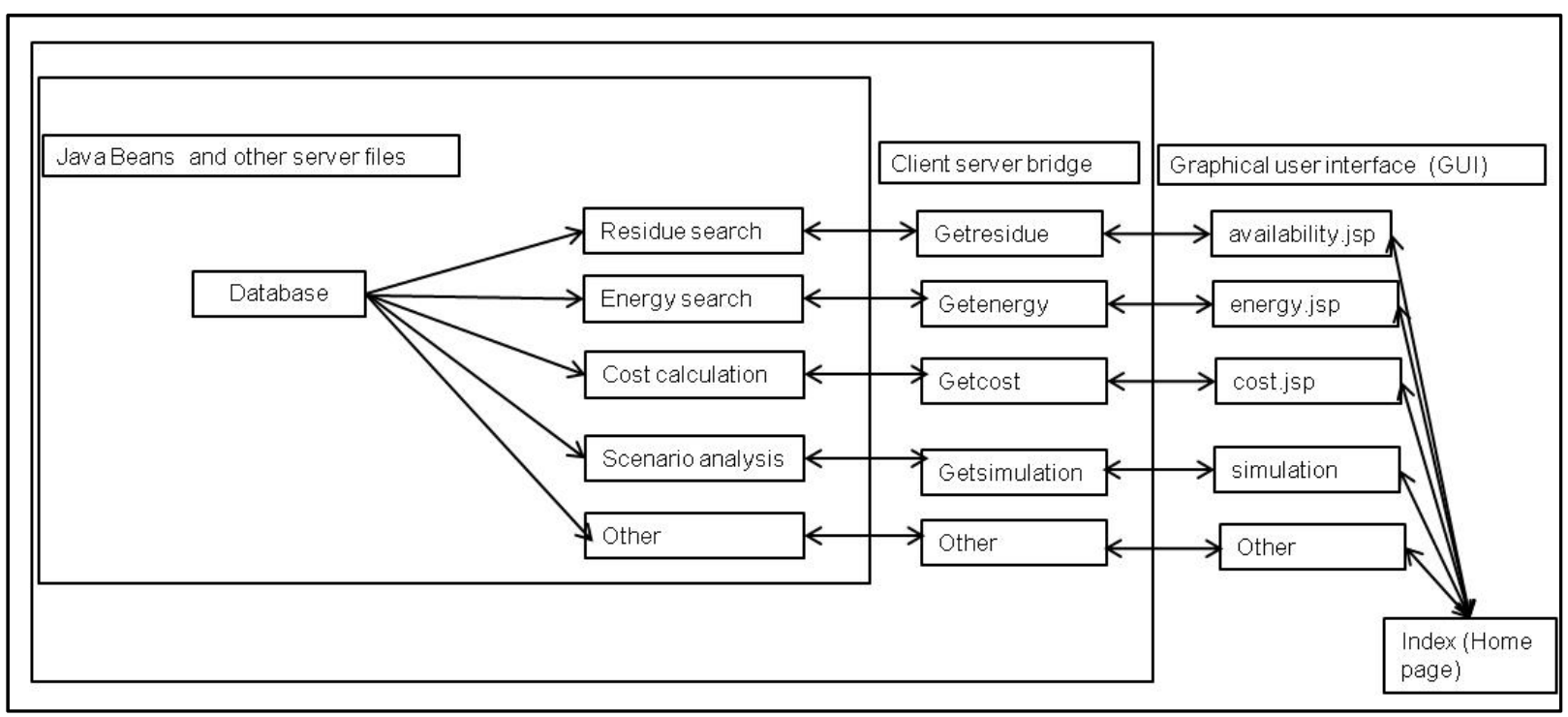

Figure 2.2 Implementation of system components.

Experts' knowledge on applicable machines, their productions and costs as well as search mechanism were assessed and stored in the system in if-then-else statements. The knowledge base was obtained from literature reviews, personal communications and past experiences from individual experts in the field of biomass and bioenergy, industrial personnel in West Virginia and quantitative information available from different sources. Appropriate residue to energy conversion models were selected as applicable to this region based on this knowledge base. Cost assessment models were developed to estimate procurement as well as transportation cost of residues. Spatial location of mills producing residues and logging sites were evaluated and refined on the basis of their accessibility in Geographic Information System and incorporated into the system. The system used wood residue information from Timber Products Output (TPO) (USFS 2008) data for five contiguous states of WV, VA, MD, OH and PA. 
Graphical user interface is the first layer of the system architecture. This is the first place where user can begin communicating with the system. The index page is the starting point of entry to the system which is linked to modules and functions. This layer takes inputs from the user as well as displays the output for the user after processing by the system. In the woody biomass energy system there are descriptions and useful information for the user made available in the interface. This information provides guidelines to use this system and learn about the program. The user interface is composed of several forms developed by using different html components. The system is available for user to communicate with web browser via application protocol http for receiving requests from the user and sending replies. The major scripting language that has been used inside the system is Java Script, which takes user's parameters via html forms and server side communication inside the system is done with JSP. The reason for using JSP was to allow java code to be mixed with the static html or xml templates where java logic handles the dynamic content generation and markup language (such as html) controls the structuring and presentation of data.

\subsection{Data Storage}

Available information is stored inside a relational database consisting of 10 different tables (Figure 2.3). Data is to be used by the system as per the need for conclusion to be drawn. Both the facts and rules used inside the system are captured and stored inside the database developed for the system. Access database has been deployed in our system and relational data model has been applied to facilitate data reuse and maintaining data relationship (Feddema 2002). SQL has been used to query information inside the system's relational database primarily using JSP, java and javabean (Taylor 2007, Mukhar et al 2001). JavaBean utilizes JDBC to access to the database to retrieve stored information and does processing to draw conclusion about the specific problems at runtime. 


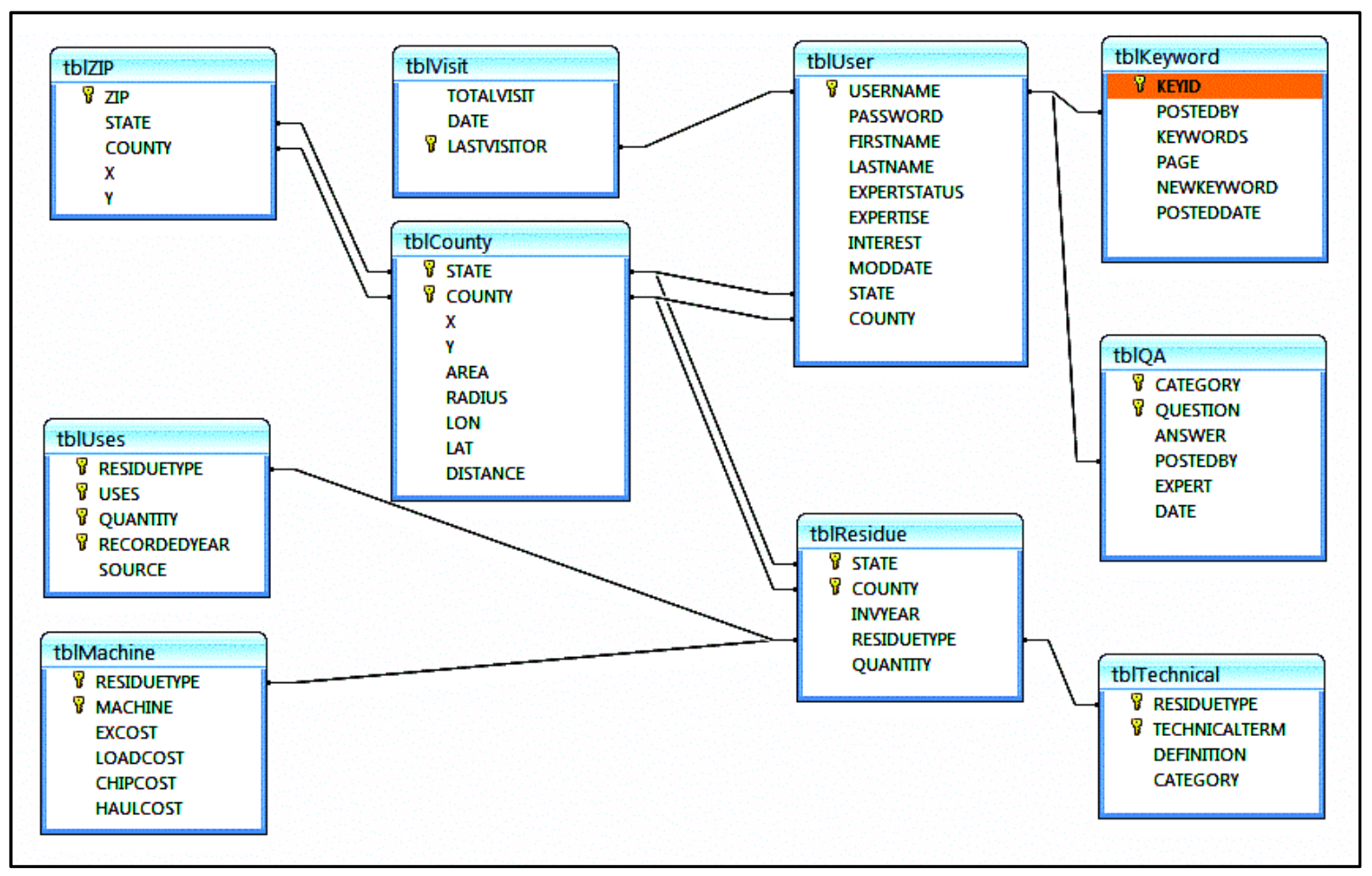

Figure 2.3 ER data model of the system.

\subsection{System Modules}

The JavaBeans ${ }^{\mathrm{TM}}$ architecture is based on a component model which enables developers to create software units called components, which are actually self-contained, reusable software units that can be visually assembled into composite components, applets, applications, and servlets (Matena, 2003). The object oriented programming technique was implemented in which each of the procedures were considered as separate class or more commonly known as objects embedded in these beans at the server. These objects are created, used, reused, and destroyed at runtime as necessary. The system consists of five major modules: cost estimation, residue search, energy search, scenario assessment, and other modules.

\subsubsection{Procurement Costs}

Cost module includes cost analysis for mill and logging residues and their energy equivalencies. For both residue types, the required labor costs are incorporated at component level. Selection of machines for a given component is based on common field practice in the region and from experts' knowledge in the related field. Machine related costs are estimated based on methods described in Miyata (1980) except for transportation. The cost models for woody biomass handling machines used in the system were based on previous studies (Wang et al. 2004a, Wang et al. 2004b, Wang et al, 2005). The process of cost module is shown in Figure 2.4. 
For mill residues, following cost components are incorporated into the system: base purchase price, loading cost, and transportation cost (Wu et al. 2008). Thus mill residue cost can be explained with the linear model shown in equation (2.1).

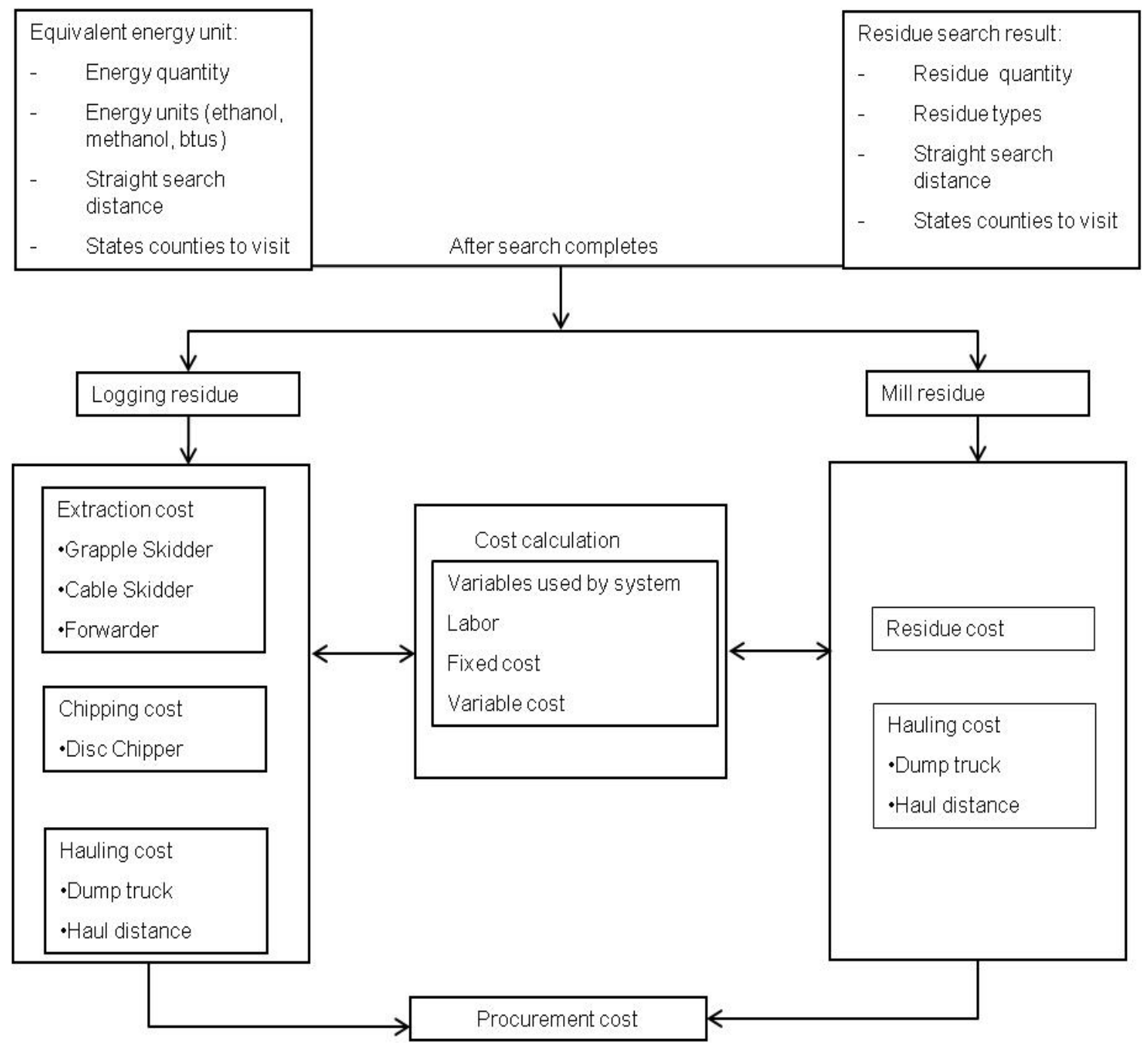

Figure 2.4 Cost calculation framework.

MCOST $=$ Qm *DIST * TCOST + Qm*BASEC + Qm*LDCOST

Where,

MCOST $=$ Mill residue procurement cost $(\$ /$ ton $)$

Qm = Quantity of mill residue (tons)

DIST = Distance needed to travel to obtain Qm (mile)

TCOST $=$ Transportation cost $(\$ /$ ton $)$

BASEC $=$ purchase price for mill residue (\$/ton)

LDCOST = Loading cost of mill residue in dump truck (\$/ton) 
For logging residue following costs are incorporated: extraction cost, chipping cost, and transportation cost (Wu et al. 2008). These costs are calculated as in equation (2.2).

$\mathrm{LCOST}=\mathrm{Q}$ * $\left(\mathrm{EXCOST}+\mathrm{CHCOST}+\mathrm{DIST}{ }^{*} \mathrm{TCOST}\right)$

Where,

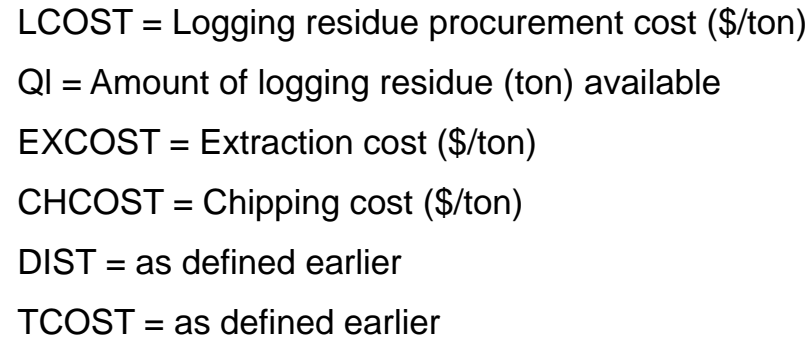

\section{(1) Mill residue}

The transportation analysis for mill residue provides estimated costs to transport mill residues from a given mill location to a location where the residue is required. The transportation cost model was based on Wood Transportation and Resource Analysis (WTRANS) (Jensen et al. 2002) and machine rate (Miyata 1980) along with other models (Wang et al. 2007, Wang et al. 2004a, 2004b). A dump truck which can carry the processed residues such as chips and saw dust was considered for transporting the products. The transportation cost assessment follows a series of mathematical models (2.3) including costs for loading (LOADC), hauling costs (HAULC) and residue purchase cost (PRESID). The loading cost is labor cost from loading at the time of residue pick up to the time of residue delivery.

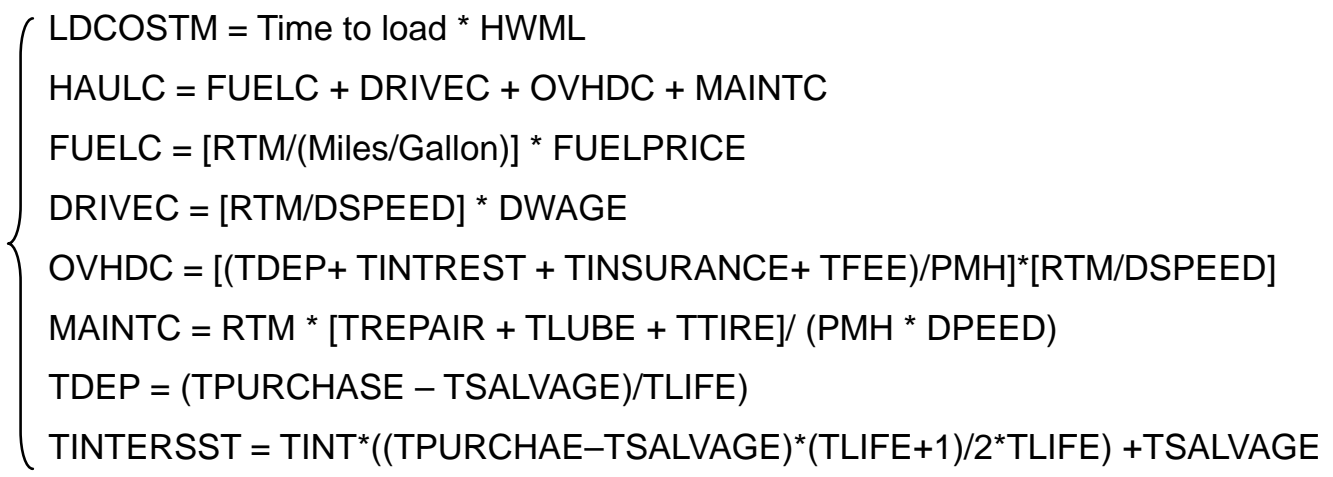

Where,

LDCOSTM $=$ Cost for loading mill residue (\$/truck load)

$\mathrm{HWML}=$ Hourly wage for mill residue loading (\$/hour)

FUELC = Fuel cost (\$)

FUELPRICE $=$ Fuel price $(\$ / g a l)$

DRIVEWAGE = Driver's wage $(\$ /$ hour $)$

DRIVEC = Driver's cost (\$) 


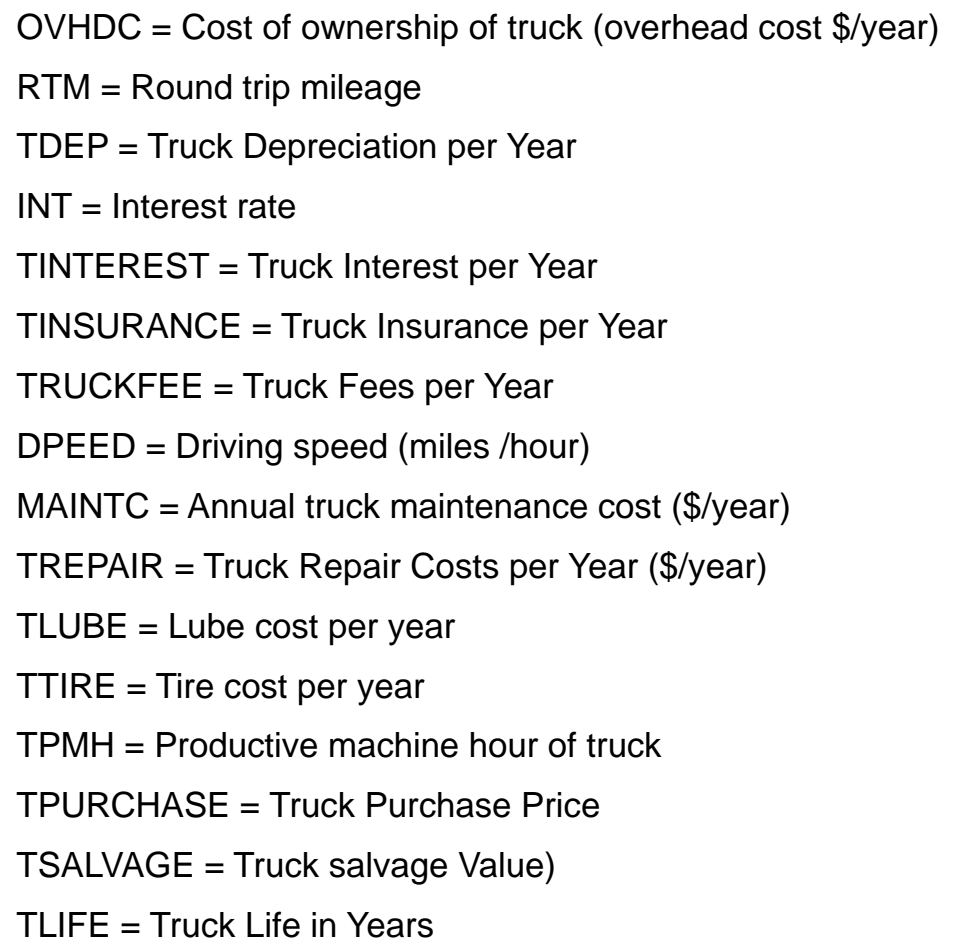

The default labor wage for loading is $\$ 15.57$ per hour (Bureau of Labor Statistics, 1999). Default loading time is assumed to be 1 hour. Users can adjust the labor hour and wage rate or they can use default values. The default driver wage is for heavy or tractor-trailer truck drivers. In WV, estimation is $\$ 17.80$ an hour for truck drivers (Bureau of Labor Statistics 1999). The default fuel price is set to the Eastern regional price for diesel as of August 11, 2008 (DOE, 2008). The regions where the mill residues are searched fall into the Eastern region for Department of Energy diesel price calculations. The average regional price was $\$ 4.36$. Default values for interest rates are assumed at the current prime-lending rate of 9.5 percent (Federal Reserve) plus 2.5 percent to adjust for risks and profits. The internet provided price estimates for truck purchase costs. The price for a new 33,000-pound haul dump truck is about $\$ 90,000$ (for International 7300 series). The life of the truck is assumed on a 10-year schedule with assumed salvage value of $\$ 20,000$. Mileage per gallon is about 9 miles (phone conversations with a truck dealer). Insurance costs are assumed at \$2,100 per year. Truck fees include licenses and registration with assumed default value of $\$ 5,000$. This value is based on information obtained from the licensing agencies in Morgantown, WV.

Operating or productive machine hours which is $50 \%$ of actual scheduled hours (travel hours, excludes load and unload times, fueling time, driver's break and maintenance and repair) were assumed at 5 hours per day with 1000 hours per year. It is assumed that the truck can haul at the speed of 60 miles per hour so total distance hauled by the truck during its lifetime is 600,000 miles which is the maximum expected distance for this type of truck. Maintenance costs are assumed at $\$ 3,600$ per year $(\$ 2,000$ for tires, $\$ 600$ for lube, and $\$ 1,000$ for repairs and other maintenance). 
Maintenance is assumed at every 10,000 miles. The hauling costs (HAULC) are for a truckload of residues. To calculate the hauling costs on a per ton basis, the weight load of residues hauled must also be included. The weight per truckload can be calculated from truck capacity and density of the wood residues, where:

TWTC $=$ Truck weight capacity in tons

TVOLC $=$ Truck volume capacity in cubic feet

The capacity of the truck will either be reached through the volume maximum or the weight maximum. If the density of the wood residue (tons/cubic feet) (DENS) is greater than TWTC/TVOLC, then the capacity will be based on the weight. If the density of the wood residue is less than TWTC/TVOLC then the capacity is based on the maximum volume the truck will hold. Densities of the residues are set to default values for common hardwood and softwood species in WV. These estimates are used as the suggested or default. An information box specifying densities for other species is also provided. It is assumed that a maximum truck capacity of 25 tons or 4,200 cubic feet in volume for trucks hauling tires. The values of 25 tons or 4,200 cubic feet are used as the default values for the truck capacity.

Once the weight in tons/truckload (RTONSTL) is calculated, the transportation costs/ton (TCOST) and cost per ton per mile is respectively estimated by equations (2.4).

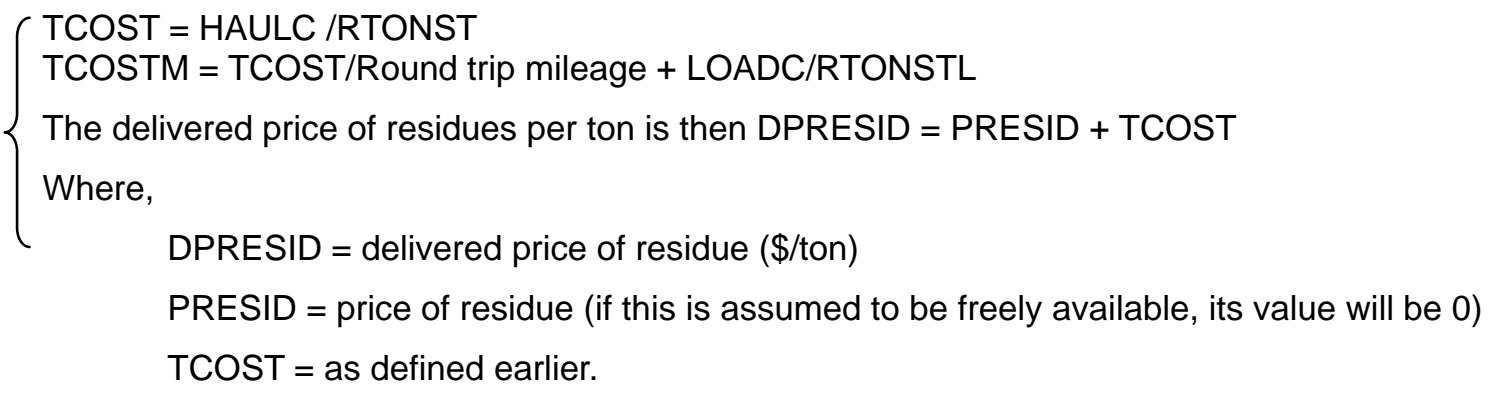

The values of PRESID are based on information from a Timber Market Output (TPO) data for West Virginia. The purchase price of mill residue is assumed to be $\$ 32 /$ ton. However, users are allowed to provide their cost based on their observations. The amount of mill residue searched in base case is assumed to be 1,000 tons. Transportation distance is assumed to be the radial distance to search for 1,000 tons in searching mechanism if no parameters will be provided by the user. 


\section{(2) Logging residue}

Cost calculation for logging residue includes three different kinds of intermediate cost components, which are logging residue extraction cost (EXCOST), chipping cost (CHCOST), and transportation cost (DPRESID).

Logging residues are assumed to be available for free and only costs associated with logging residue are related to processing and transportation. This assumption is reasonable as in absence of somebody else taking away these logging residues, the land owner has to spend money in managing those residues and prepare site for regeneration. As the market for these residues develops in the future, the purchase cost of logging residues should also be considered.

In the system, there are mainly three common types of machines available for logging residue extraction and processing (Wang et al. 2004a, Wang et al. 2004b). However, users are allowed to change their machine and customize cost by providing different cost parameters for machine cost calculation as described in Wu et al. (2008).

Chipping cost for logging residue depends on the machine. Basically chipping operation is conducted on the spot right after residue extraction. Disc chipper is the most widely used chipping machine for logging residue for chipping operations. Therefore, the disc chipper has been considered as the default chipping equipment in this system which will feed to truck for transportation.

For extraction and chipping cost of logging residue, machine rate methods were used to estimate the unit costs (Miyata 1980, Wang et al. 2004a \& 2004b, Wang 2007) based on labor cost, variable or operating cost (VARIABLEC) i.e. fuel, lubes and other maintenance; and fixed or ownership cost (FIXEDC) i.e., machine purchase price, interest, insurance and tax needed to pay for machine on annual basis (equation 2.5). Machine assumptions and productivity information for these machines are described in Table 2.1 and Table 2.2 (Wu et al. 2008).

Based on the productivity models for logging residue extraction developed in the central Appalachian region (Wang et al. 2004, Li et al. 2006, and Grushecky et al. 2007), the average extraction distance was assumed as 1,000 feet. The payload size was $106 \mathrm{ft}^{3}$ for cable skidder, $107.87 \mathrm{ft}^{3}$ for grapple skidder, and $304.62 \mathrm{ft}^{3}$ for forwarder. The logging residue density of 0.02 dry tons per cubic foot was multiplied by the productivity in cubic feet per hour to get the productivity in dry tons per hour. 


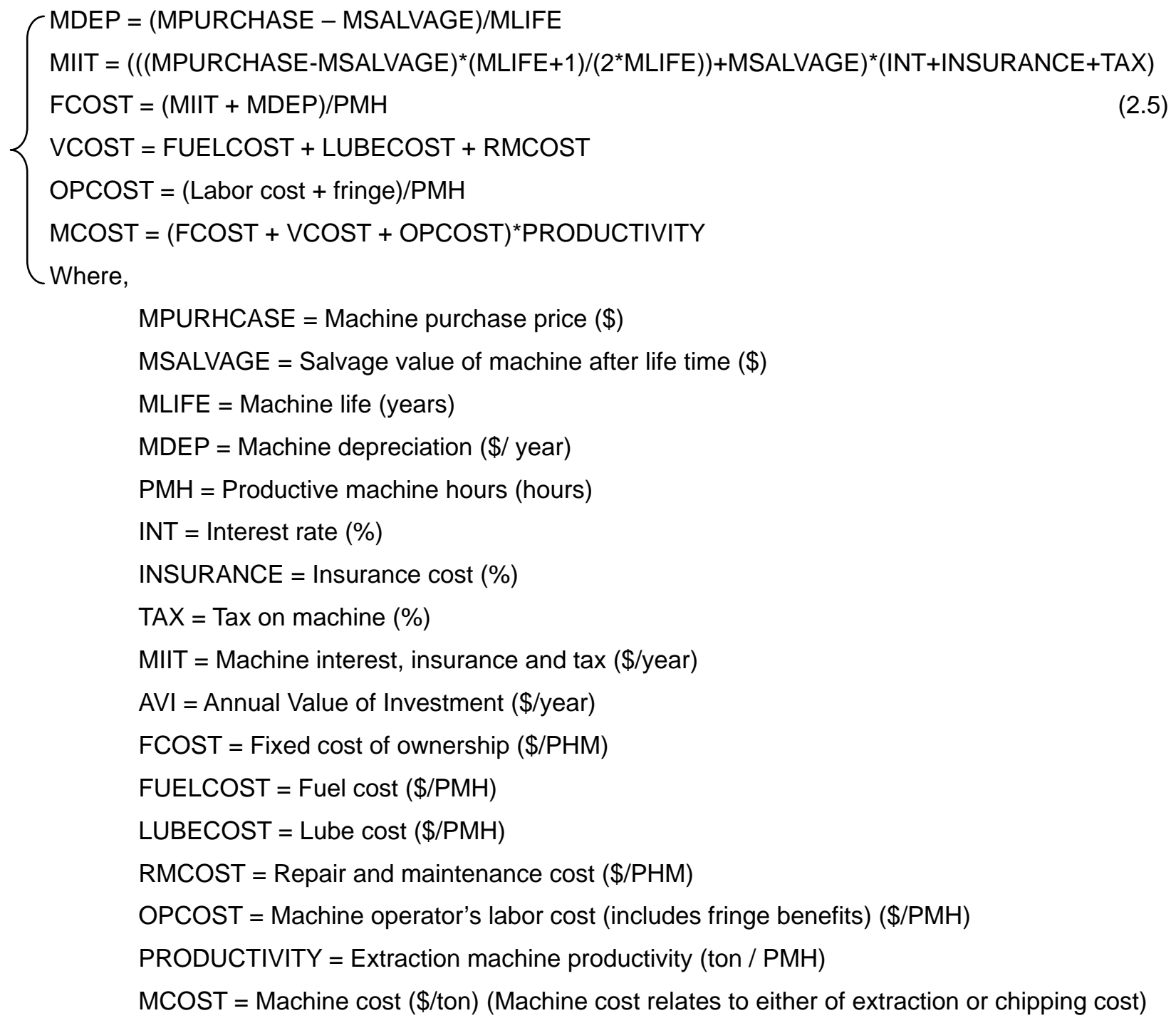

Table 2.1 Assumptions for logging residue extraction/handling machines.

\begin{tabular}{lcccc}
\hline Items & Cable & Grapple & Forwarder & Disc Chipper \\
\hline Purchased price (\$) & 170,000 & 19,0000 & 250,000 & 610000 \\
Savage value (\% of price) & 25 & 25 & 25 & 25 \\
Economic life (years) & 5 & 5 & 5 & 5 \\
Interest, insurance, and tax (\%) & 20 & 20 & 20 & 20 \\
Labor cost (\$/hour) & 15.57 & 11.57 & 11.57 & 11.57 \\
Labor fringe (\% of labor cost) & 35 & 35 & 35 & 35 \\
Maintenance and repair (\% of & 90 & 90 & 90 & 90 \\
Mechanical availability (\%) & 65 & 65 & 65 & 65 \\
Horse power (hp) & $100-110$ & $110-120$ & 110 & 110 \\
Fuel consumption (gal/hp.hr) & 0.028 & 0.028 & 0.0248 & 0.0248 \\
Lubricant (\% of fuel cost) & 36.77 & 36.77 & 36.77 & 36.77 \\
Scheduled machine hours/year & 2000 & 2000 & 2000 & 2000 \\
\hline
\end{tabular}


Table 2.2 Fuel consumption per ton handling and processing of logging residue.

\begin{tabular}{lc}
\hline Machine & Productivity (tons/hr) \\
\hline Cable skidder & 2.81 \\
Grapple skidder & 4.713 \\
Forwarder & 8.35 \\
Disc chipper & 16 \\
\hline
\end{tabular}

The transportation analysis for logging residue provides estimated costs to transport logging residues from site to destination. Once the residues are chipped, it is easier to transport using a dump truck or a chip van and thus the cost factor is similar to what has already been described for mill residue. Thus equations 1 to 13 hold true for logging residue transportation cost calculation as well.

\subsubsection{Residue and Energy Search}

Residue search module searches for required amount of mill, logging or both mill and logging from a specified location. The database in the system currently holds data for five contiguous states of WV, PA, $\mathrm{MD}, \mathrm{VA}$, and $\mathrm{OH}$. The search module can also be used to search for given amounts of residue by restricting the search within certain spatial location, i.e. one or more states. For a search, users are required to supply some basic information such as required residue amount, location of search in state and county and residue type. If, however, users do not supply all the information, the system is designed to use some default values for search module (Table 2.3).

Table 2.3 Default search parameter.

\begin{tabular}{ll}
\hline Parameters & Default value \\
\hline Residue type & Both \\
Location state & West Virginia \\
Location county & Monongalia \\
Quantity & 1000 tons \\
States to avoid & None \\
\hline
\end{tabular}

The system looks for availability of given residue type in the county from where search has originated and continues to look for nearest counties from that location until all the required residues are identified (Figure 2.4). In order to determine the nearest county, the centroid of each county is used to estimate the distance. These centroids, extracted from GIS, for counties in five states are stored in the database in latitude and longitude format. At runtime, straight line distance between user's entered county's centroid coordinate location, i.e. lat/long and all other counties' centroid locations, i.e. lat/long is calculated using equation (2.6). 


$$
\mathrm{XY}=\sqrt{\left(X_{2}-X_{1}\right)^{2}+\left(Y_{2}-Y_{1}\right)^{2}}
$$

Where,

$X Y=$ straight line distance between centroid of one county to centroid of another county.

$\mathrm{X}_{1}=$ Centroid latitude of searching start county

$Y_{1}=$ Centroid longitude of searching start county

$\mathrm{X}_{2}=$ Centroid latitude of other county

$Y_{2}=$ Centroid longitude of other county.

After straight line distance calculation, available distance is sorted in increasing distance. Once the point where required amount is >= available amount is identified, search process stops for further processing and results are displayed in a tabular and text format. The result displays state, and counties to visit, and search distance for different quantities until all the required quantities are achieved (Figure 2.5). A map is also displayed with the identified search locations and other results.

If required amount of residue is available in the same county from where the user searches, then the average of maximum and minimum radial distances of that county is considered as procurement distance for that search. System displays default residue if no parameters for search is entered by the user. If the user wants to continue with cost calculation for residue searched, the system suggests accordingly. 


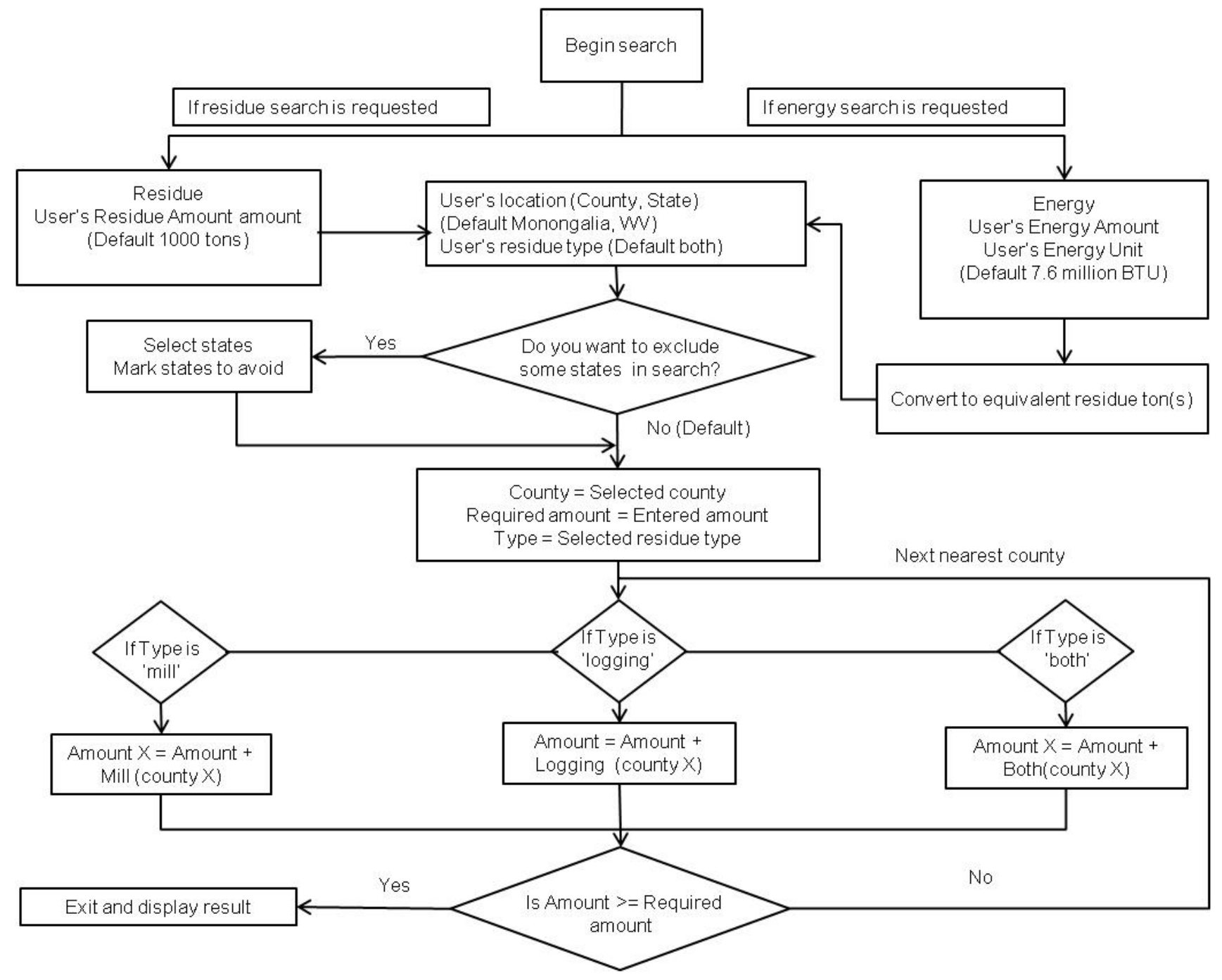

Figure 2.5 Schematic representation of search mechanism.

Energy searching mechanism first converts the given energy amount in different units of BTU, ethanol, and methanol into equivalent wood residues and functions similar to mechanism used in the residue search module.

\subsubsection{Other Modules}

\section{(1) Ask Expert}

This module has four different categories, definition, technology, economy, and environment related to woody biomass energy. User can either search in a particular category that have been reviewed and answered previously or they also have opportunities to post their questions. Users can send a specific question they have in the field of woody biomass energy. For this purpose, users need to enter their email address with questions they have for the expert and they can simply hit the button to post in the "ask expert" page. Then questions are stored in a database. There could be thousands of questions from other users in that database and those questions will be reviewed by the expert and answers will be sent back via email. Those questions will also be available on the web site under an appropriate 
category if they fit. Otherwise a new category can be identified if volume of suitable questions is large.

\section{(2) Simulate Data}

This module makes use of existing framework of the system to generate information on residue availability and displays a summarized graph for procurement distance and cost of woody biomass. The module communicates with search and cost module for different residue type within a certain range of amounts and requires users to specify the parameters. If the user does not specify these parameters a default value specified is used to generate the results (Table 2.4).Based on minimum and maximum amount, the system internally seeks cost and distance information at 20 equal intervals.

Table 2.4 Required parameters and default values for simulation module.

\begin{tabular}{ll}
\hline Parameter & Default value \\
\hline Residue type & Mill \\
Location (state and county) & WV, Monongalia \\
Minimum amount & 1,000 tons \\
Maximum amount & 50,000 tons \\
Default cost parameters (as in cost module) & - \\
\hline
\end{tabular}

\section{(3) Other Functions}

System design link in the web site has conceptual framework of different modules of the program which users can view and download. Data sources link displays the data sources that has been used in the system. User's guide provides a comprehensive walk through of the program (Appendix A). Bioenergy fact is another page that provides facts related to woody biomass energy uses, opportunities and availability. This page contains charts, graphs and other useful information on biomass and bioenergy.

Unit conversion is the page that is developed to provide conversion related information of woody biomass to different energy units. For example, simple conversion functions for ethanol, methanol, BTUs and tons are available. The conversion information is given in Appendix B. Term definition is the page that is developed for this system with definitions and descriptions about all technical terms that have been used to develop the system. 


\section{RE S U L T S}

\subsection{Residue Availability}

The search domain consists of five states as mentioned previously. The availability of wood residues in these five states is summarized in Table 3.1. These figures are stored in the database at county level. West Virginia has a large amount of logging residues after Pennsylvania. This probably indicates that targeting logging residues in WV is more feasible for biomass based industries than mill residue. About 12 million dry tons of woody residues are available in five contiguous states.

Table 3.1 Availability of mill and logging residue in five states included in the system.

\begin{tabular}{lrrr}
\hline State & Mill residue(dry tons) & Logging residue(dry tons) & Total (dry tons) \\
\hline MD & 165,592 & 308,832 & 474,424 \\
OH & 942,943 & 932,496 & $1,875,439$ \\
PA & $1,629,889$ & $1,986,391$ & $3,616,280$ \\
VA & $2,865,177$ & $1,320,442$ & $4,185,619$ \\
WV & 967,977 & $1,629,729$ & $2,561,786$ \\
\hline Total (dry tons) & $6,571,578$ & $6,177,890$ & $12,749,468$ \\
\hline
\end{tabular}

(Source: USFS 2008)

For mill residue, maximum amount searched is 6,571,576 tons and the cost per ton for this amount ranged from $\$ 47.17$ to $\$ 55.56$ with average per ton cost of $\$ 50.71$. Similarly, hauling distance ranged from 285 to 454 miles with an average distance of 361 for all the counties in the state of West Virginia. For logging residue, maximum searched amount is 6,141,972 and cost per ton for this amount ranged from \$52.99- \$ 61.54 with average \$55.80. Distance ranged from 295 miles to 454 miles and average distance 367 miles.

The developed system was tested for its suitability in assessing cost and availability of woody biomass residue in WV. For this, a hypothetical biomass utilizing plant facility was assumed with a daily demand of 1000 tons of dry biomass residue. Thus, the annual requirement of this plant would be 360,000 tons of residues. Depending upon the location of this hypothesized plant in different counties, unit cost of mill residue would be in between $\$ 35.4-\$ 38.27$ (average of $\$ 36.82$ ) per ton. The required hauling distance would be in between 36 - 77 miles (average 56 miles). The same amount would be available from logging residue at unit cost range of $\$ 38.63-\$ 41.83$ (average $\$ 40.08$ ) requiring hauling of 28 63 (average 47) miles. If the demand for logging residue is high, fulfilling demands from both logging and mill residue is economical because hauling mill residue from very long distance may not be viable. 
For example, if hypothesized plants acquire both mill and logging residue, the cost per ton would range in between $\$ 36.05$ - \$ 38.97 (average \$37.44) and required hauling distance would range in between $23-51$ (average 37 ) miles.

Except for $\mathrm{VA}$ and $\mathrm{OH}$, mill residue availability is lower than that of logging residue in all other states. Therefore, higher hauling distance is required if residue demands are to be fulfilled from mill residues. In general, mill residues are available at cheaper rate even though they need to be purchased at $\$ 32$ per ton. They, however, require additional hauling in comparison to logging residues. Logging residues, although assumed to be available free, the extraction and preprocessing involved with them usually push total cost up. The eventual development of markets for logging residues lying in the forests in future would certainly limit free availability of these residues. For example, some landowners are selling the logging residues at the stumpage price of $\$ 2$ per ton in WV (USDA 2004) and in future this price may increase. These analyses show that the model can be used in identifying opportunities for establishing biomass residue utilization plants.

\subsection{Procurement Distance}

County's location and biomass availability in adjoining counties determine the distance to travel to obtain certain amount of residues at a given county. System's simulation module was run for different amount of residue search and retrieved the information on average distance to be travelled to collect that amount of residue. Minimum 10000 dry tons/ year of mill residue was searched and maximum of 6.14 million dry tons/ year of residue were searched. Similarly, in case of logging residue minimum amount of residue searched was 10000 dry tons /year and maximum residue searched was 6.7 million dry tons/ year from all counties in West Virginia and searching were unlimited in 5 states including WV. Based on the simulation results distance and residue searched graphs were created.

Tables C.1, C.2 and C.3 in Appendix C show the relationship between distances required to travel to obtain a given amount of residues respectively for mill, logging, and both mill and logging residues for 55 counties in West Virginia obtained by running the simulation module.

Relationship between distances to be travelled to collect different amount of mill residues are presented for different residue amounts (Table C.1). Trend of distance to travel for different residue amount does not remain the same if the amount demanded is increased for the same county. Thus, a linear relationship cannot be established. In such a situation, the system can provide the runtime results. For example, just to obtain 1,000 tons of mill residues, distance varied from $7-22$ miles in different counties. Availability in Pleasants and Calhoun require least distance and counties like Summers and McDowell require higher distance for the same amount of residues. But for 6.5 million tons of mill residue, 285 miles is the shortest hauling distance i.e in Preston county and 454 miles is the longest 
distance i.e in Mingo county (Table C.1).

In order to analyze the variability in distance for different amount of residues (i.e. minimum 1000 dry tons to maximum available for mill and logging residue) in different counties, simulation module was run for respective amount for each of the 55 counties individually. These results were used to generate the box plot which shows the required distance for different residues applicable to percentile of counties in WV.

The result showed that 6.5 million tons of mill residues would require 290 miles or less distance for $25 \%$ of the counties of state. Up to 340 miles of distance is required for $50 \%$ of the counties and up to 370 miles distance is required for $75 \%$ of the counties. Finally, if allowed procurement distance is 420 miles, this amount of residue is available in all the counties of WV (Figure 3.1).

For 1000 tons of logging residue, Hancock and Brooke counties require 5 miles of hauling and Randolph county requires a maximum of 18 miles of hauling distance. For 6.1 million tons of residue minimum distance needed to be travelled is from Monongalia county with 295 miles and maximum distance is from Mingo county with 454 miles of distance (Table C.2). For $25 \%$ of counties this amount of residue is available within 280 miles, for $50 \%$ counties within 310 miles, and for $75 \%$ of counties within 355 miles (Figure 3.2).

For both logging and mill residues (Table C.3), 1000 tons of residue minimum distance needed to be travelled is 7 miles i.e., from Pleasants county and maximum distance is 22 miles from Summers county. Depending on the residue availability in different counties and county's location where that amount is demanded, the procurement distance varied significantly in most instances except for instances where change in demand is very small. As indicated earlier, combining both mill and logging residue would result in smaller hauling distance. As mill residues require less processing, the system has been designed such that available mill residue is given priority over available logging residue when both type is requested during search process. When both mill and logging residue is requested, the system looks for logging residue only if requirement cannot be fulfilled from mill residue at a given place. 


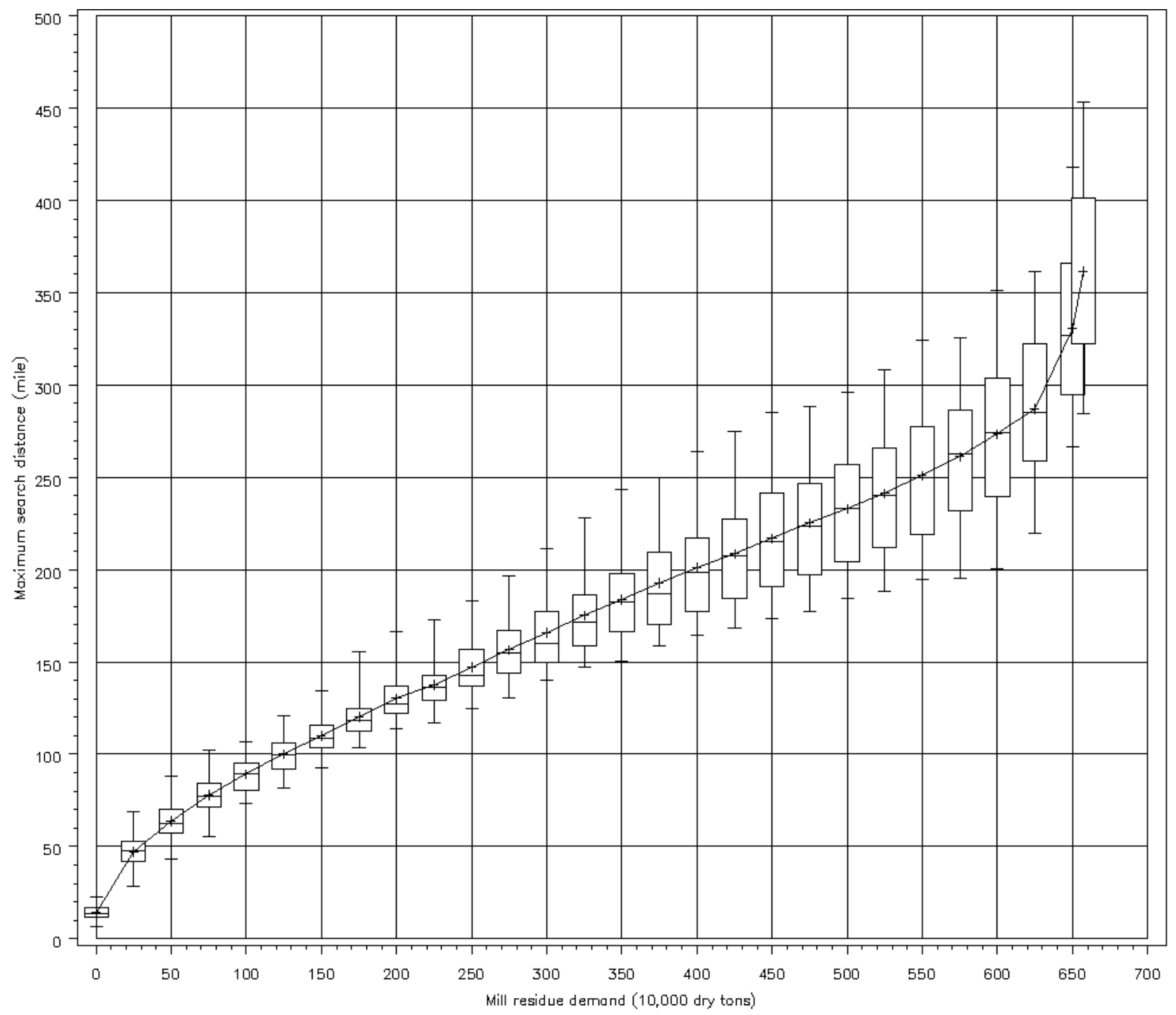

Figure 3.1 Procurement distance for various amounts of mill residues in WV. This box plot was generated by simulating the procurement distance for each of the 55 counties in $\mathbf{W V}$ for different amounts of mill residue. The boxes show minimum, maximum and quartile of number of counties where given residue amounts indicated in X-axis are available within the distance shown in Y-axis. The mean value for the entire state is shown by a ' + ' and connected with a line. 


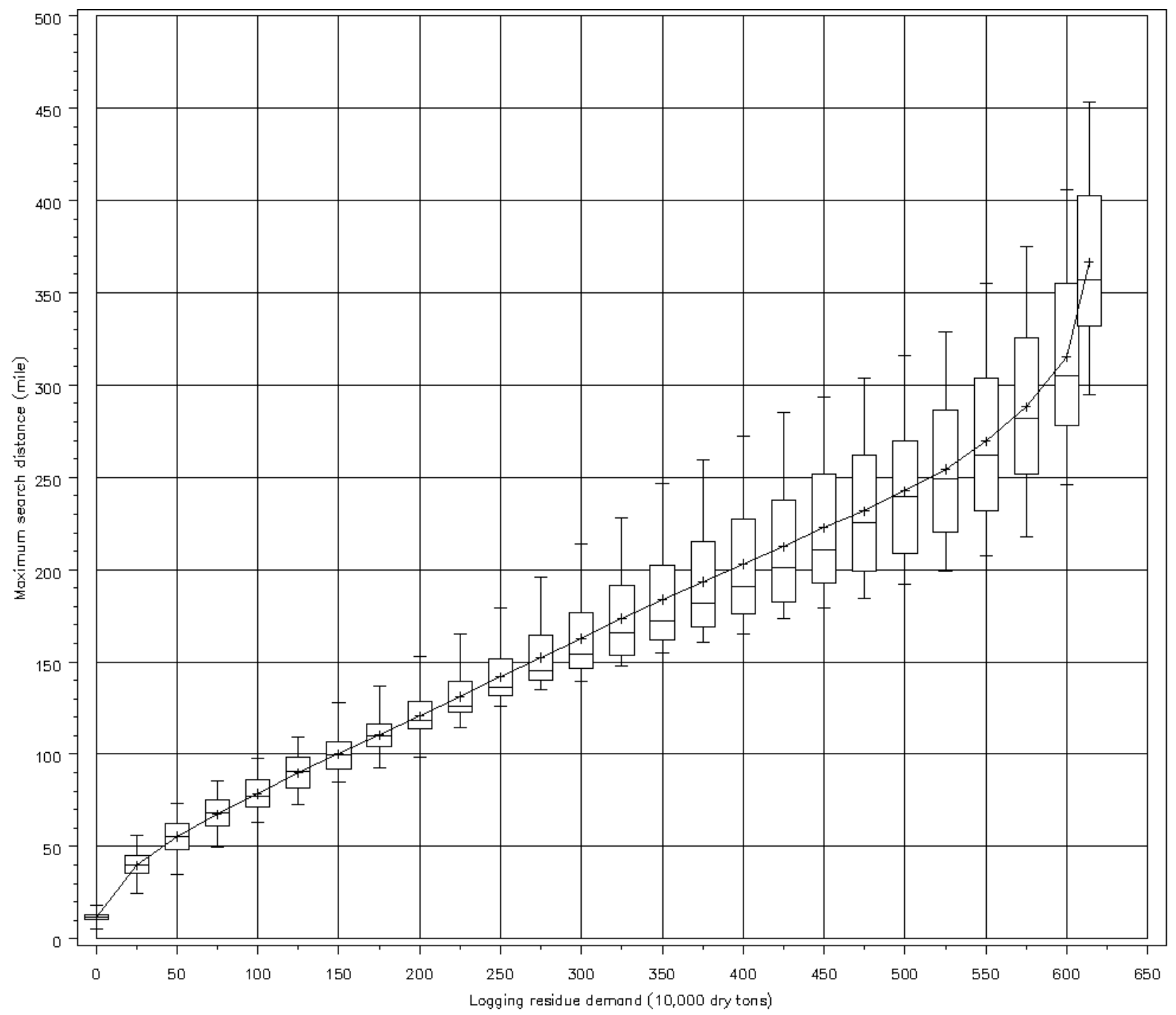

Figure 3.2 Procurement distance for various amounts of logging residues in WV. This box plot was generated by simulating the procurement distance for each of the 55 counties in WV for different amounts of logging residue. The boxes show minimum, maximum and quartile of number of counties where given residue amounts indicated in X-axis are available within the distance shown in Y-axis. The mean value for the entire state is shown by a ' + ' and connected with a line. 


\subsection{Procurement Cost}

Delivered cost is defined as weighted average of the costs of procuring different amounts of residues from different locations. For cost information simulation model for required wood residues were run and thereafter cost calculation for the entire searched residue amount was done from all the counties in West Virginia and searching was unlimited throughout the five states. Based on the obtained simulation results graphs to show relationship between cost and residue searched were created for mill and logging.

The delivered costs of biomass residues in 55 counties of WV were analyzed for mill, logging and both mill and logging residues (Figures C.4, C.5 and in Appendix C). The delivered costs for 1,000 tons of mill residue varied between $\$ 33.5$ /ton - $\$ 35.9$ /ton and for 6.5 million tons of mill residue the cost varied between $\$ 47.5 /$ ton - $\$ 55.5 /$ ton. The maximal amount would cost about $\$ 49 /$ ton for $25 \%$ counties, $\$ 50.5 /$ ton for $50 \%$ counties, and $\$ 52 /$ ton for $75 \%$ of the counties in WV (Figure 3.3).

For logging residue, delivered cost ranged between $\$ 36.5 /$ ton - $\$ 38.5 /$ ton for 1000 tons, and between $\$ 53 /$ ton - \$63/ton for 6.14 million tons. The maximal amount would cost about $\$ 51.5 /$ ton for $25 \%$ counties, $\$ 55 /$ ton for $50 \%$ counties, and $\$ 58.5 /$ ton for $75 \%$ of the counties in WV (Figure 3.4).

As with distance, the cost for mill residue is cheaper for a given amount of biomass than logging residue. Except for a small quantity change where delivered cost per ton of mill residue and cost of both mill and logging residue remain same, the delivered cost of residue increases from mill, both to logging residue types. 


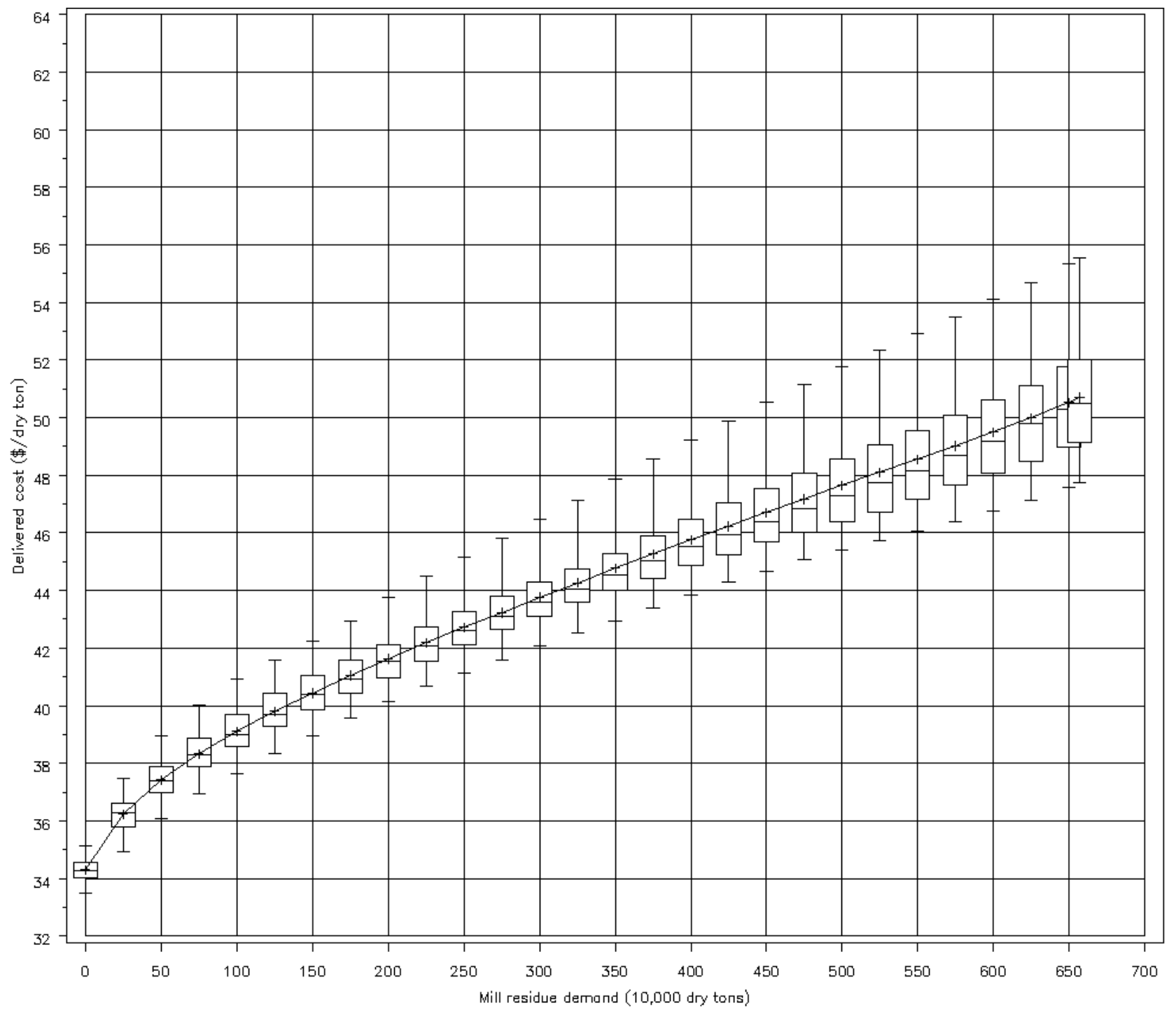

Figure 3.3 Delivered costs for various amounts of mill residues in WV. This box plot was generated by simulating the procurement cost for each of the 55 counties in WV for different amounts of mill residue. The boxes show minimum, maximum and quartile of number of counties where given residue amounts indicated in $X$-axis are available within the distance shown in Y-axis. The mean value for the entire state is shown by a ' + ' and connected with a line. 


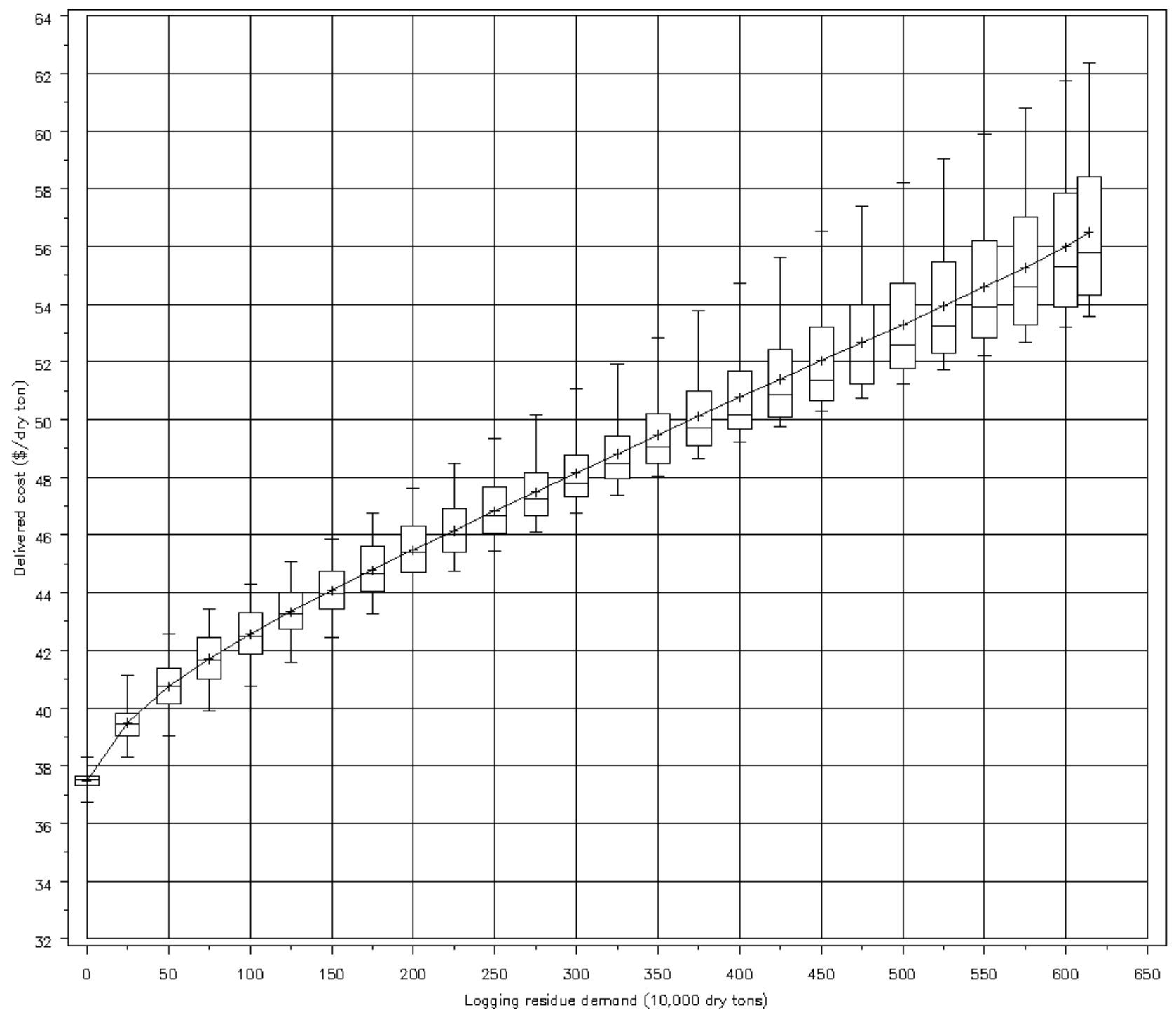

Figure 3.4 Delivered costs for various amounts of logging residues in WV. This box plot was generated by simulating the procurement cost for each of the 55 counties in WV for different amounts of logging residue. The boxes show minimum, maximum and quartile of number of counties where given residue amounts indicated in X-axis are available within the distance shown in Y-axis. The mean value for the entire state is shown by a ' + ' and connected with a line. 


\section{CONCLUSIONSANDFUTURE WORK}

Due to the rising cost of foreign fossil fuels, increasing concerns about green house gas (GHG) emissions and global climate change, alternative energy source has drawn considerable interests in recent years. Woody biomass resources are being considered as important alternative to foreign born fossil fuels and can be grown and used sustainably for energy independence. The analytical tool developed could be a useful resource kit that can be used to fulfill the gap of information on availability and cost of woody biomass utilization for energy alternatives.

The system developed has been tested at several levels. The demonstrated application of this expert system shows potentials in giving insights into the real world scenarios related to woody biomass as energy. The system can be used for potential applications by interested users on the web. The database aspect of this program offers easy update to handle changing factors of availability and costs at different levels without having to change the system. The system used several classes and libraries to offer such functionalities. This system provides a user friendly interface and flexible functions to analyze procurement distances, costs, and their interrelationships with biomass availability.

The system facilitates user to try every possible way to start a residue search and choose the most appropriate way for handling residues. Analysis for both procurement distance and cost demonstrated comparisons of woody biomass procurements, and model applications in analyzing procurement distance and cost relationships. Opportunity and cost for establishing biomass utilizing facilities can be assessed by using this system as described in results section for a hypothesized woody residue utilizing plant with certain residue demands.

In this study, although cost and distance relationship of different woody residues are described for counties in WV, the system can equally be applied for generating similar information for other states covered in the system. The system's applications can be broadened by incorporating other states too. The system is flexible and enables users to select their own machine in residue handling and processing at different levels. The results are presented in tables and texts as well as location maps of search domain. In regards to developmental aspect of the system some future works have been noted. The system currently uses Google map API to generate maps, and in future such maps could be generated by a module in the system so that dependency of this system on external resources can be minimized in future. The system relies on estimating aerial distance for searching residues. Although, in the test data set, the aerial distance and actual road distance varied by less than 2 percent for some counties, this can be modeled with optimized actual road distance for residue transportation.

Woody residues are adequately available for use in WV at reasonable cost and distance. Although, cost and haul distance varied in different counties in the state, the cost and distance of procuring biomass 
are reasonable. For example, about 6 million tons of residues (both mill and logging) are available at the cost of under $\$ 50$ per ton and within 250 miles distance in different counties. This cost is below $\$ 47 /$ ton and distance is less than 175 miles for over $50 \%$ of counties in WV.

The simulation module of the system gives functionality of assessing trends and variations in cost and distance for different residue demands in different counties. For example, the cost of certain amount of residues may not be same for all the counties in WV. The simulation gave insights into suitable counties in terms of distance to haul as well as cost per ton of woody residue procurement. Fulfilling demands for a given amount of residue from mill residue is cheaper than that from logging residue. For larger amounts, mixing both mill and residues to fulfill demands would be cost efficient. Hauling distance for a mill residue is larger than that of logging residue.

In the system, mill residues are given a cost of $\$ 20$ / green ton based on available literatures and logging residues are assumed to be freely available. With emergence of markets for these waste products in future, it is anticipated that the landowners would be willing to put some price on logging residue too. So far one literature have indicated that logging residues have become marketable products that sells for stumpage price of $\$ 2 /$ ton in some areas in WV (USDA 2004). Given this information, it can be assumed that there will be some cost for logging residue in future and the cost would increase from currently available cost information of $\$ 2 /$ ton. Thus, for making decisions based on costs, it is recommended to put an additional 2-5\% of delivered cost for risks and uncertainty so that the system's results can accommodate the variations in real world situations. 


\section{R E F E R E N C E S}

Beck, H.W., Gilman, E.F. Fowler, P.A. 1994. An expert system for tree selection in urban forestry. Applied Engineering in Agriculture.10(5):743-747.

Duncan M. 2004. U.S. federal initiatives to support biomass research and development. Journal of Industrial Ecology. Vol (3-4): 193-201.

Eckerson, W.W. 1995. Three Tier Client/Server Architecture: Achieving Scalability, Performance, and Efficiency in Client Server Applications. Open Information Systems 1093):1-20.

Feddema, H. 2002. Microsoft Access Version 2002 Inside out (First Edition). Microsoft Press. 1105 pp.

Giarratano, J.C., Riley, R.D. 2004. Expert Systems: Principles and Programming (Fourth Edition). Course Technology. $856 \mathrm{pp}$.

Griffith, D.M and R.H Widmann. 2003. Forest Statistics for West Virginia: 1989 and 2000. USDA Forest Service, Northeastern Research Station, Forest Inventory and Analysis Unit, Resource Bulletin NE-157, 2003.

Grushecky, T., Wang, J., McGill, D.W. 2007 Influence of site characteristics and costs of extraction and trucking on logging residue utilization in southern West Virginia. Forest Products Journal, 57(7/8):63-67.

Jensen K., Menard, J., English, B. Park, W., Wilson, B. 2002. The Wood Transportation and Resource Analysis System (WTRANS): An analysis tool to assist wood residue producers and users. Forest Products Journal 52(5):27-33.

Kaloudis, S. Anastopoulos, D. Yialouris, C.P. Lorentzos, N.A. Sideridis, A.B. 2005. Insect identification expert system for forest protection. Expert Systems with Applications. 28(3):445-452.

Ledoux, C.B., Gopalakrishnan, B., Pabba, R.S. 1998. THINEX: an expert system for estimating forest harvesting productivity and cost. In Gopalakrishnan, B. and Murugesan, S . (eds) Proc. SPIE Vol. 3517, p. 262-272, Intelligent Systems in Design and Manufacturing.

Li, Y., Wang, J. Miller, G., McNeel, J. 2006. Production economics of harvesting small-diameter hardwood stands in central Appalachia. Foresty Products Journal. 56(3):81-86.

Maker, T.M. 2004. Wood-Chip Heating Systems. Monthpelier VT: Biomass Energy Resource Center.

Mann, M. K. and Spath, P.L. 2000. A life cycle assessment of biomass cofiring in a coal fored power plant.

Marquis, D.A. and Ernst, R.L. 1992 User's guide to SILVAH: stand analysis, prescription, and management simulator program for hardwood stands of the Alleghenies. Gen. Tech Rep. NE162. Radnor, PA: U. S. Department of Agriculture, Forest Service, Northeastern Forest Experiment Station. $124 \mathrm{p}$.

Matena, V., Krishan, S., DemiChiel, L, Stearns, B. 2003. Applying Enterprise JavaBeans ${ }^{\mathrm{TM}}$ : ComponentBased Development for the J2EE ${ }^{\text {TM }}$ Platform (Second Edition). Prentice Hall. 496 pp.

McKeever, David B. 2004. Inventories of woody residues and solid wood waste in the United States, 
2002 The Ninth International Conference on Inorganic-Bonded Composite Materials Conference, October 10-13, 2004 ... Vancouver, British Columbia, Canada [CD-ROM]. [Moscow, ID] : University of Idaho: $12 \mathrm{pp}$.

McNeel, J. Wang, J. Wu, J., Goff, T. 2008. Woody Biomass Sustainability for Bioenergy Production in West Virginia. Paper presented at the USDA CSREES Bio Energy Awareness Days - Grand Challenge, June 19-22, 2008. Washington, DC.

Miyata, E.S. 1980. Determining fixed and operating costs of logging equipment. Gen. Tech. Rept. NC55. USDA Forest Serv., St. Paul, MN.

Mukhar, K., Lauinger, T. Carnell, J. 2001. Beginning Java Databases: JDBC, SQL, J2EE, EJB, JSP, XML (First Edition). Wrox Press. 800 pp.

Mukhar, K., Zelenak, C., Weaver, J.L., Crume, J. 2005. Beginning Java EE. Apress. 641 pp.

Nagarajan, S.V. 1995. Design and development of expert system for energy conservation in manufacturing industries. Thesis West Virginia University. Pp 85.

Nair, S.V. Daud, M., Ganapathi, N., Ramli, A.R. 1999. Expert System for Terrestrial Vegetation Distribution, Potential Impact and Mitigation Abatement Measures. Environmental Monitoring and Assessment. 58(2):213-225

Pabba, R.S. 1998. THINEX: An expert system for estimating forest harvesting, productivity and cost. Thesis Industrial and management systems Engineering Department, West Virginia.

Perlack, R.D., L.L. Wright, A.F. Turhollow, R.L. Graham, B.J. Stokes, and D.C. Erbach. 2005. Biomass as Feedstock for a Bioenergy and Bioproducts Industry: The Technical Feasibility of a Billion-Ton Annual Supply. Washington DC: U.S. Department of Agriculture, U.S. Department of Energy.

Sims, R.E.H., Rogner, H., Gregory, K. 2003. Carbon emission and mitigation cost comparisons between fossil fuel, nuclear and renewable energy resources for electricity generation. Energy Policy 31(3):1315-1326.

Taylor, M. 2007. Java and SQL. Malcom Taylor Publisher. 240 pp.

Thomson, J.A., Willoughby, I. 2004: A web-based expert system for advising on herbicide use in Great Britain. Computers and Electronics in Agriculture. 42(1): 43-49.

USFS [United States Forest Service] 2008. Timber Product Output MapMaker Versioin 1.0 United States Forest Service available online at http://www.ncrs2.fs.fed.us/4801/fiadb/rpa tpo/wc rpa tpo.ASP accessed on August 15.

USDA [United States Department of Agriculture] 2004. Turning logging resiudes into marketable wood products. An economic action program success story: West Virginia Logging Residue Study. Forest Service, Northeaster Area, State and Private Forestry.

Voirin, Y.B., Dong, C.G.B., Goita, K. 2000. Forest Map Updating Expert System based on the Integration of Low Level Image Analysis and Photointerpretation Techniques. In proceeding of Geoscience and Remote Sensing Symposium, 2002. IGARSS '02. 2002 IEEE International. 3:1618-1650. 50.0 
Wang J., Spong, B., McNeel, J. 2007. Central Appalachian Harvesting Analyzer. In manual of Timber harvesting production and cost analysis workshop held on June 12007 at West Virginia University, Division of Forestry and Natural Resoruces, Morgantown, WV.

Wang, J, Grushecky, S., McNeel, J. 2005. Production analysis of helicopter logging in West Virginia: A prelimineary case study. Forest Products Journal. 55(12):71-76.

Wang, J. 2007. Hardwood log bucking and loading efficiency in West Virginia. Forest Products Journal. 57(5):1-7.

Wang, J., Long, C., McNeel, J., Baumgras, J. 2004a. Productivity and cost of manual felling and cable skidding in central Appalachian hardwood forests. Forest Products Journal, 54(12):45-51.

Wang, J., Long, C., McNeel, J. 2004b. Production and cost analysis of feller-buncher and grapple skidder in central Appalachian hardwood forests. Forest Products Journal, 54(12):159-167.

Wang, J., McNeel, J. and Grushecky, S 2006. Biomass resources, uses and opportunities in West Virginia. West Virginia University. Pp 109.

Waterman, K. 1986. Expert systems. Techniques, tools and applications. 432 pp.

Wu, J., Wang, J., McNeel, J. 2008. Economic modeling of woody biomass utilization for biofuels: a case study in West Virginia. In proceedings: $31^{\text {st }}$ Annual meeting of Council on Forest Engineering, June 22-2005, 2008. Charleston, SC.

Wang, J. Grushecky, S., McNeel, J. 2007. Biomass resources, uses and opportunities in West Virginia. West Virginia University. 224 p.

Smith, WB. 1991. Assessing removals for North Central forest inventories. Res. Pap. NC-299. St. Paul, MN: U.S. Department of Agriculture, Forest Service, North Central Forest Experiment Station. $48 \mathrm{p}$. 
The guide relates to woody biomass energy system. The objective of this guide is to let users walk through the system and explore the major functionalities and procedures. The accuracy and validity of the results given by the system determines the measure of success of developing a system. As an illustration, a brief consultation is performed in order to provide better understanding of the work that involved the application of system, a modern tool of artificial intelligence, to the area of woody biomass for energy production. This program is web based system available online to users. Some download from JVM (java virtual machines) are required but these are automatically available to most computers of present days. If however, this software is not currently residing in user's computer, the web browser should be able indicate the limitation and suggest the download at runtime. Once the url of this system is opened, index page of the system appears which is presented in Figure A.1.

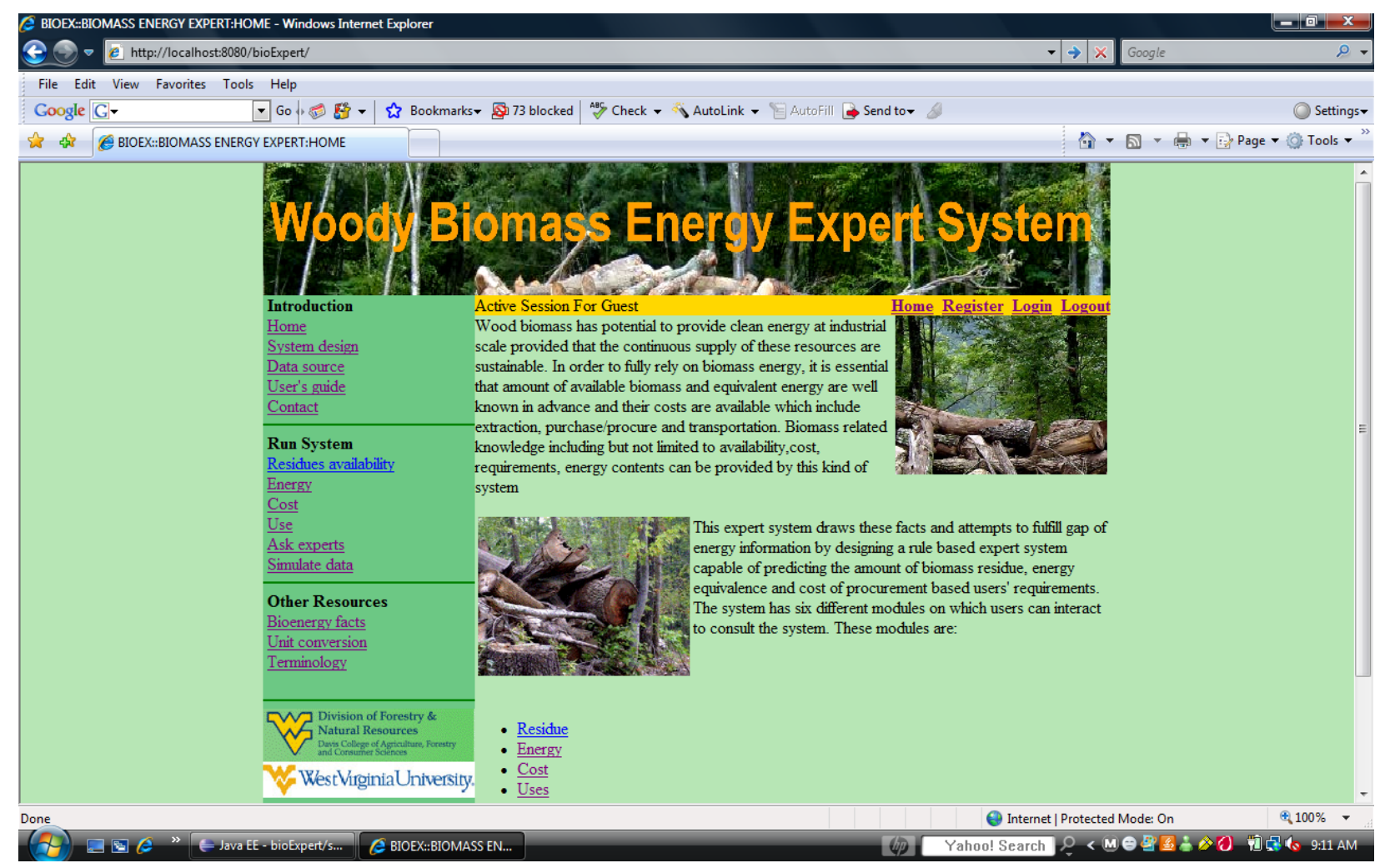

Figure A.1 System index page that appears when the program is first run on a web browser.

Index page provides woody biomass energy system related information such as what does this program do and how to start using the system. There are three main sections in the left hand side of this page. An introduction section contains introductory information links such as design, user's guide (this document) illustrating how to use the program and contact information for the user. Run system section has links to main functions of system i.e., residue search, energy search, cost estimation, biomass energy related information, search from keywords, ask expert, simulate data for different theoretical 
scenarios analysis. Finally, the third resource named "Other resources" has links to information such as bioenergy facts and figures, energy conversion and technical terms information.

In successive section, only some of the most important functionalities are explained as most others are self explanatory and users are suggested to explore the system on their own. If however, some questions and problems occur, users are requested to contact us using the link provided on webpage to provide the feedback so that concerns and improvement can be incorporated into the system in future.

\section{A.1. Consultation with residue search}

Residue search link takes user to the page where user can start searching for residue at a given location. The system works at county level at this moment. User has to enter some information to start searching for residue for energy production such as what type of residue to search, location of search i.e. county and state, and required amount (Figure A.2).

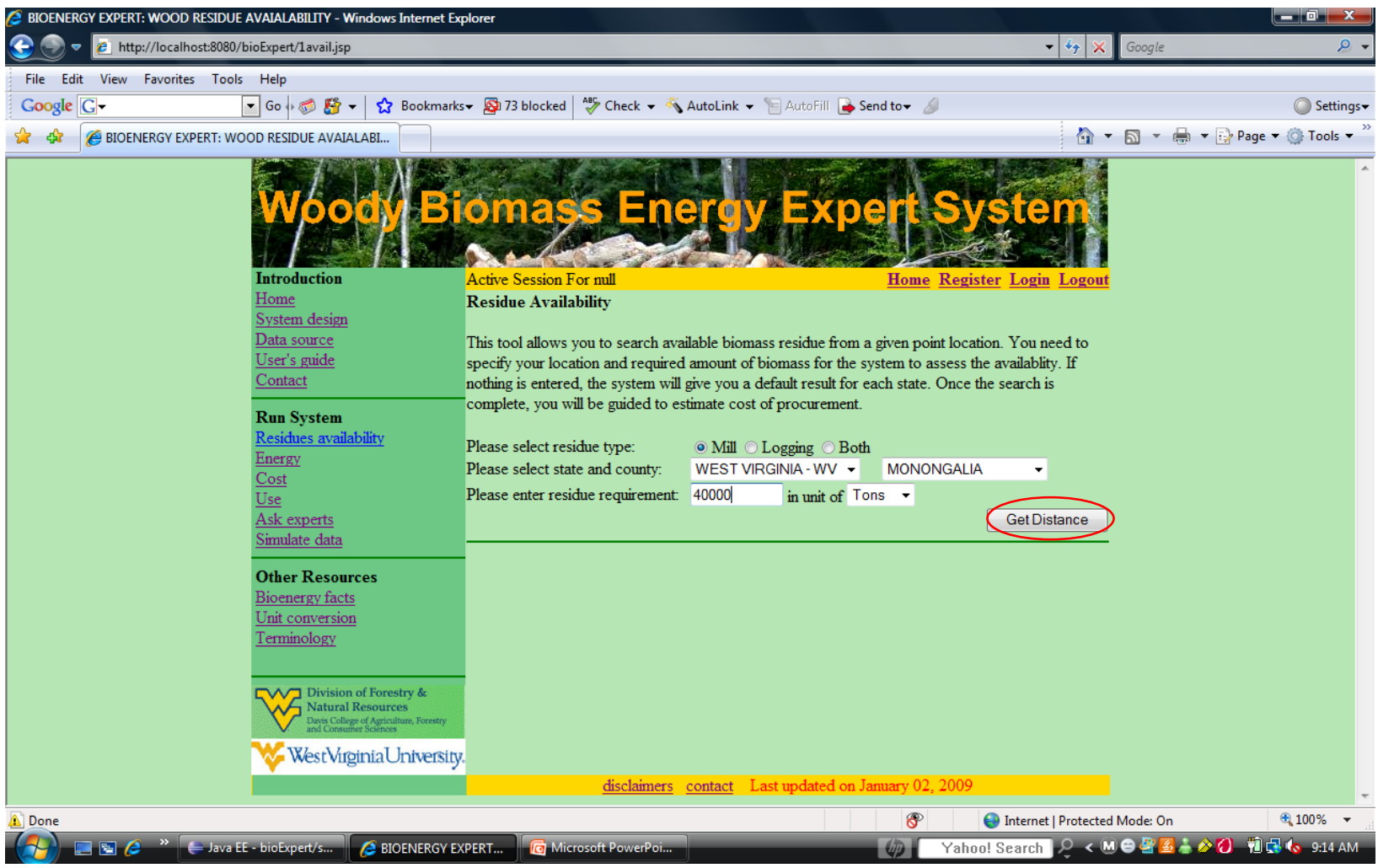

Figure A.2 Search for available woody residue (the default screen).

In Figure A.2, user has specified residue type as mill, state as WV, county as Monongalia, states to avoid as none, residue quantity as 4,00,00 tons. Once this information is entered, "Get Distance" button shown in red oval should be clicked to retrieve the search result as in Figure A.3. 


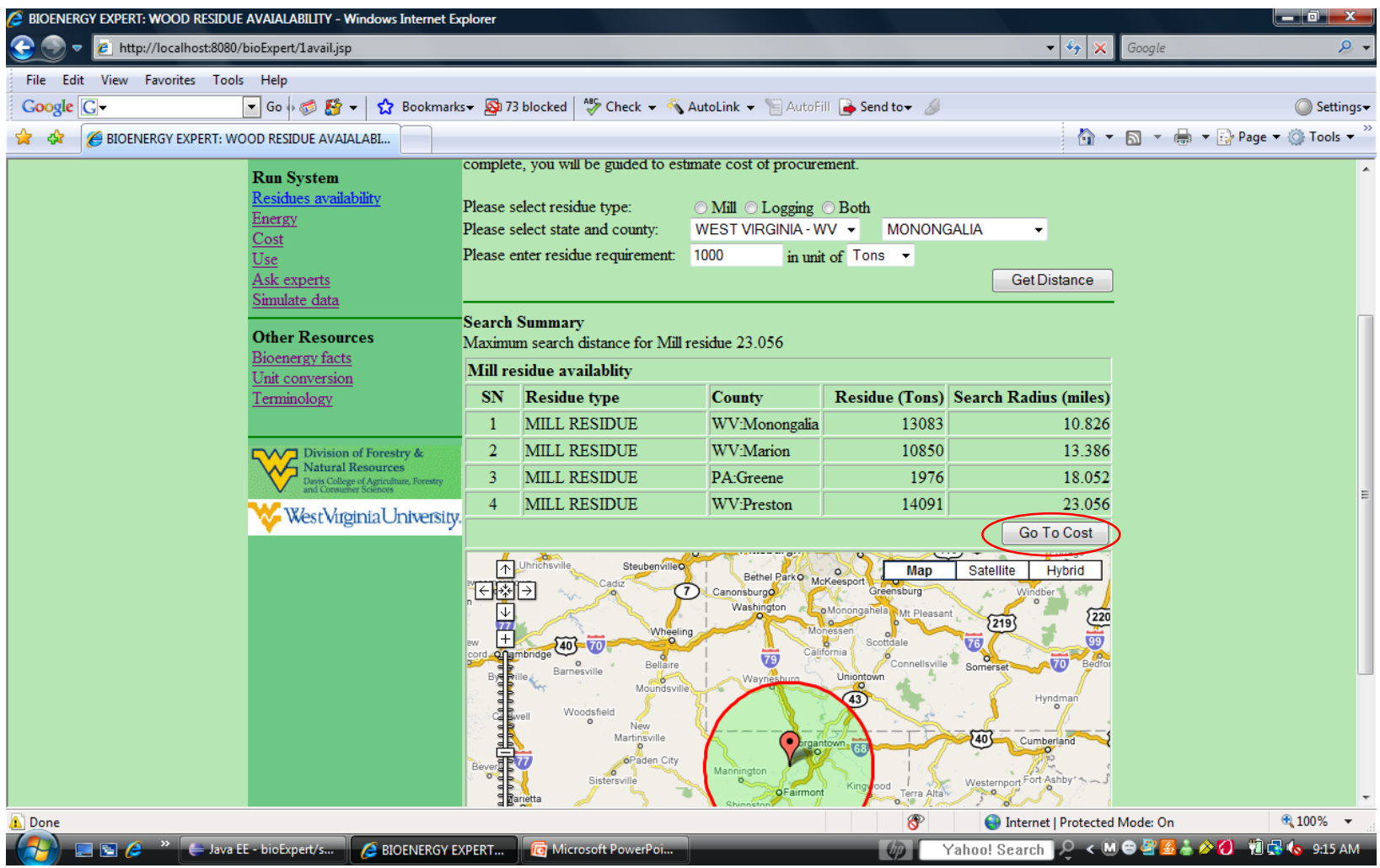

Figure A.3 Result of search for residue.

Search distance is radial (straight line distance) from the point of starting location to the maximum search distance and available residue in each location searched. Residue type, state and county where residue is available, available quantity and distance are presented in tabular format and search map in result page. In this case, because we did not specify any restriction on search zone, the result showed combination of counties in WV and PA for different amount in the order of search distance. Once this result is presented, user can proceed to go to cost estimation by entering "Go To Cost" button shown in red oval in Figure A.3.

This leads to cost assessment page Figure A.4 where user can either change cost parameters to customize their search or they can use parameters readily provided by the system. 


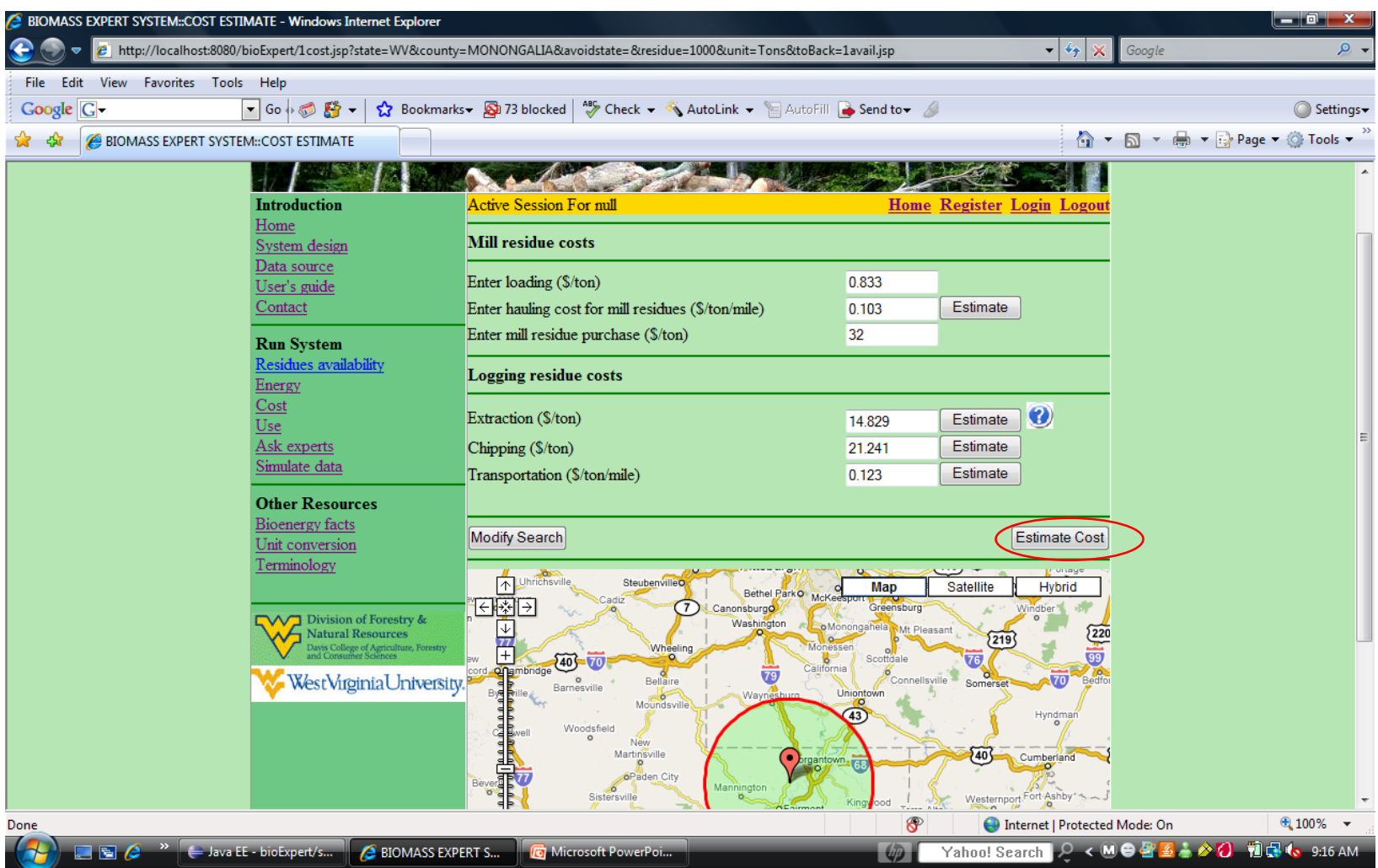

Figure A.4 Cost parameter specification page. By clicking on Estimate button of any parameter, user can customize the parameter and override the default.

For information on these parameters, users are suggested to view the design document. Once cost parameters are finalized, "Estimate Cost" button will lead to estimation page and "Modify Search" button will lead to the search page previously explained.

Final page with the estimated cost for the searched residue will appear as shown in Figure A.5. The process may take some time depending on search quantity and location and number of concurrent users connected to the system. 


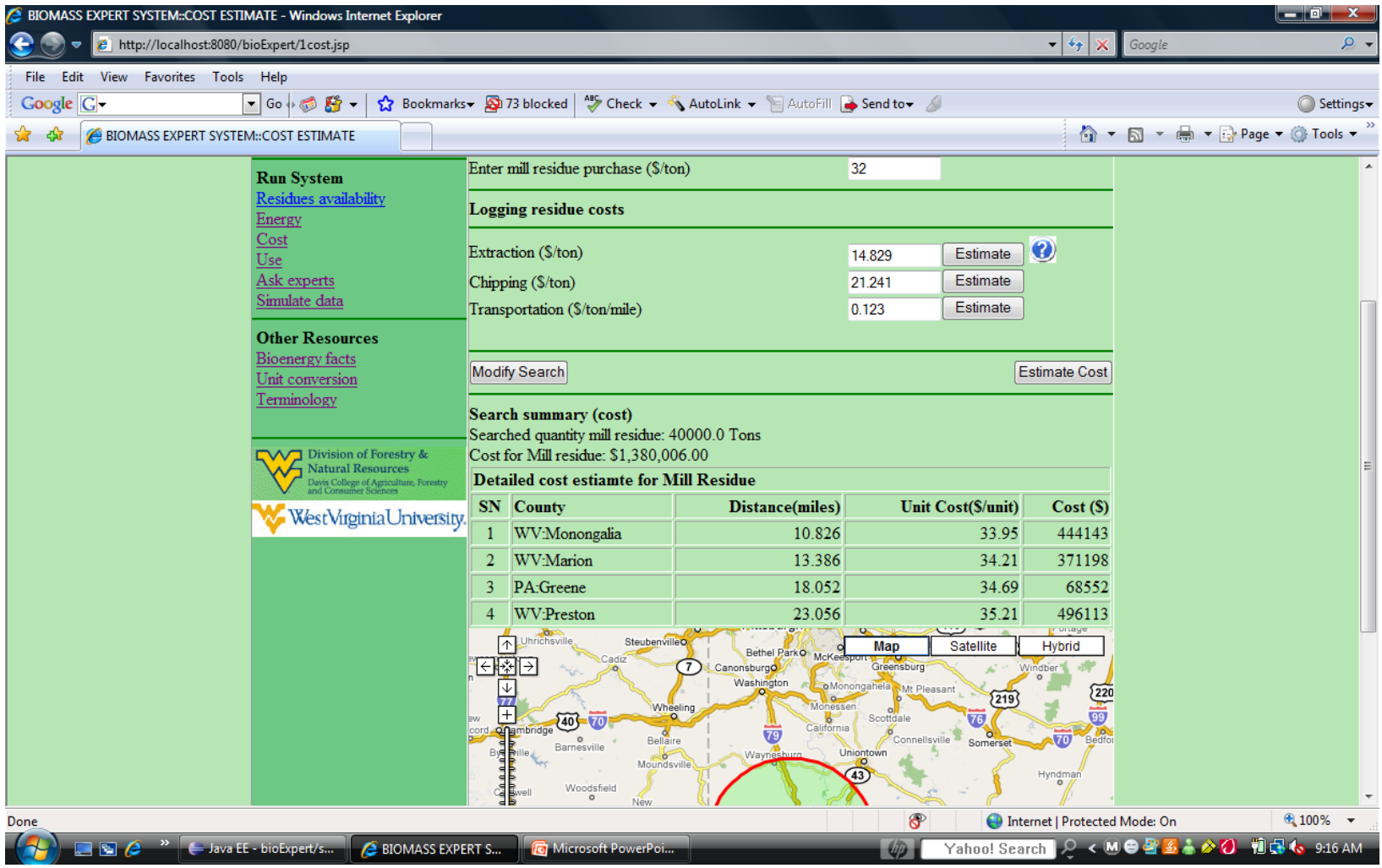

Figure A.5 Final cost calculation for mill residue search with information on distance, unit delivered cost and total cost for the required amount of residues.

\section{A.2 Consultation with cost}

This is the available interface for the cost page whether user come to this page through search or directly into the page. Figure A.6 contains the detail information about the cost components for different kinds of residue types i.e., mill and logging. As a base case if nothing has been entered by the user the system will assume the residue search was 1,000 tons or energy equivalent and based on that cost analysis for both types of residue will be conducted. This page alone can be used to test for required unit cost assessments.

As shown in Figure A.6 cost components for mill residue are labor cost, hauling cost and mull residue purchase cost. For logging residue cost estimation extraction, chipping and transportation costs are calculated. 


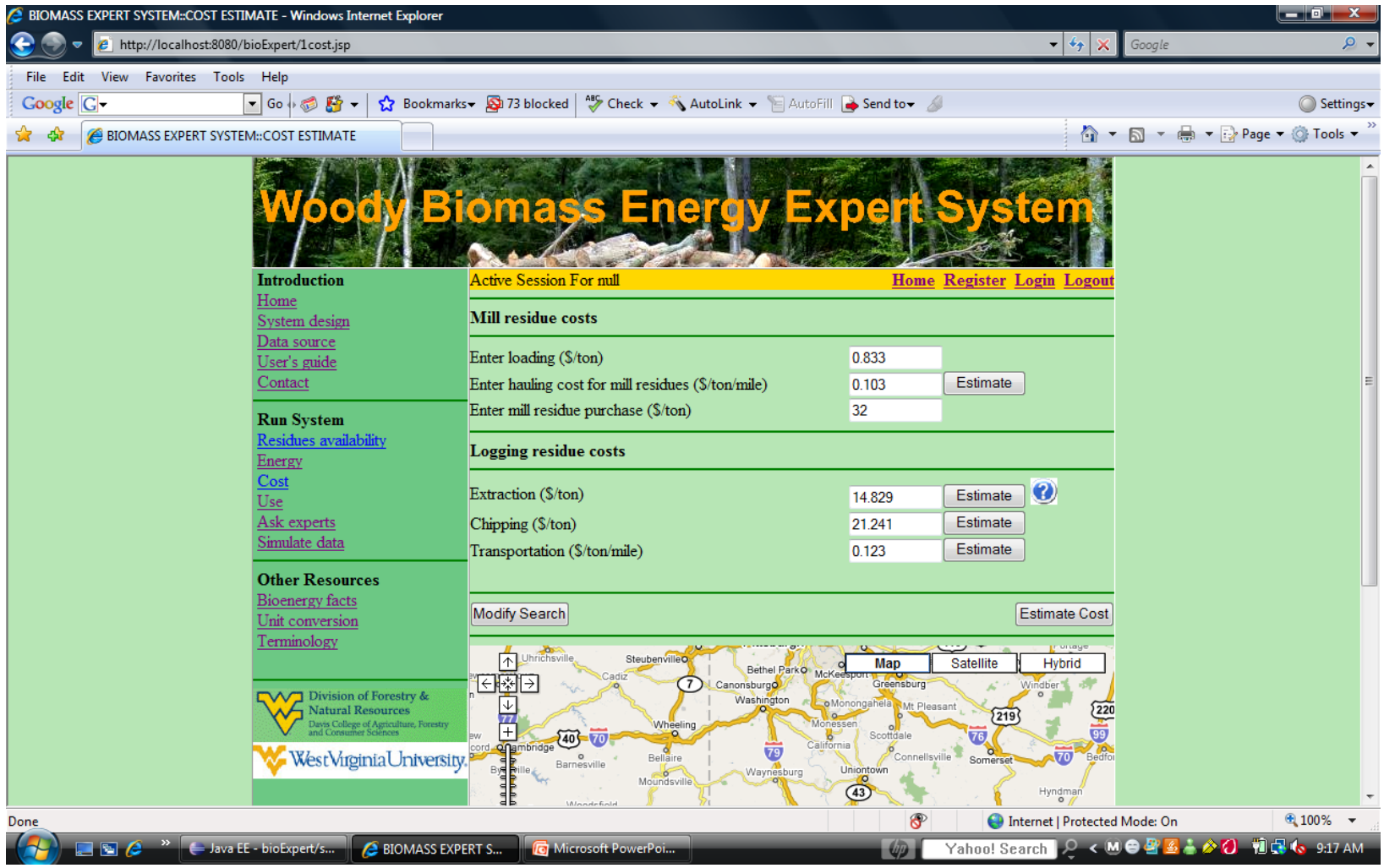

Figure A.6 Cost page from this page, search can be changed by clicking "modify search".

Some or all of the default cost parameters can be overridden to customize the results by pressing "Estimate" button in both mill and logging residue cost assessment. Those buttons if clicked by the user will open a new window for the customized cost parameters modification. It's up to user whether or not to use cost provided by the system. 


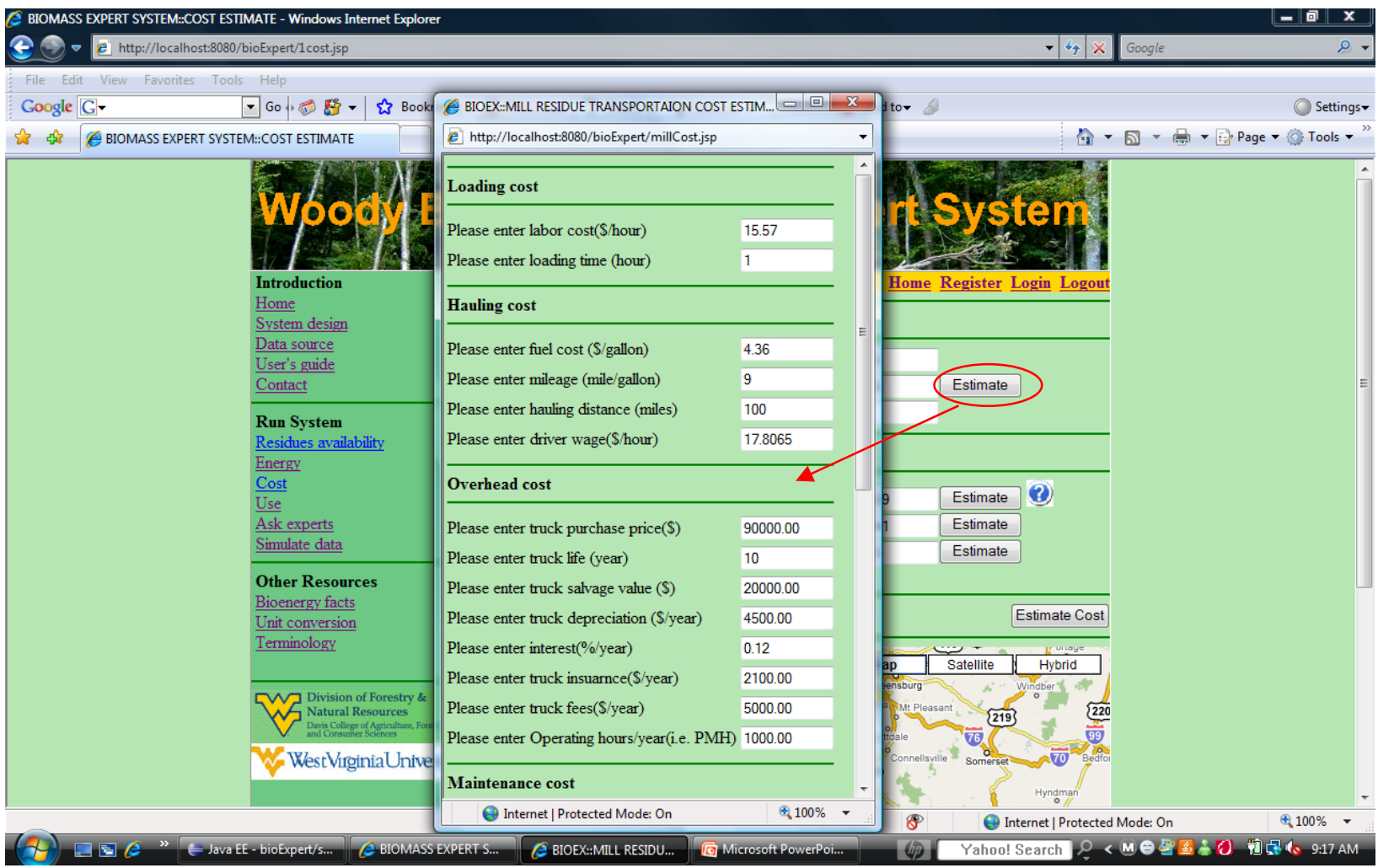

Figure A.7 Popup window with estimate button.

Once user hits estimate button, a pop up window with all the cost components will appear (Figure A.7). In the pop-up window, user can estimate their customized cost and when "Use rate" is clicked, the main window will be updated with new cost parameters (Figure A.8). 


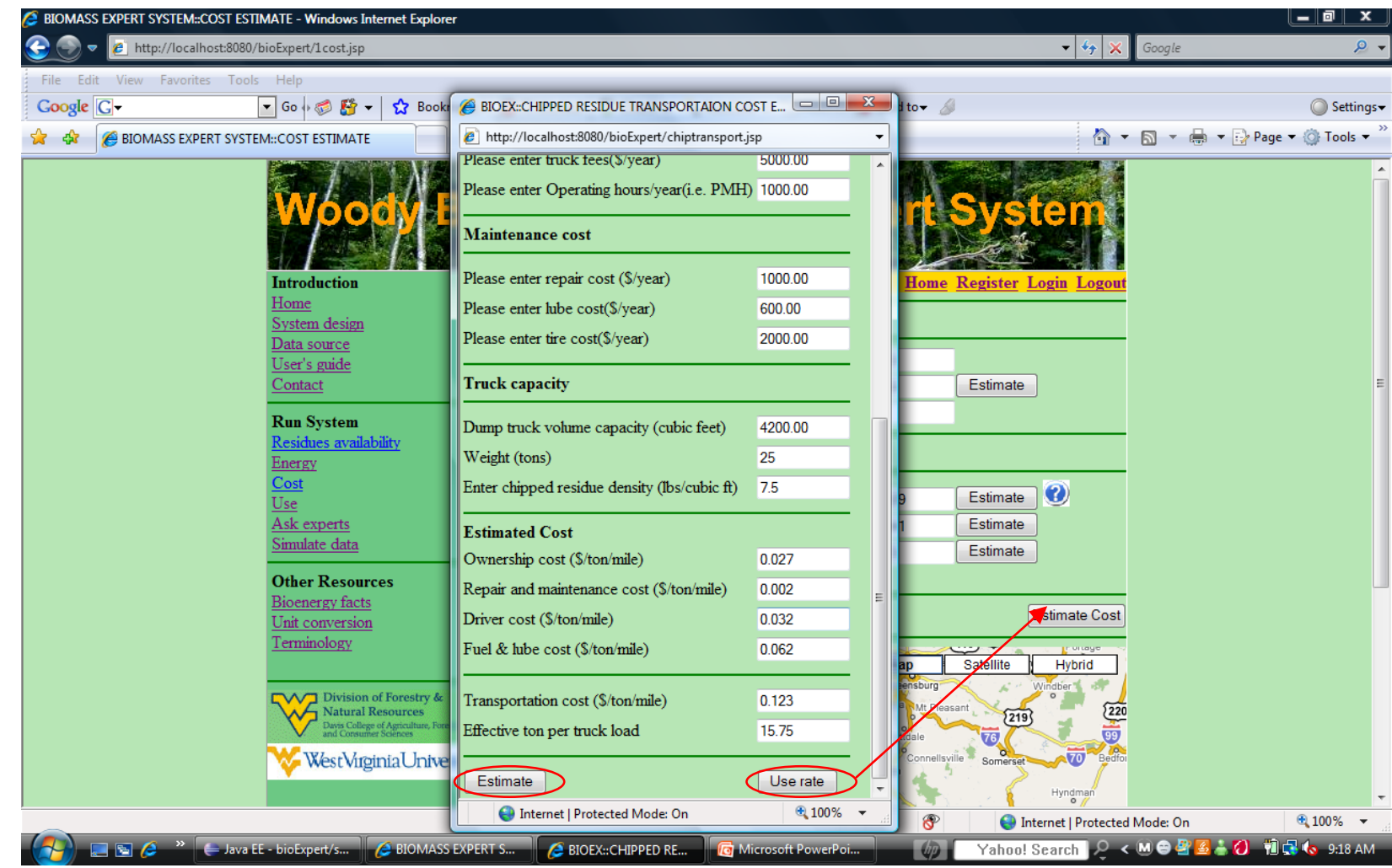

Figure A.8 By changing values in machine rates, "Estimate" button will update the final cost and "User rate" button will close the pop-up window and update the main window with new rate.

\section{A.3 Consultation with energy search}

Energy search page also needs user's parameters to start energy search. User has options to select for the energy residue types (Figure A.9). Except for energy quantity and units, all other parameters are similar to what are required for residue availability. User can search energy in terms of ethanol, methanol or BTUS. 


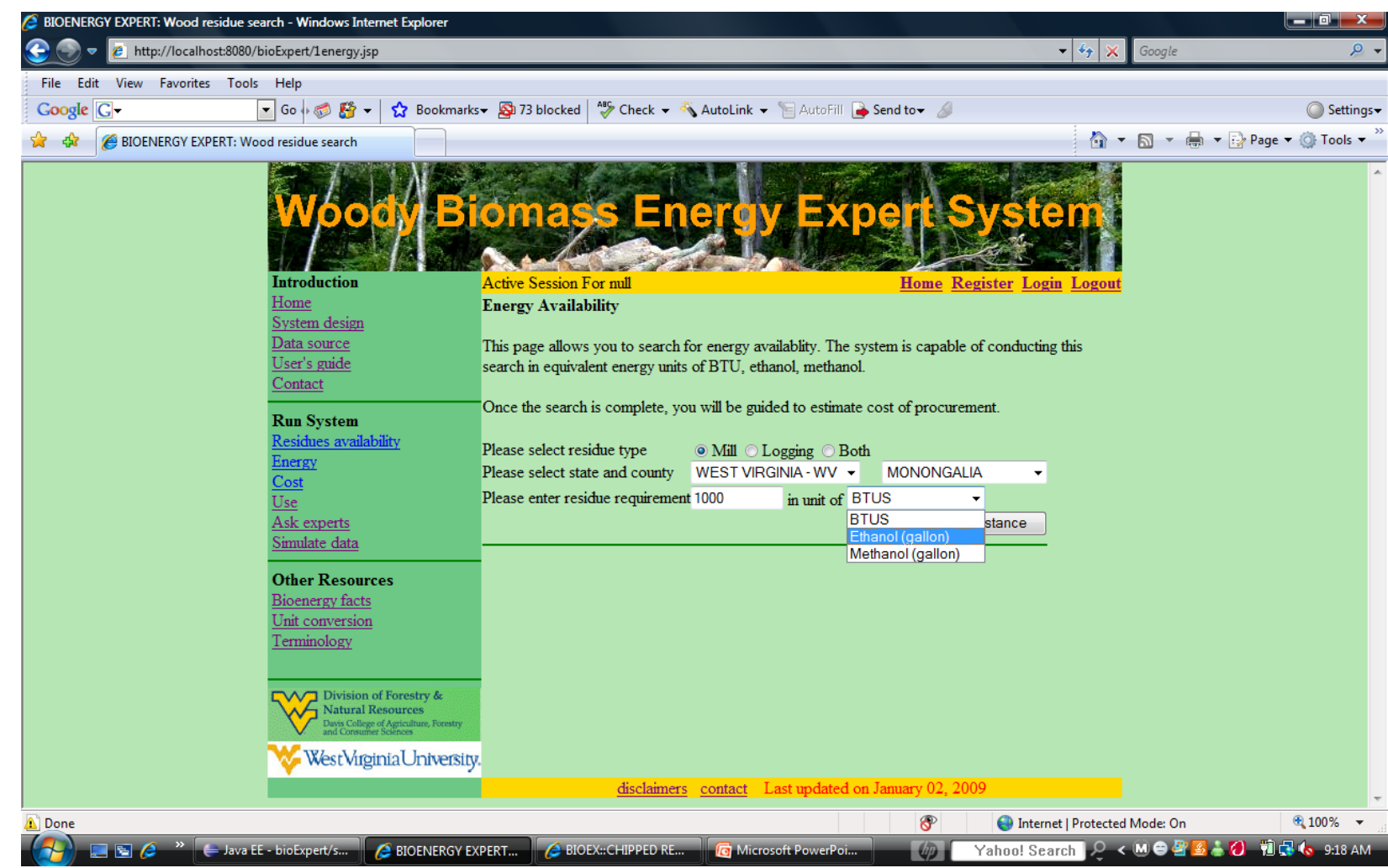

Figure A.9 Energy search page which is seeking 1000 Ethanol gallon equivalent from mill residue from WV, Monongalia.

In this case we have chosen mill as a residue type for energy production, WV and Monongalia as starting point for energy search for 1,000 BTUS of energy. Once these parameters are entered, clicking "Get Distance" button returns a result page with search summary as shown in Figure A.10. Google map with search radius will also appear on the search result page for energy.

The result page shows that residue type searched is mill residue, county to visit is WV, Monongalia and energy available is 1,000 . Although, more than this amount could be available at this location, the system only displays the required amount. The search radius from the Monongalia is 10.16 miles with a location map. Once this result page appears user can continue to go with cost estimation by clicking "Go to Cost" or can stop here with the energy information. 


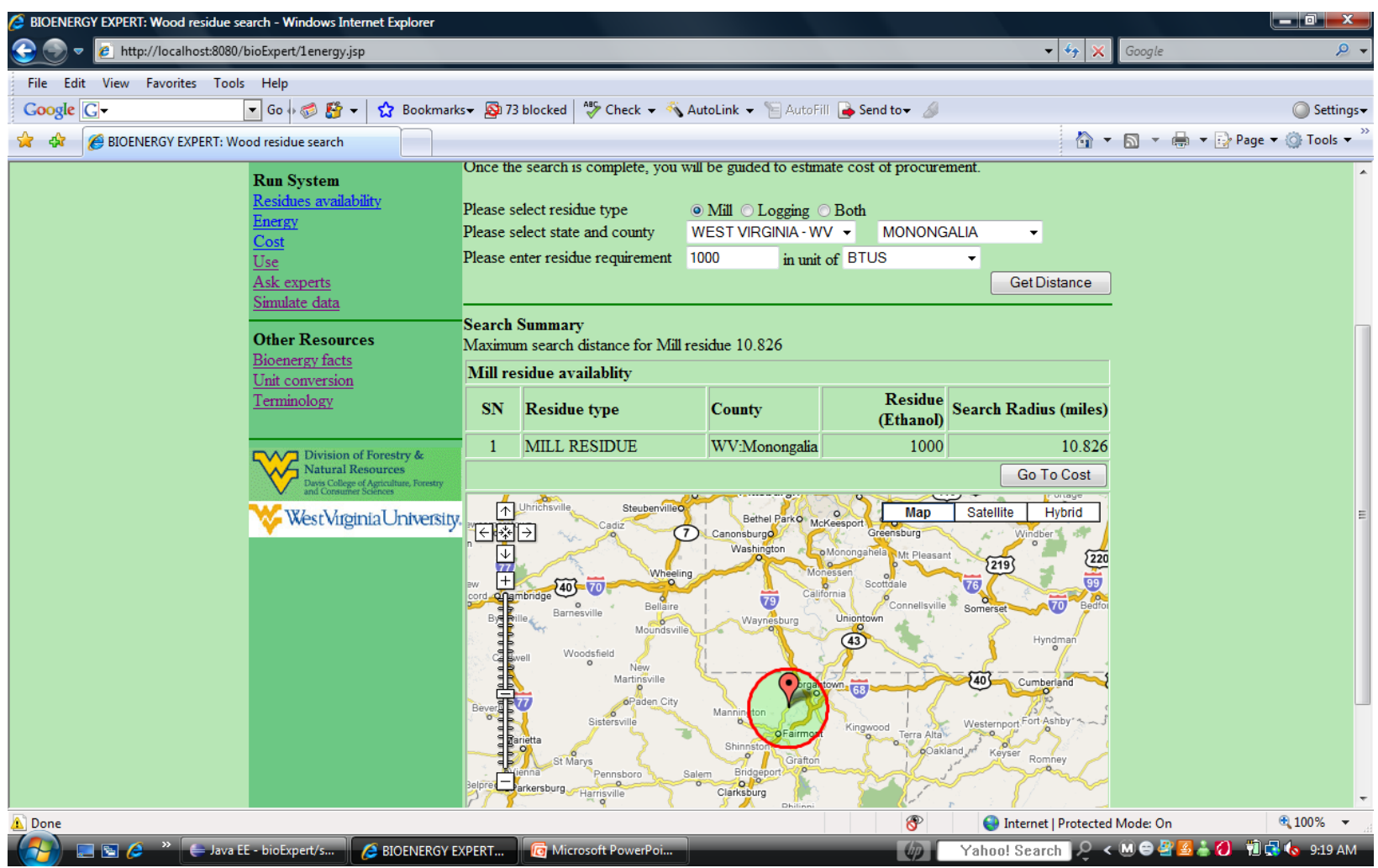

Figure A.10 Ethanol equivalent energy search.

\section{A.4 Simulation for scenario assessment}

Simulation page in system provides user to analyze different cost and distance scenarios in residue search and energy search. Basically this module mimics user's frequent response for different amount of residues but from within the system. User can get information on different residue search and distance relationship and generate graphs. Simulate data page is shown in Figure A.11 where user needs to enter several information in system to start their data simulation. Residue types mill or logging, minimum and maximum residue amount to search and search location in terms of county and state.

Once the required information are entered and simulation button is clicked, you have entered all the necessary parameters for simulation simulate button needed to be clicked, the system divides the maximum and minimum residue quantity in 20 equal intervals to generate a graph. Communication with the residue search page and cost page are conducted inside the system and two final graphs appear each for distance and cost (Figure A.12). 


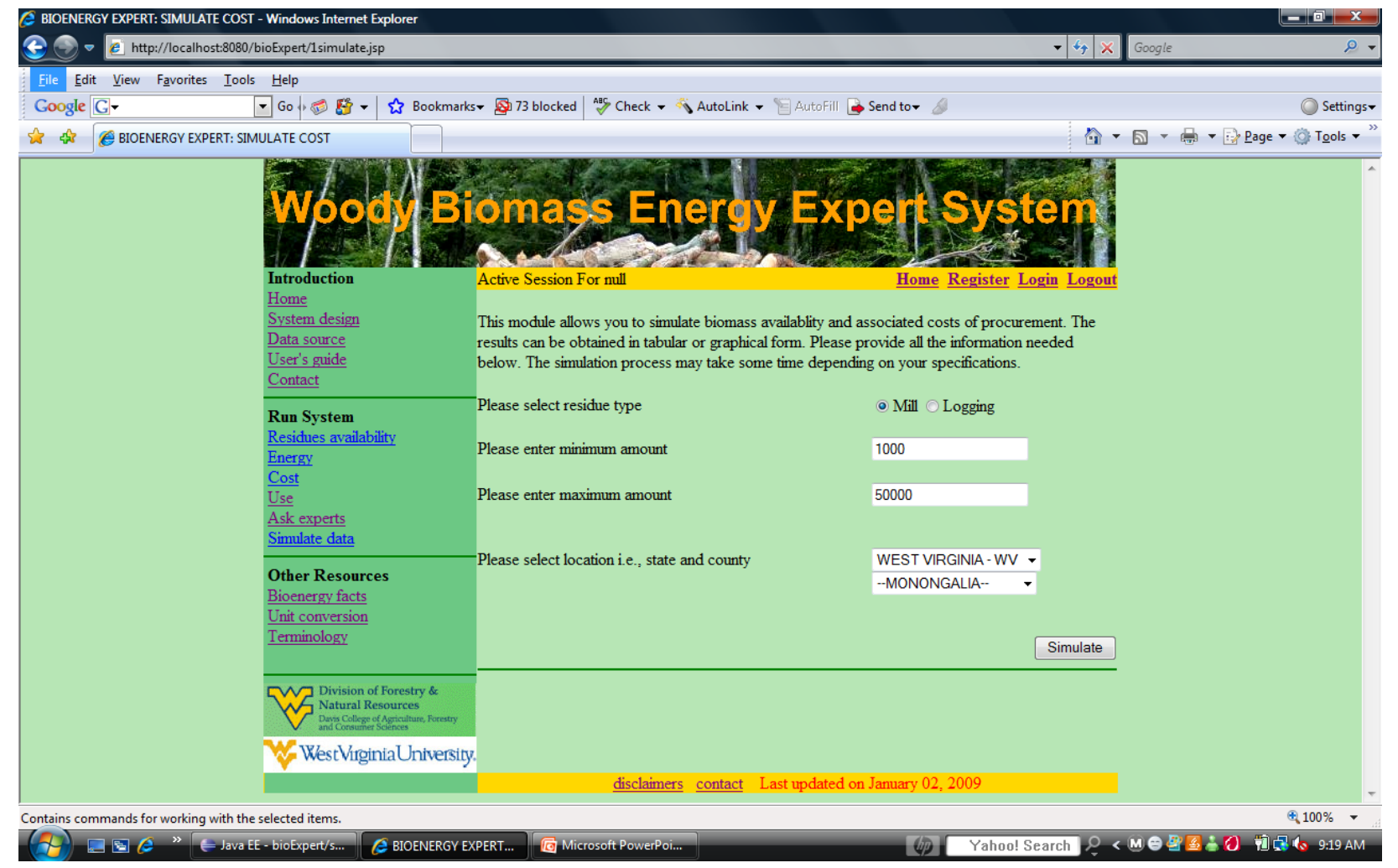

Figure A.11 Simulation data page.

Figure A.12 shows the simulation result for the following parameters:

Residue types: mill

Minimum residue quantity to be searched: 1,000 tons

Maximum residue quantity to be searched: 50,000 tons

State: West Virginia

County: Monongalia 


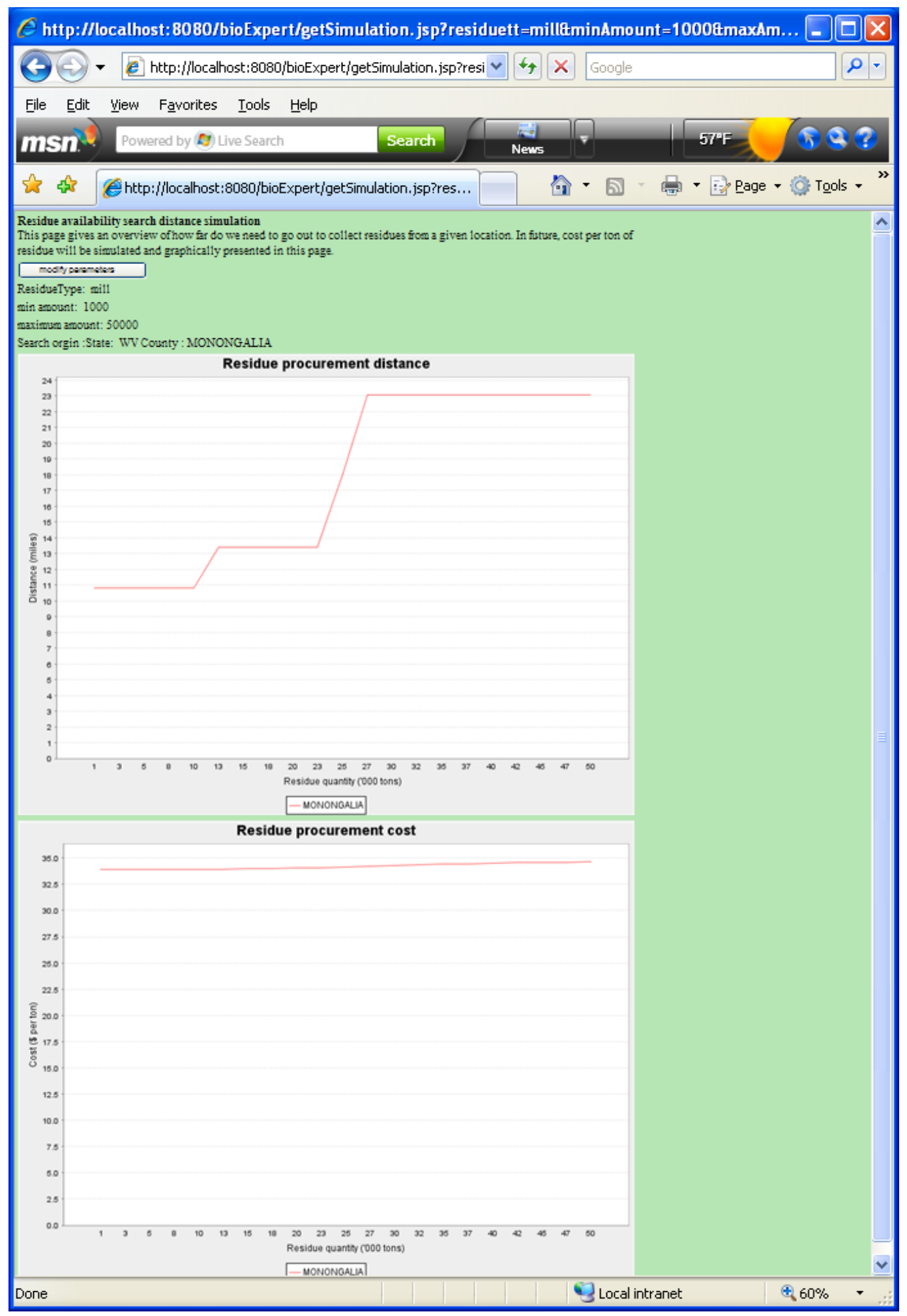

Figure A.12 Simulation result demonstration.

\section{A.5 Other illustrative functions}

The system provides some basic illustrative functionality of the system for information purpose. One of 
such functions is assessing current and potential use of biomass in the region. If user wants to get the information about the possible uses of different kinds of woody residue then they can go to uses page following the link and obtain information (Figure A.13). Also, user can post specific question to system which are not answerable at this moment. This function is named under "Ask Expert" module (Figure A.14) in which information is categorized into four different categories. These categories are definition related to definition about terms definition in this field, technology - related to different conversion technology and other energy related technological information, environmental - related to benefits and consequences of biomass use and economy - related to economics aspect of biomass such as constraints and possible benefits. By clicking on different categories of the system the questions that have been previously answered by the experts can be seen. User can click and unclick the link to turn on and off questions in different categories. For illustration, Figure A.15 shows some of the questions in technologies in the system.

If someone has specific question for the expert in any of the categories inside the system or any new category questions, user can post such questions. User needs to provide their email address to get notified once a question is reviewed and responded by the expert in bioenergy and woody biomass field. Reviewed questions and answers are continuously updated in the system by the administrator.

A term dictionary page has been created to understand the systems technical terms. These terms are related to biomass, bioenergy as well as technical aspect of expert system. These terms are provided with definition and illustration to make users familiar with the system. User can learn more about terms used in the system by following this link (Figure A.16). Finally a contact page for users to send messages, questions and concerns have been placed in the system to obtain feedback from the general public. 


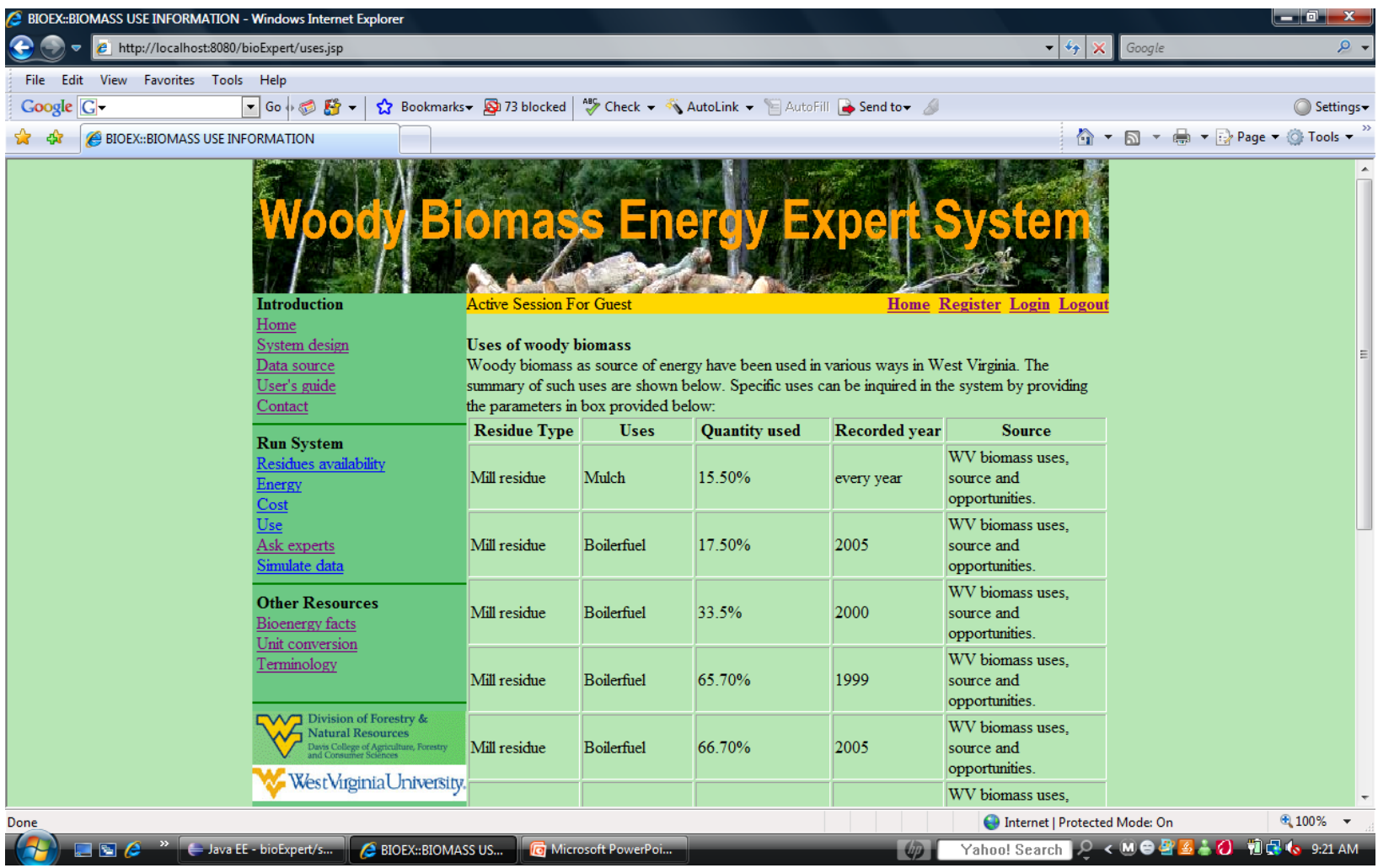

Figure A.13 Biomass residue use illustration in West Virginia.

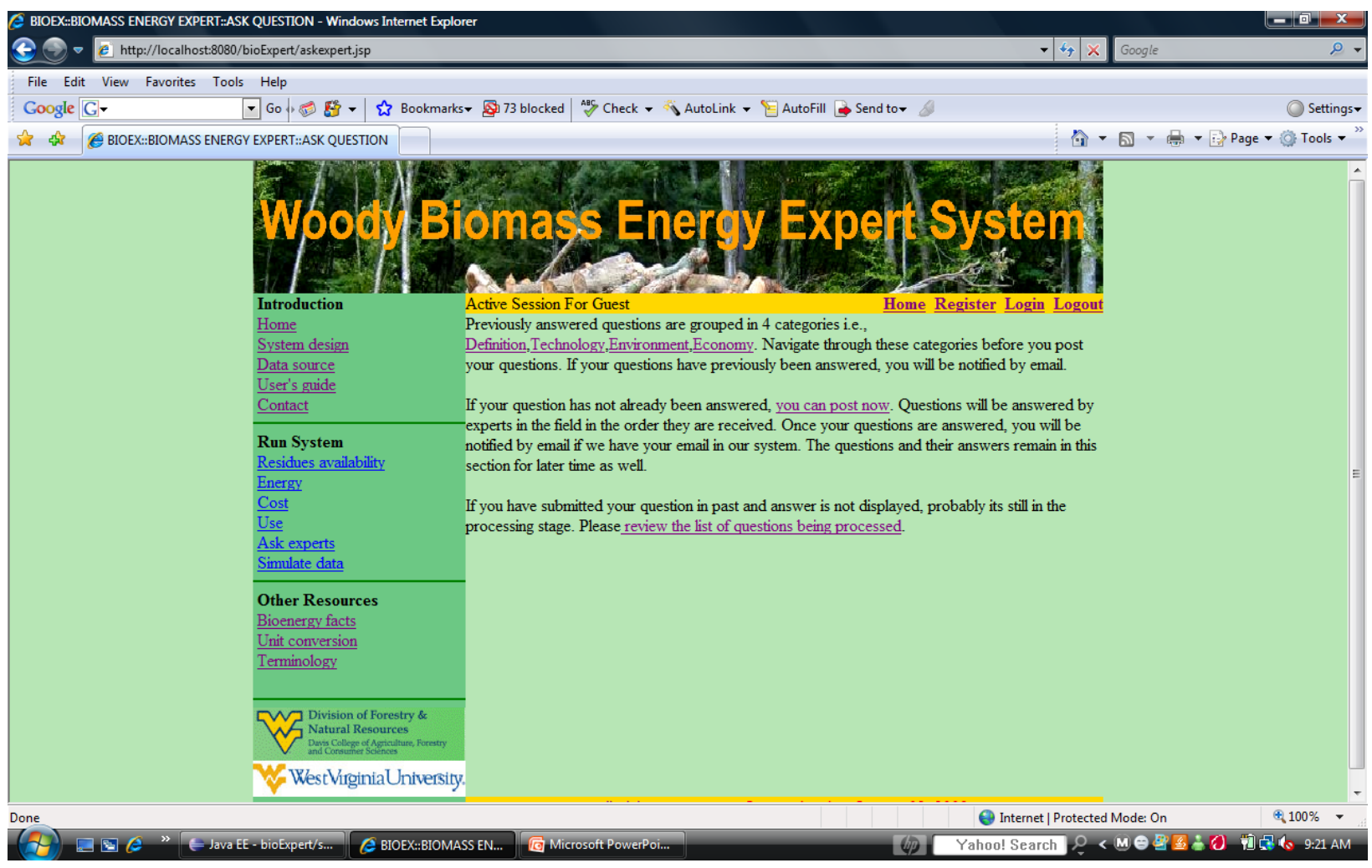

Figure A.14 Ask expert module. 


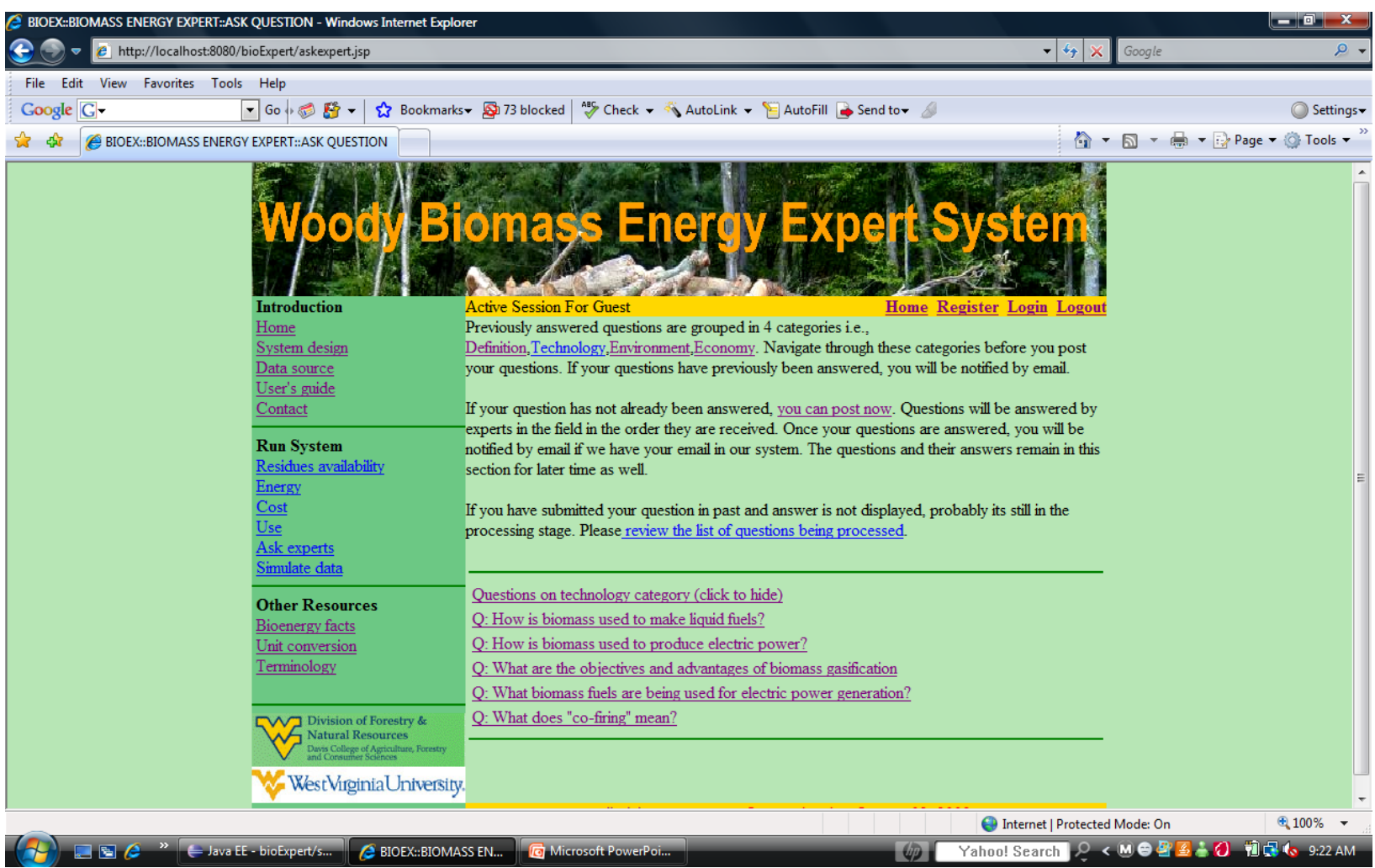

Figure A.15 Technology category in ask expert module.

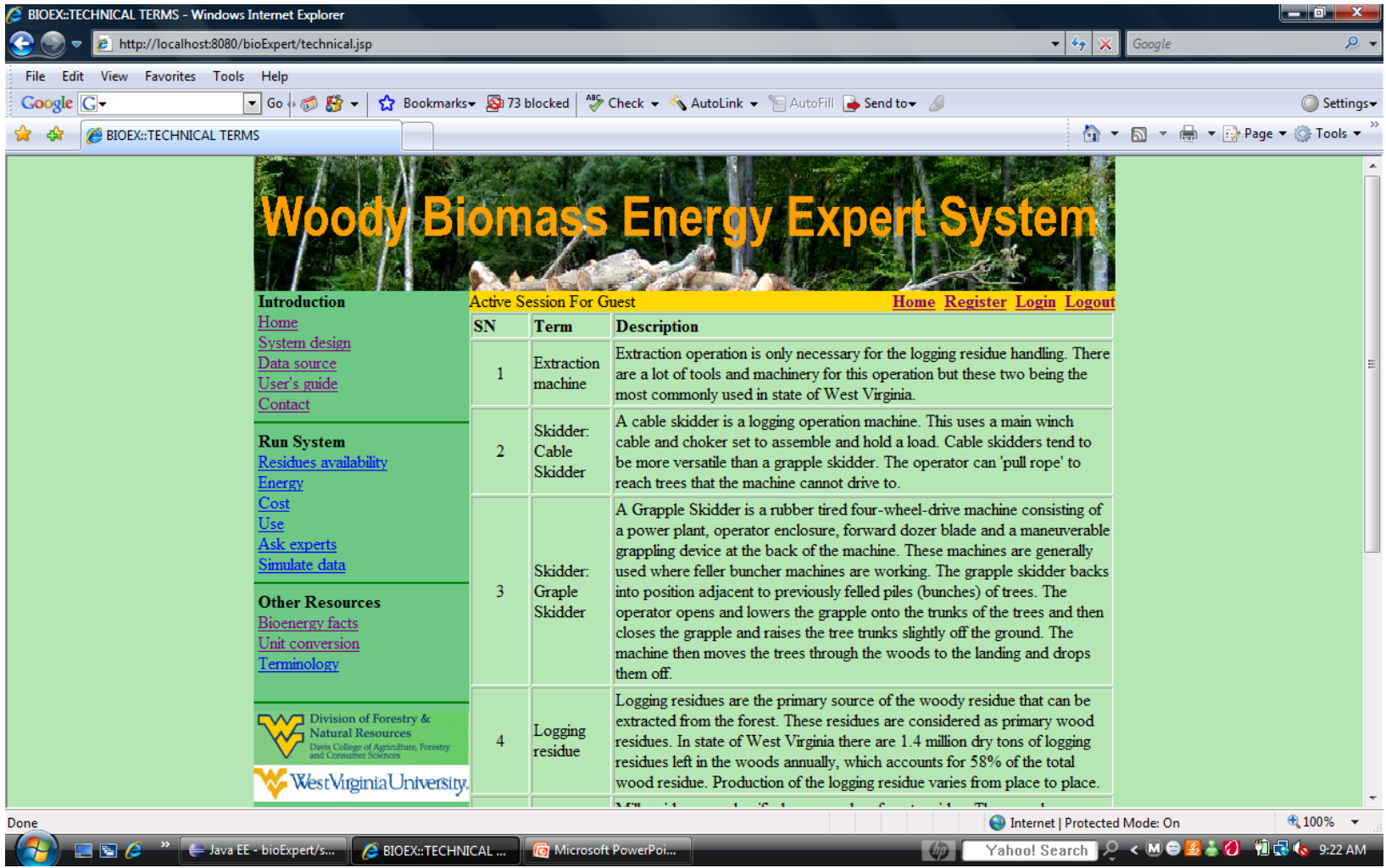

Figure A.16 Terms used in the system. 


\section{A P P N IDX B. ENERG Y CONVERSION FACTORS}

(Source: http://bioenergy.ornl.gov/papers/misc/energy_conv.html)

\section{C.1 Energy Units}

Quantities

- $\quad$ joule $(\mathrm{J})=$ one Newton applied over a distance of one meter (= $1 \mathrm{~kg} \mathrm{~m} 2 / \mathrm{s} 2)$.

- joule $=0.239$ calories (cal)

- $\quad$ calorie $=4.187 \mathrm{~J}$

- gigajoule $(\mathrm{GJ})=109$ joules $=0.948$ million $\mathrm{Btu}=239$ million calories $=278 \mathrm{kWh}$

- $\quad$ British thermal unit $(\mathrm{Btu})=1055$ joules $(1.055 \mathrm{~kJ})$

- $\quad$ Quad = One quadrillion Btu (1015 Btu) $=1.055$ exajoules (EJ), or approximately 172 million barrels of oil equivalent (boe)

- $1000 \mathrm{Btu} / \mathrm{lb}=2.33$ gigajoules per tonne $(\mathrm{GJ} / \mathrm{t})$

- 1000 Btu/US gallon = 0.279 megajoules per liter $(\mathrm{MJ} / \mathrm{l})$

Biomass Energy

- Cord: a stack of wood comprising 128 cubic feet (3.62 m3); standard dimensions are $4 \mathrm{x}$ $4 \times 8$ feet, including air space and bark. One cord contains approx. 1.2 U.S. tons (ovendry)

$=2400$ pounds $=1089 \mathrm{~kg}$

o metric tonne wood $=1.4$ cubic meters (solid wood, not stacked)

o Energy content of wood fuel (HHV, bone dry) $=18-22 \mathrm{GJ} / \mathrm{t}(7,600-9,600 \mathrm{Btu} / \mathrm{lb})$

- Energy content of wood fuel (air dry, 20\% moisture) = about $15 \mathrm{GJ} / \mathrm{t}(6,400 \mathrm{Btu} / \mathrm{lb})$

- Energy content of agricultural residues (range due to moisture content) $=10-17 \mathrm{GJ} / \mathrm{t}(4,300$ 7,300 Btu/lb)

- Metric tonne charcoal $=30 \mathrm{GJ}(=12,800 \mathrm{Btu} / \mathrm{lb})$ (but usually derived from 6-12 $\mathrm{t}$ air-drywood, i.e. $90-180 \mathrm{GJ}$ original energy content)

- $\quad$ Metric tonne ethanol $=7.94$ petroleum barrels $=1262$ liters o ethanol energy content $(\mathrm{LHV})=11,500 \mathrm{Btu} / \mathrm{lb}=75,700 \mathrm{Btu} / \mathrm{gallon}=26.7 \mathrm{GJ} / \mathrm{t}=21.1 \mathrm{MJ} /$ iter. $\mathrm{HHV}$ for ethanol $=84,000 \mathrm{Btu} / \mathrm{gallon}=89 \mathrm{MJ} / \mathrm{gallon}=23.4 \mathrm{MJ} / \mathrm{liter}$ o ethanol density (average) $=0.79 \mathrm{~g} / \mathrm{ml}$ ( = metric tonnes $/ \mathrm{m} 3$ )

- Metric tonne biodiesel $=37.8 \mathrm{GJ}(33.3-35.7 \mathrm{MJ} / \mathrm{liter})$

o biodiesel density (average) $=0.88 \mathrm{~g} / \mathrm{ml}(=$ metric tonnes $/ \mathrm{m} 3$ ) 
APPENDIX C. GRAPHS AND TABLES

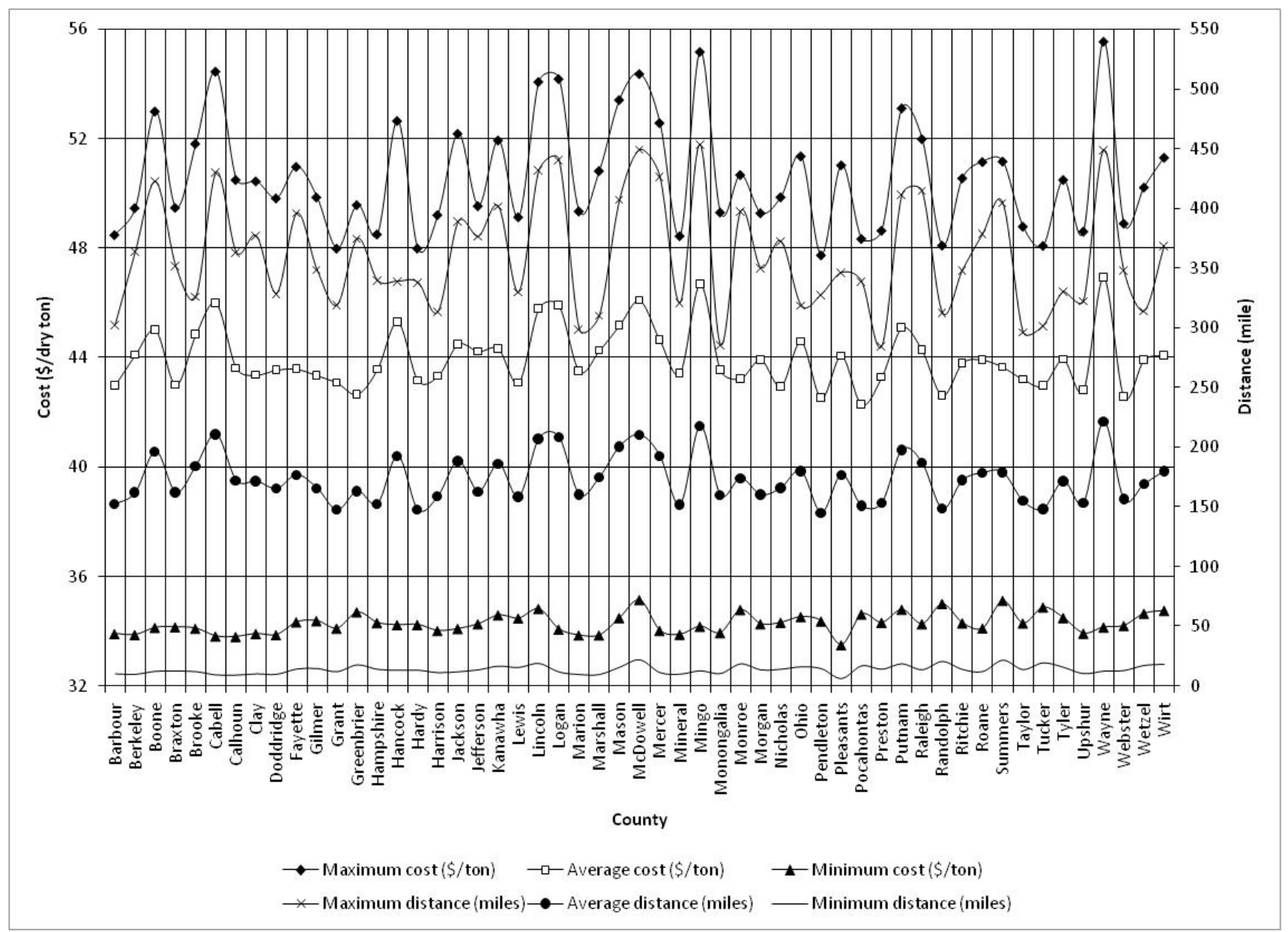

Figure C.1 Minimum, maximum and average cost and distance of mill residue in WV. 


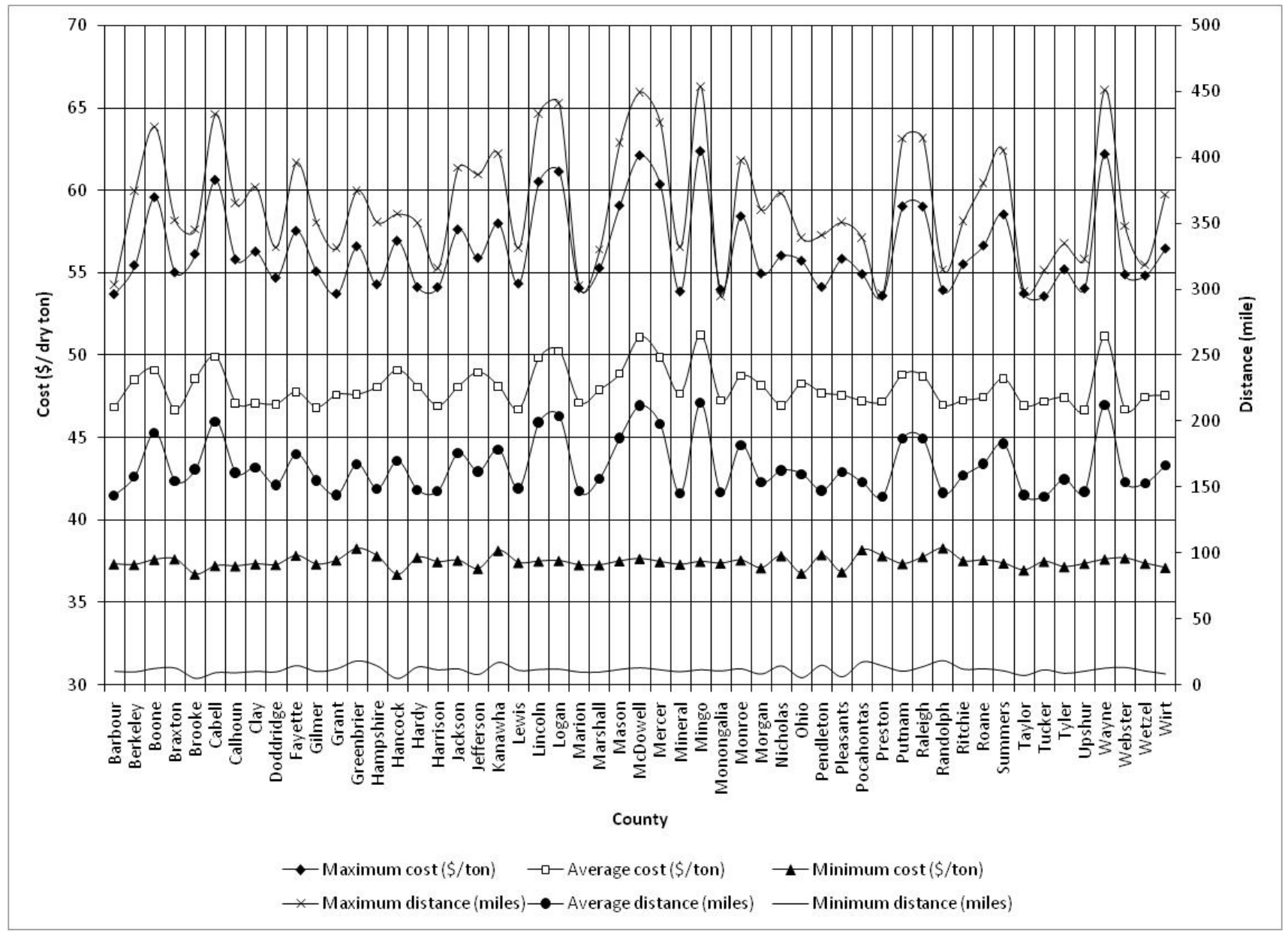

Figure C.2 Minimum, maximum and average cost and distance of logging residue in WV. 


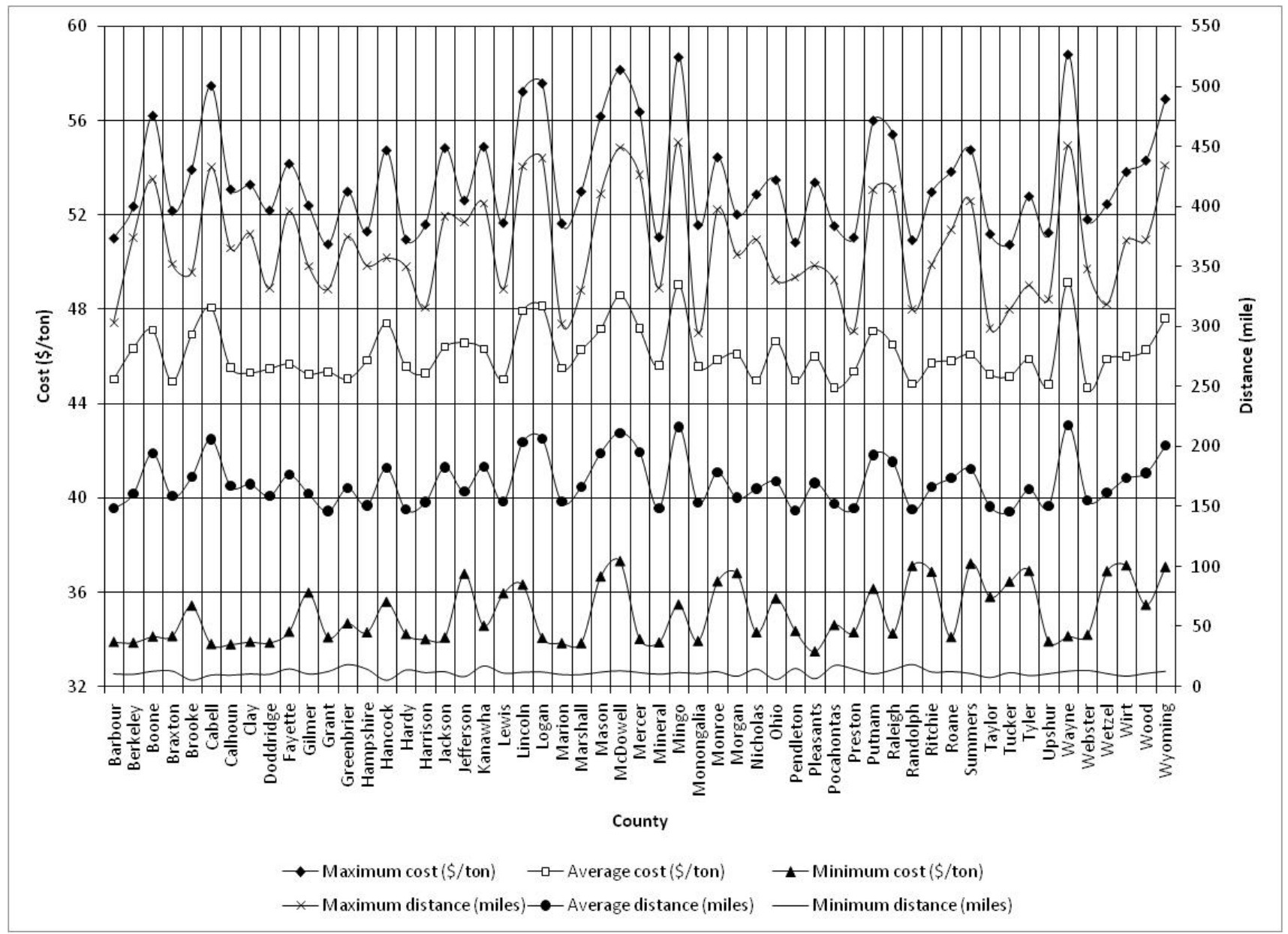

Figure C.3 Minimum, maximum and average cost and distance of both mill and logging residues in WV. 


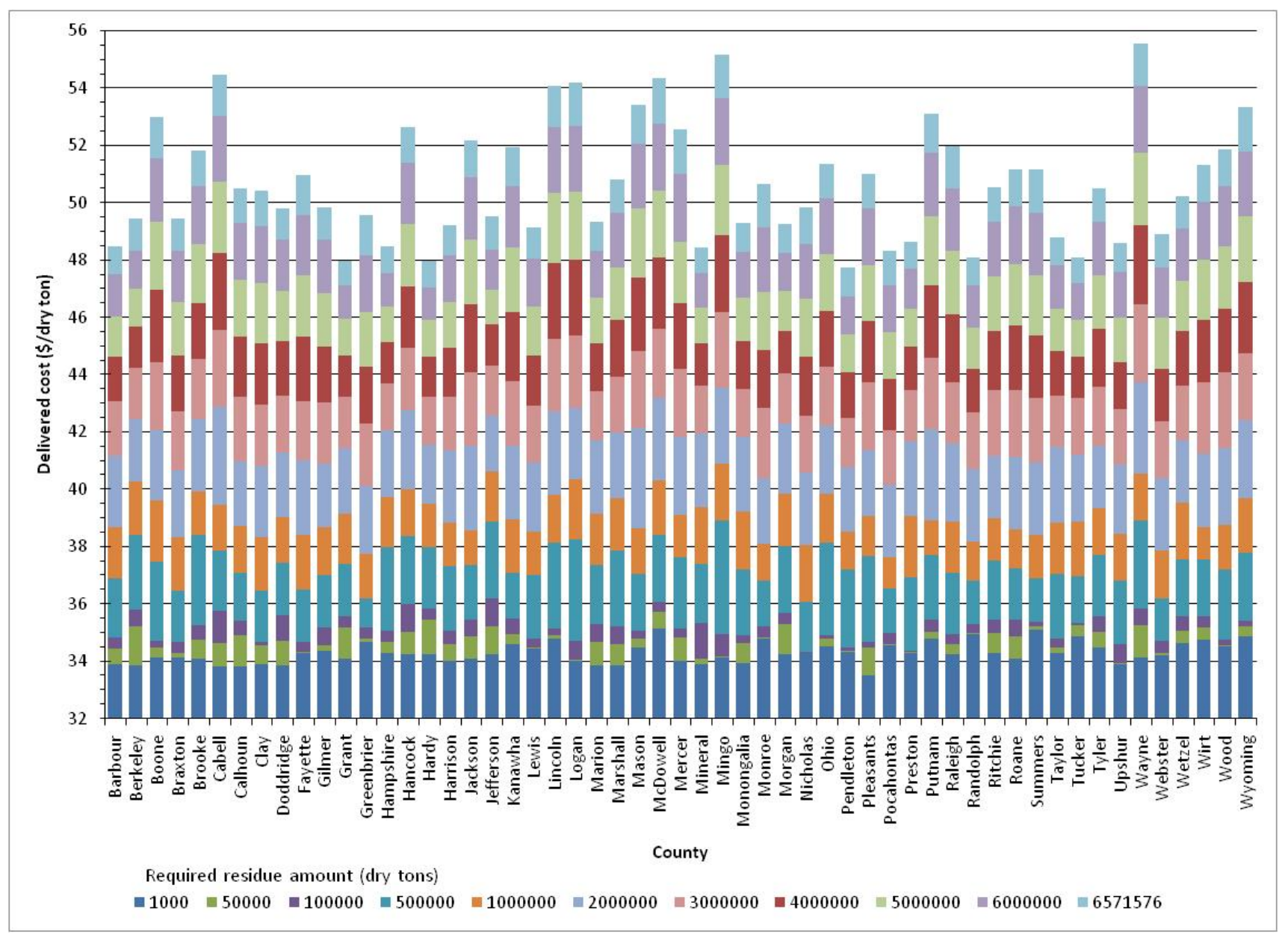

Figure C.4 Delivered cost and amount of mill residue searched by county in WV.

(Colored bars represent tons of residues and individual bars are stacked over delivered cost for the available amount of residue) 


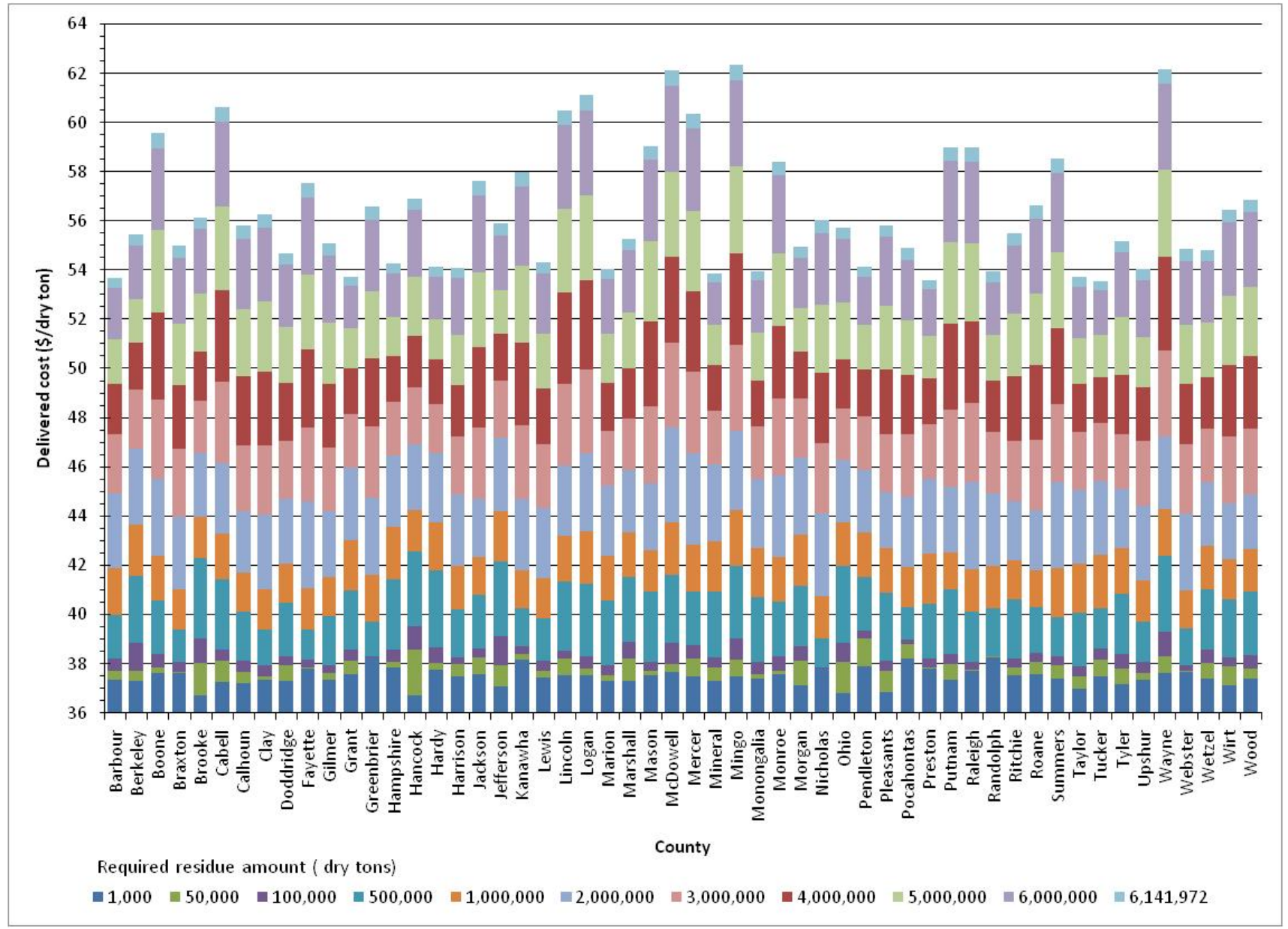

Figure C.5 Delivered cost and amount of logging residue searched by county in WV.

(Colored bars represent tons of residues and individual bars are stacked over delivered cost for the available amount of residue) 


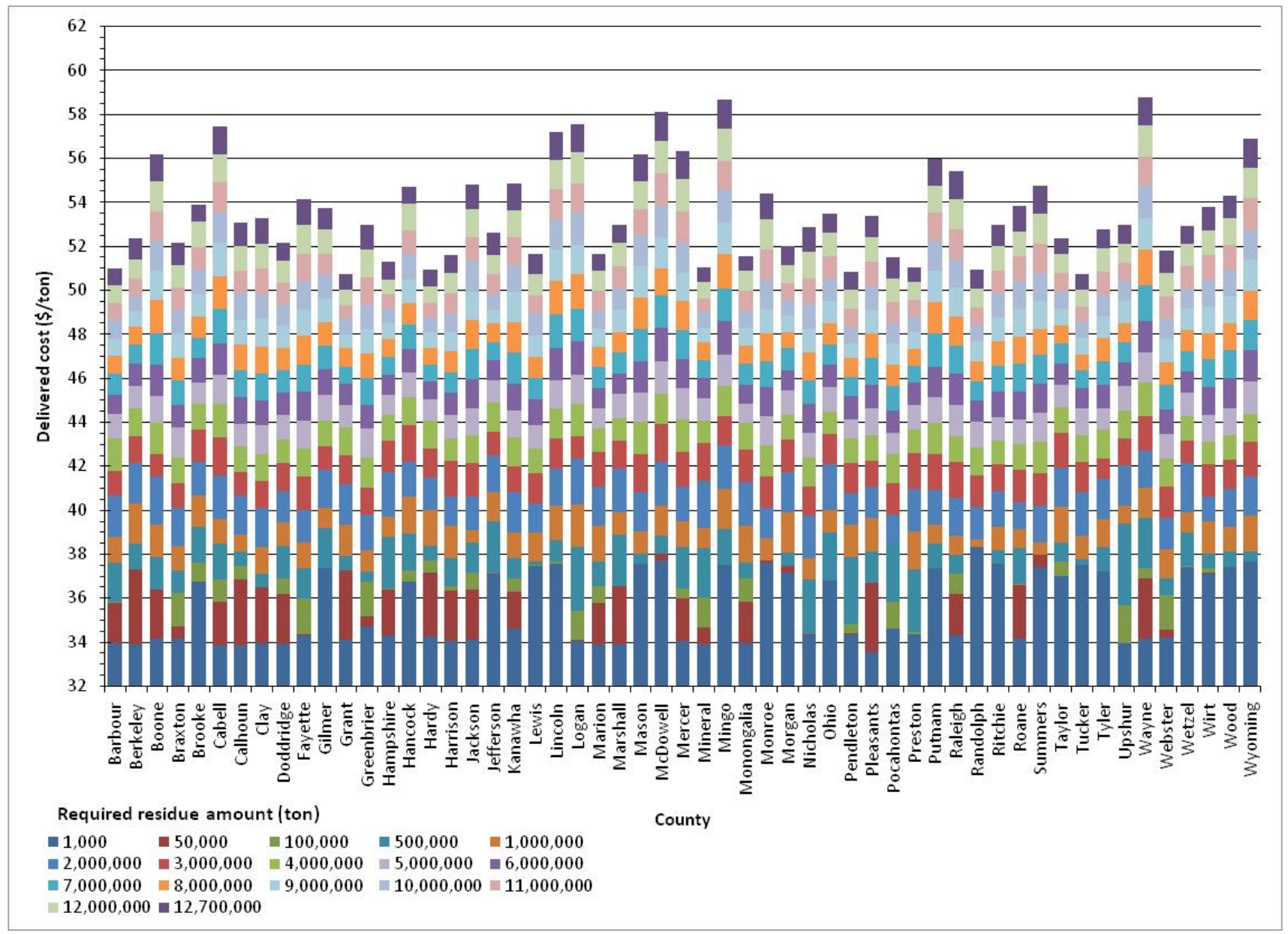

Figure C.6 Delivered cost and amount of mill and logging residues searched by county in WV.

(Colored bars represent tons of residues and individual bars are stacked over delivered cost for the available amount of residue) 
Table C.1 Distance to travel (miles) for mill residue procurement in different counties of WV.

\begin{tabular}{|c|c|c|c|c|c|c|c|c|c|c|c|}
\hline Amount (1,000 tons) & 1 & 50 & 100 & 500 & 1,000 & 2,000 & 3,000 & 4,000 & 5,000 & 6,000 & 6,571 \\
\hline Barbour & 10 & 20 & 29 & 57 & 85 & 128 & 146 & 169 & 201 & 232 & 303 \\
\hline Berkeley & 10 & 32 & 36 & 81 & 103 & 132 & 158 & 179 & 196 & 239 & 364 \\
\hline Boone & 13 & 18 & 24 & 71 & 94 & 137 & 181 & 234 & 267 & 324 & 423 \\
\hline Braxton & 13 & 21 & 25 & 54 & 77 & 116 & 150 & 188 & 222 & 258 & 352 \\
\hline Brooke & 12 & 28 & 34 & 74 & 99 & 137 & 173 & 212 & 248 & 297 & 326 \\
\hline Cabell & 10 & 39 & 42 & 64 & 99 & 158 & 202 & 246 & 290 & 325 & 430 \\
\hline Calhoun & 9 & 24 & 37 & 56 & 81 & 122 & 164 & 200 & 244 & 275 & 363 \\
\hline Clay & 10 & 19 & 19 & 59 & 85 & 121 & 163 & 205 & 234 & 280 & 377 \\
\hline Doddridge & 10 & 30 & 36 & 59 & 88 & 121 & 160 & 191 & 226 & 255 & 329 \\
\hline Fayette & 15 & 15 & 24 & 56 & 90 & 123 & 170 & 212 & 241 & 293 & 396 \\
\hline Gilmer & 15 & 17 & 34 & 61 & 83 & 121 & 158 & 191 & 232 & 261 & 349 \\
\hline Grant & 12 & 30 & 30 & 65 & 90 & 125 & 147 & 170 & 184 & 204 & 319 \\
\hline Greenbrier & 18 & 27 & 27 & 52 & 73 & 117 & 146 & 186 & 219 & 274 & 375 \\
\hline Ham & 14 & 20 & 48 & 69 & 95 & 127 & 148 & 172 & 191 & 210 & 340 \\
\hline Hancock & 14 & 36 & 41 & 74 & 93 & 143 & 180 & 224 & 263 & 311 & 339 \\
\hline Hard & 14 & 28 & 35 & 70 & 88 & 122 & 145 & 168 & 187 & 201 & 338 \\
\hline Harrison & 12 & 23 & 28 & 61 & 89 & 118 & 150 & 181 & 214 & 239 & 313 \\
\hline Jackson & 12 & 25 & 35 & 56 & 78 & 138 & 180 & 225 & 269 & 299 & 389 \\
\hline Jefferson & 14 & 37 & 43 & 88 & 97 & 134 & 158 & 175 & 195 & 248 & 377 \\
\hline Kanawha & 17 & 26 & 32 & 61 & 83 & 130 & 175 & 224 & 253 & 304 & 402 \\
\hline Lew & 16 & 16 & 24 & 55 & 82 & 121 & 155 & 180 & 217 & 244 & 330 \\
\hline Lincoln & 19 & 22 & 25 & 72 & 94 & 151 & 198 & 251 & 278 & 331 & 432 \\
\hline Log & 12 & 12 & 38 & 76 & 102 & 152 & 190 & 251 & 277 & 339 & 441 \\
\hline Mario & 10 & 29 & 31 & 67 & 92 & 123 & 154 & 187 & 209 & 244 & 299 \\
\hline Marshall & 10 & 20 & 37 & 70 & 99 & 128 & 166 & 199 & 233 & 277 & 310 \\
\hline Mason & 16 & 22 & 27 & 56 & 95 & 145 & 195 & 242 & 284 & 317 & 407 \\
\hline McDowell & 22 & 35 & 35 & 78 & 104 & 143 & 202 & 240 & 281 & 347 & 449 \\
\hline Merc & 12 & 23 & 34 & 63 & 88 & 138 & 177 & 215 & 253 & 323 & 427 \\
\hline Minel & 10 & 25 & 39 & 68 & 97 & 126 & 150 & 170 & 191 & 212 & 321 \\
\hline Ming & 13 & 13 & 33 & 84 & 107 & 163 & 202 & 262 & 290 & 352 & 454 \\
\hline Monongalia & 11 & 23 & 23 & 64 & 92 & 125 & 153 & 183 & 204 & 245 & 286 \\
\hline Monroe & 19 & 27 & 28 & 54 & 76 & 127 & 158 & 195 & 234 & 298 & 398 \\
\hline Morgan & 14 & 26 & 33 & 76 & 100 & 131 & 155 & 177 & 202 & 227 & 350 \\
\hline Nicholas & 14 & 14 & 14 & 55 & 81 & 119 & 156 & 193 & 223 & 273 & 373 \\
\hline Ohio & 16 & 20 & 27 & 67 & 101 & 129 & 170 & 205 & 239 & 289 & 319 \\
\hline Pendleton & 15 & 15 & 25 & 59 & 78 & 120 & 140 & 167 & 189 & 220 & 328 \\
\hline & 7 & 19 & 25 & 71 & 80 & 129 & 169 & 200 & 237 & 279 & 346 \\
\hline Poca & 17 & 17 & 25 & 43 & 77 & 114 & 143 & 176 & 205 & 249 & 339 \\
\hline Prestc & 14 & 14 & 23 & 60 & 94 & 123 & 152 & 173 & 191 & 230 & 285 \\
\hline Putnam & 19 & 24 & 35 & 60 & 88 & 142 & 185 & 232 & 273 & 308 & 412 \\
\hline Raleigh & 14 & 20 & 31 & 66 & 93 & 122 & 180 & 217 & 257 & 313 & 415 \\
\hline Randolph & 21 & 21 & 29 & 58 & 77 & 118 & 144 & 169 & 193 & 228 & 313 \\
\hline Ritchie & 14 & 30 & 30 & 63 & 79 & 126 & 170 & 199 & 241 & 270 & 348 \\
\hline Roar & 12 & 28 & 34 & 52 & 78 & 126 & 169 & 210 & 251 & 283 & 379 \\
\hline Summers & 22 & 25 & 28 & 59 & 78 & 129 & 160 & 205 & 242 & 302 & 405 \\
\hline Taylor & 14 & 20 & 22 & 61 & 95 & 129 & 147 & 177 & 201 & 237 & 297 \\
\hline Tucker & 20 & 25 & 25 & 63 & 90 & 123 & 150 & 165 & 188 & 218 & 302 \\
\hline Tyler & 16 & 30 & 33 & 66 & 87 & 126 & 166 & 199 & 226 & 264 & 330 \\
\hline Upshur & 11 & 11 & 30 & 52 & 78 & 122 & 150 & 170 & 212 & 237 & 322 \\
\hline Wayne & 13 & 34 & 40 & 76 & 103 & 166 & 211 & 264 & 296 & 346 & 449 \\
\hline Webster & 13 & 21 & 25 & 54 & 78 & 121 & 146 & 184 & 204 & 249 & 348 \\
\hline Wetzel & 18 & 26 & 34 & 63 & 94 & 128 & 158 & 203 & 223 & 263 & 314 \\
\hline Wirt & 19 & 30 & 30 & 61 & 87 & 134 & 174 & 205 & 256 & 283 & 368 \\
\hline Wood & 17 & 17 & 27 & 60 & 84 & 138 & 177 & 215 & 259 & 294 & 368 \\
\hline Wyoming & 20 & 26 & 30 & 67 & 101 & 137 & 195 & 232 & 271 & 330 & 434 \\
\hline
\end{tabular}


Table C.2 Distance to travel for logging residue procurement in different counties of WV.

\begin{tabular}{|c|c|c|c|c|c|c|c|c|c|c|c|}
\hline Amount (1000 tons) & 1 & 50 & 100 & 500 & 1,000 & 2,000 & 3,000 & 4,000 & 5,000 & 6,000 & 6,142 \\
\hline Barbour & 10 & 20 & 24 & 49 & 74 & 116 & 147 & 169 & 201 & 262 & 304 \\
\hline Berkelev & 10 & 22 & 33 & 66 & 90 & 129 & 159 & 179 & 215 & 286 & 374 \\
\hline Boone & 13 & 18 & 24 & 53 & 77 & 123 & 183 & 247 & 288 & 375 & 423 \\
\hline Braxton & 13 & 17 & 21 & 46 & 67 & 109 & 150 & 191 & 228 & 305 & 352 \\
\hline Brooke & 5 & 28 & 36 & 71 & 88 & 123 & 153 & 187 & 240 & 300 & 345 \\
\hline Cabell & 10 & 20 & 27 & 64 & 79 & 130 & 201 & 254 & 299 & 382 & 433 \\
\hline Calhoun & 9 & 15 & 24 & 45 & 67 & 109 & 161 & 200 & 245 & 317 & 365 \\
\hline Clav & 10 & 19 & 19 & 46 & 68 & 116 & 154 & 211 & 248 & 329 & 377 \\
\hline Doddridge & 10 & 20 & 23 & 56 & 72 & 109 & 146 & 184 & 226 & 292 & 332 \\
\hline Favette & 15 & 15 & 20 & 35 & 73 & 123 & 168 & 223 & 262 & 348 & 396 \\
\hline Gilmer & 10 & 17 & 20 & 44 & 71 & 110 & 152 & 191 & 232 & 303 & 350 \\
\hline Grant & 12 & 20 & 30 & 60 & 85 & 121 & 145 & 168 & 193 & 249 & 331 \\
\hline Greenbrier & 18 & 18 & 18 & 45 & 72 & 118 & 164 & 203 & 249 & 326 & 375 \\
\hline Hampshire & 14 & 19 & 25 & 64 & 84 & 125 & 148 & 172 & 196 & 255 & 351 \\
\hline Hancock & 5 & 29 & 44 & 71 & 90 & 126 & 156 & 193 & 250 & 311 & 357 \\
\hline Hardv & 14 & 19 & 28 & 67 & 92 & 122 & 146 & 171 & 196 & 253 & 350 \\
\hline Harrison & 12 & 18 & 23 & 45 & 72 & 114 & 144 & 177 & 214 & 275 & 316 \\
\hline Jackson & 12 & 20 & 26 & 52 & 72 & 110 & 171 & 225 & 270 & 342 & 392 \\
\hline Jefferson & 8 & 27 & 40 & 74 & 94 & 134 & 163 & 183 & 219 & 287 & 387 \\
\hline Kanawha & 17 & 24 & 26 & 48 & 68 & 119 & 175 & 230 & 268 & 355 & 403 \\
\hline Lewis & 11 & 16 & 22 & 48 & 72 & 112 & 143 & 179 & 21 & 285 & 331 \\
\hline Lincoln & 12 & 22 & 25 & 65 & 84 & 131 & 198 & 255 & 295 & 386 & 433 \\
\hline Logan & 12 & 18 & 26 & 65 & 88 & 136 & 196 & 263 & 304 & 393 & 441 \\
\hline Marion & 10 & 16 & 24 & 54 & 76 & 112 & 140 & 170 & 209 & 271 & 302 \\
\hline Marshall & 10 & 23 & 33 & 60 & 86 & 115 & 144 & 184 & 226 & 290 & 330 \\
\hline Mason & 12 & 16 & 22 & 56 & 74 & 118 & 186 & 242 & $2 \varepsilon$ & 361 & 411 \\
\hline McDowell & 13 & 18 & 35 & 68 & 98 & 153 & 206 & 264 & 315 & 401 & 449 \\
\hline Mercer & 12 & 23 & 26 & 54 & 88 & 143 & 189 & 249 & 294 & 378 & 427 \\
\hline Mineral & 10 & 19 & 25 & 60 & 86 & 123 & 148 & 170 & 192 & 246 & 332 \\
\hline Mingo & 12 & 31 & 33 & 72 & 93 & 144 & 208 & 272 & 31 & 40 & 454 \\
\hline Monongalia & 11 & 18 & 23 & 59 & 81 & 118 & 144 & 168 & 205 & 265 & 295 \\
\hline Monroe & 12 & 18 & 27 & 52 & 79 & 133 & 179 & 224 & 268 & 349 & 398 \\
\hline Morg & 9 & 25 & 26 & 61 & 87 & 130 & 156 & 176 & 20 & 27 & 360 \\
\hline Nicholas & 14 & 14 & 14 & 40 & 63 & 117 & 153 & 209 & 243 & 324 & 373 \\
\hline Ohio & 6 & 21 & 35 & 67 & 85 & 120 & 149 & 182 & 235 & 301 & 339 \\
\hline Pendleton & 15 & 29 & 29 & 59 & 83 & 120 & 147 & 173 & 20 & & 341 \\
\hline Pleasants & 7 & 16 & 25 & 60 & 76 & 106 & 156 & 196 & 240 & 309 & 351 \\
\hline Pocahontas & 17 & 25 & 25 & 43 & 75 & 114 & 154 & 181 & 223 & 295 & 339 \\
\hline Preston & 14 & 14 & 22 & 53 & 80 & 117 & 142 & 167 & 19 & & 296 \\
\hline Putn & 11 & 19 & 25 & 60 & 75 & 123 & 18 & 239 & $2 \varepsilon$ & 36 & 414 \\
\hline Raleigh & 14 & 14 & 20 & 45 & 77 & 130 & 180 & 234 & 281 & 366 & 415 \\
\hline Randolph & 18 & 18 & 18 & 54 & 70 & 116 & 146 & 175 & 203 & 274 & 315 \\
\hline Ritchie & 12 & 20 & 22 & 57 & 70 & 107 & 154 & 190 & 241 & 30 & 352 \\
\hline Roane & 12 & 21 & 28 & 49 & 72 & 107 & 16 & 212 & 252 & 332 & 381 \\
\hline Summers & 11 & 18 & 23 & 44 & 77 & 132 & 176 & 227 & 275 & 356 & 405 \\
\hline Tavlor & 8 & 16 & 20 & 52 & 78 & 115 & 142 & 165 & 20 & & 299 \\
\hline Tucker & 12 & 24 & 25 & 56 & 84 & 119 & 146 & 166 & 193 & 250 & 314 \\
\hline Tvler & 9 & 17 & 30 & 54 & 74 & 110 & 150 & 189 & 227 & 300 & 335 \\
\hline Upshur & 11 & 16 & 21 & 50 & 67 & 114 & 149 & 174 & 209 & 278 & 323 \\
\hline Wavne & 13 & 32 & 38 & 70 & 89 & 145 & 214 & 271 & 312 & 402 & 451 \\
\hline Webster & 13 & 13 & 21 & 38 & 67 & 115 & 148 & 193 & 223 & 302 & 348 \\
\hline Wetzel & 11 & 22 & 28 & 55 & 77 & 115 & 141 & 183 & 223 & 293 & 319 \\
\hline Wirt & 9 & 20 & 21 & 56 & 70 & 98 & 166 & 205 & 256 & 327 & 372 \\
\hline Wood & 11 & 17 & 27 & 55 & 77 & 104 & 170 & 208 & 259 & 331 & 373 \\
\hline Wvoming & 13 & 20 & 20 & 62 & 87 & 140 & 195 & 251 & 300 & 386 & 434 \\
\hline
\end{tabular}


Table C.3 Distance to travel (miles) for both mill and logging residue procurement in different counties of WV.

\begin{tabular}{|c|c|c|c|c|c|c|c|c|c|c|c|c|c|c|c|c|c|}
\hline $\begin{array}{l}\text { Amount } \\
(10,000 \text { dry ton }\end{array}$ & -1 & in & 욱 & 유 & ষ্ন & ¿્సి & ষ্লি & \& & \& & 8 & ঃ & రి & ৪ి & $\underset{-i}{8}$ & $\underset{7}{8}$ & : & 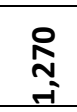 \\
\hline Barbour & 10 & 14 & 20 & 29 & 51 & 82 & 99 & 119 & 134 & 146 & 163 & 169 & 183 & 201 & 216 & 236 & 303 \\
\hline & 10 & 15 & 32 & 49 & 72 & 96 & 110 & 132 & 145 & 158 & 168 & 179 & 192 & 203 & 222 & 265 & 358 \\
\hline Boone & 13 & 13 & 18 & 40 & 56 & 92 & 110 & 132 & 155 & 181 & 212 & 238 & 257 & 281 & 295 & 332 & 423 \\
\hline Braxton & 13 & 13 & 17 & 28 & 49 & 74 & 94 & 116 & 133 & 150 & 171 & 189 & 209 & 222 & 245 & 266 & 352 \\
\hline & 5 & 12 & 28 & 55 & 73 & 91 & 112 & 128 & 143 & 164 & 176 & 200 & 226 & 248 & 269 & 297 & 326 \\
\hline Cabell & 10 & 19 & 21 & 47 & 64 & 85 & 119 & 145 & 170 & 202 & 229 & 252 & 276 & 292 & 321 & 348 & 430 \\
\hline & 9 & 15 & 23 & 42 & 48 & 74 & 95 & 115 & 137 & 162 & 184 & 200 & 221 & 244 & 263 & 286 & 363 \\
\hline Clay & 10 & 10 & 19 & 30 & 49 & 73 & 98 & & 139 & & 185 & 206 & 228 & 242 & 264 & 291 & 377 \\
\hline Doddridge & 10 & 17 & 20 & 40 & 56 & 79 & 96 & 118 & 131 & 155 & 168 & 188 & 201 & 226 & 245 & 272 & 329 \\
\hline & 15 & 15 & 15 & 30 & 48 & 83 & 103 & 123 & 141 & 170 & 195 & 215 & 234 & 252 & 278 & 307 & 396 \\
\hline Gilm & 10 & 15 & 17 & 38 & 50 & 74 & 94 & & 133 & 157 & 174 & 191 & 208 & 232 & 250 & 276 & 349 \\
\hline Gra & 12 & 19 & 25 & 43 & 61 & 90 & 103 & 125 & 136 & 147 & 158 & 169 & 177 & 189 & 200 & 219 & 305 \\
\hline & 18 & 18 & 18 & 30 & 46 & 73 & 93 & 118 & 142 & 156 & 177 & 195 & 216 & 236 & 259 & 295 & 375 \\
\hline & 14 & 19 & 19 & 50 & 64 & 92 & 113 & 127 & 137 & 148 & 162 & 172 & 181 & 191 & 205 & 237 & 330 \\
\hline & 5 & 17 & 31 & 56 & 72 & 93 & 116 & 137 & 154 & 166 & 187 & 208 & 231 & 262 & 277 & 311 & 339 \\
\hline Hardy & 14 & 19 & 25 & 54 & 67 & 88 & 106 & 122 & 136 & 146 & 155 & 169 & 179 & 188 & 196 & 227 & 325 \\
\hline & 12 & 17 & 18 & 40 & 59 & 79 & 104 & 115 & 134 & 147 & 160 & 180 & 191 & 214 & 233 & 259 & 313 \\
\hline & 12 & 20 & & 4 & 55 & 77 & 97 & & 155 & & 203 & & 241 & 269 & 283 & 313 & 389 \\
\hline & 8 & 19 & 2 & 57 & 77 & 96 & 113 & 134 & 148 & 160 & 168 & 177 & 188 & 207 & 233 & 267 & 369 \\
\hline & 17 & 17 & 24 & 40 & 51 & 82 & 101 & 126 & 147 & 175 & 204 & 229 & 246 & 262 & 286 & 315 & 402 \\
\hline & 11 & 16 & & & 51 & 74 & 99 & & & & 164 & & 196 & 217 & 234 & 257 & 330 \\
\hline & 12 & 19 & 2 & 53 & 69 & 90 & 113 & 5 & 165 & 15 & 229 & 51 & 269 & 291 & 312 & 345 & 432 \\
\hline & 12 & 12 & 1 & 49 & 70 & 95 & 118 & 138 & 170 & 195 & 225 & 252 & 272 & 295 & 311 & 349 & 441 \\
\hline & 1 & 13 & 1 & 4 & 61 & 87 & & & & & & & 194 & 09 & 230 & 257 & 299 \\
\hline & 10 & 20 & $2 C$ & 52 & 64 & 89 & 108 & 119 & 139 & 153 & 173 & 195 & 216 & 227 & 255 & 281 & 313 \\
\hline Masc & 12 & 16 & 20 & 41 & 56 & 79 & 112 & 136 & 162 & 193 & 218 & 242 & 259 & 284 & 300 & 328 & 407 \\
\hline & 1 & $1 \varepsilon$ & 3 & 5 & 77 & 102 & & 1 & 175 & 26 & 230 & 249 & 275 & 295 & 322 & 362 & 449 \\
\hline & 1 & 19 & 2 & 51 & 63 & & & & 162 & & 210 & & 252 & 282 & 307 & 345 & 427 \\
\hline & 10 & 10 & 15 & 39 & 60 & 91 & 112 & & 136 & 148 & 164 & 170 & 180 & 192 & 204 & 222 & 312 \\
\hline & 12 & 13 & 3 & 55 & 81 & & & & 180 & & & 262 & & 304 & 322 & 362 & 454 \\
\hline & 1 & 1 & 2 & 42 & 60 & 8 & 107 & & 133 & & 162 & 76 & 194 & 204 & 229 & 257 & 288 \\
\hline & 12 & 18 & 1 & 41 & 54 & 77 & & & & & & & & 260 & 285 & 21 & 398 \\
\hline & 9 & 24 & 2 & 38 & 69 & 97 & 111 & 130 & 143 & 155 & 164 & 177 & 194 & 203 & 217 & 257 & 344 \\
\hline & 14 & 1 & 1 & 2 & 4 & & 9 & & & & 174 & DO & & 237 & 256 & 289 & 373 \\
\hline & 6 & 20 & 2 & 53 & 67 & 90 & 111 & & 140 & 157 & 178 & 201 & 221 & 238 & 259 & 289 & 319 \\
\hline & 15 & 15 & 15 & 47 & 59 & 83 & 99 & 120 & 128 & 144 & 155 & 170 & 177 & 193 & 211 & 226 & 309 \\
\hline & 7 & 1 & & & 63 & & 100 & & 142 & & & & & 237 & 264 & 96 & 346 \\
\hline & 17 & 17 & 2 & 3 & 43 & 7 & 94 & & 129 & 14 & 16 & 178 & 194 & 206 & 231 & 261 & 339 \\
\hline & 1 & 14 & 14 & 39 & 57 & 87 & 108 & & 134 & & 159 & 1 & & 192 & 214 & 239 & 276 \\
\hline & 1 & 19 & & & & & & & & & & & & & & 30 & 412 \\
\hline & 1 & 14 & 2 & 42 & & & & & & & & 227 & & 265 & 296 & 327 & 415 \\
\hline & 18 & 18 & 18 & 35 & 56 & 70 & 99 & & & & & 1 & & 195 & 216 & 235 & 313 \\
\hline & 12 & 20 & 2 & 4 & 58 & 77 & & & & & & & & 241 & 258 & 284 & 348 \\
\hline & 1 & 19 & 2 & 4 & & & 97 & & & & & & & & & 298 & 379 \\
\hline & 11 & 18 & 23 & 30 & 53 & 78 & 102 & & & & & 215 & & 264 & 285 & 323 & 405 \\
\hline & 8 & 14 & 18 & 37 & 59 & 83 & 106 & 123 & 132 & 145 & 161 & 175 & 186 & 201 & 224 & 247 & 297 \\
\hline & 12 & 24 & 2 & 33 & 59 & 88 & 104 & & & & & & & 189 & 202 & 228 & 287 \\
\hline & 9 & 1 & 2 & 45 & 65 & 81 & 99 & & & & & & & 226 & 253 & 280 & 330 \\
\hline & 11 & 11 & 16 & 32 & 50 & 78 & 97 & 11 & 132 & 149 & 159 & 172 & 190 & 212 & 227 & 249 & 322 \\
\hline & 13 & 21 & 3 & 6 & 74 & 100 & 130 & & & & & & & 304 & 326 & 61 & 449 \\
\hline & 13 & 13 & 13 & 2 & 45 & & 95 & & & & & & & 217 & 237 & 65 & 348 \\
\hline & 11 & 18 & 23 & 47 & 57 & 89 & 102 & & 135 & & 169 & 187 & 206 & 223 & 248 & 277 & 314 \\
\hline Wirt & 9 & 19 & 21 & 42 & 59 & & 93 & 11 & 147 & 169 & 186 & 205 & 229 & 256 & 267 & 298 & 368 \\
\hline & 11 & 17 & 17 & 5 & & & 98 & & & & & 210 & 236 & 259 & 278 & 306 & 368 \\
\hline Wyoming & 13 & 20 & 20 & 48 & 64 & 94 & 116 & 138 & 164 & 195 & 217 & 241 & 262 & 281 & 313 & 345 & 434 \\
\hline
\end{tabular}

